\title{
Analysis of factors influencing the stationarity of surface electromyography signals measured in non-fatigued shoulder muscles
}

Hui Ci

West Virginia University, hc0040@mix.wvu.edu

Follow this and additional works at: https://researchrepository.wvu.edu/etd

Part of the Ergonomics Commons, and the Risk Analysis Commons

\section{Recommended Citation}

$\mathrm{Ci}$, Hui, "Analysis of factors influencing the stationarity of surface electromyography signals measured in non-fatigued shoulder muscles" (2020). Graduate Theses, Dissertations, and Problem Reports. 7715. https://researchrepository.wvu.edu/etd/7715

This Thesis is protected by copyright and/or related rights. It has been brought to you by the The Research Repository @ WVU with permission from the rights-holder(s). You are free to use this Thesis in any way that is permitted by the copyright and related rights legislation that applies to your use. For other uses you must obtain permission from the rights-holder(s) directly, unless additional rights are indicated by a Creative Commons license in the record and/ or on the work itself. This Thesis has been accepted for inclusion in WVU Graduate Theses, Dissertations, and Problem Reports collection by an authorized administrator of The Research Repository @ WVU. For more information, please contact researchrepository@mail.wvu.edu. 


\section{Analysis of factors influencing the stationarity of surface electromyography signals measured in non-fatigued shoulder muscles}

\section{Hui Ci}

Thesis submitted to the Benjamin M. Statler College of

Engineering and Mineral Resources at

West Virginia University in partial fulfillment

of the requirement for the degree of

\section{Master of Science \\ in \\ Industrial Hygiene}

Ashish D. Nimbarte, Ph.D., Committee Chairperson

Warren R. Myers, Ph.D., CIH (1991-2017)

Gary L. Winn, Ph.D.

Department of Industrial and Management Systems Engineering

Morgantown, West Virginia

Summer 2020

Keywords: surface electromyography, shoulder muscles, stationary fatigue

Copyright 2020 Hui Ci 


\title{
Abstract \\ Analysis of factors influencing the stationarity of surface electromyography signals measured in non-fatigued shoulder muscles
}

\begin{abstract}
Hui Ci
A reduction in the \% stationarity of surface electromyography (SEMG) signals with respect to the initial or fresh condition is used to predict localized muscle fatigue. However, factors other than muscle fatigue can also influence the stationarity of SEMG signals. This study was aimed at analyzing the effect of various work/task related factors on the stationarity of SEMG signals obtained from non-fatigued shoulder muscles. Twelve participants were recruited for data collection and each one performed 120 trials characterized by the combination of 2 shoulder angles $\left(60^{\circ}\right.$ and $\left.120^{\circ}\right), 2$ planes of exertions (sagittal and scapular), 3 force levels ( $\left.0 \mathrm{lb}, 2.5 \mathrm{lb}, 5 \mathrm{lb}\right), 5$ force directions (pull back, pull up, pull down, pull right and pull left) and 2 repetitions. The SEMG data were recorded from seven shoulder muscles (supraspinatus, infraspinatus, middle deltoid, anterior deltoid, posterior deltoid, biceps, triceps). Modified Reverse Arrangement Test with five window sizes $(128,256,512,768$, and 1024 millisecond(ms)) was used to process the SEMG data. The effects of work/task related factors on \% stationarity of shoulder muscles was analyzed using ANOVA. The mean stationarity of SEMG signals ranged from $87.8 \%$ to $94.9 \%$. Among the work/task related factors, the joint angle and the plane of exertion affected the $\%$ stationarity in fewer instances compared to the force level and the force direction. The exertions that produced higher activation (SEMG amplitude) resulted in lower \% stationarity, indicating an inverse relationship between $\%$ stationarity and muscle activation. The variability in $\%$ stationarity increased from $3.3 \%$ to $10.0 \%$ when the window size was increased from $128 \mathrm{~ms}$ to $1024 \mathrm{~ms}$. The study findings could be useful in improving real-time fatigue prediction methods.
\end{abstract}




\section{Acknowledgments}

At this point, I would like to express my deepest gratitude to my advisor, Dr. Ashish D. Nimbarte for the continuous encouragement, guidance, and assistance. He is very knowledgeable professor, and always understand what the student concern is and provide valuable advice. I would also like to express my profound gratitude to Dr. Warren R. Myers and Dr. Gary Winn for their insightful comments and encouragement. I would also like to thank all my teachers, classmates, friends who helped me throughout this study process. It was your help that gave me a better understanding for this industry.

At last, I would like to thank my parents and my family. Your love has given me the energy and support me to complete the education. Thank you, and love to you all. 


\section{Table of Contents}



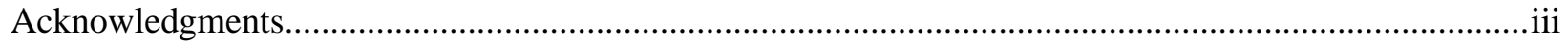

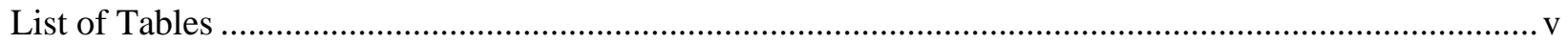

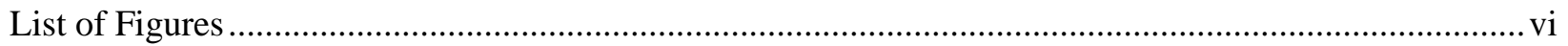

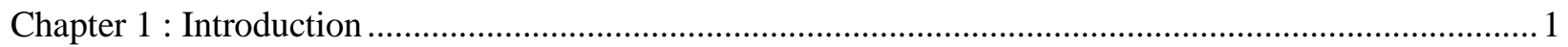

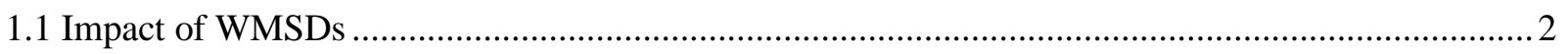

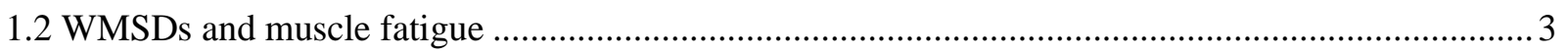

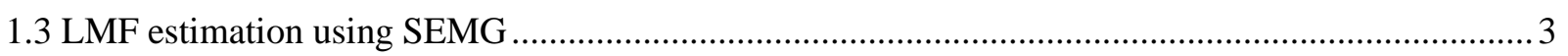

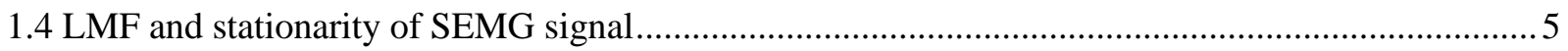

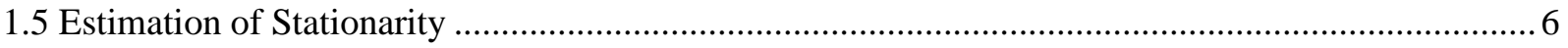

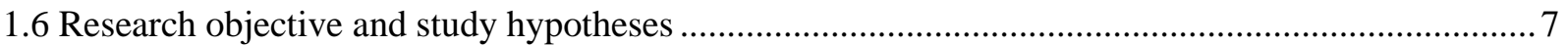

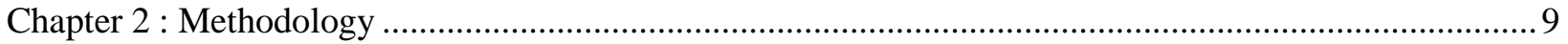

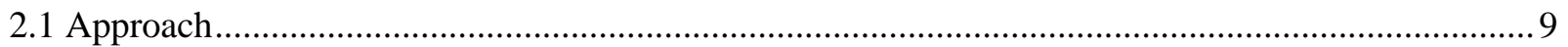

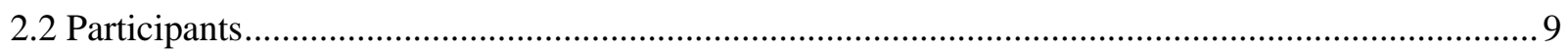

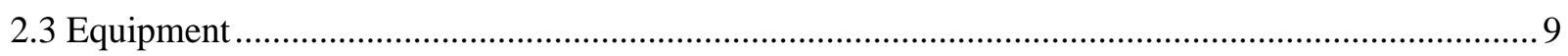

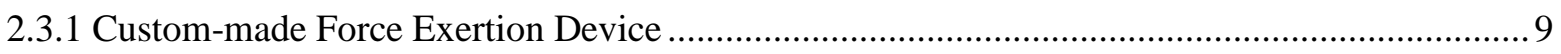

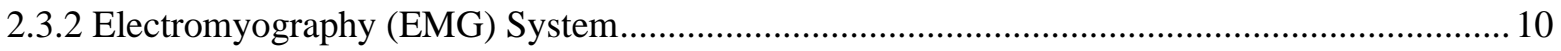



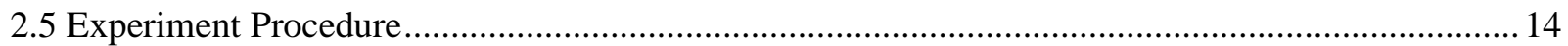

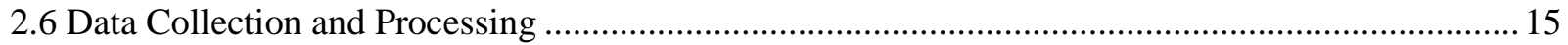

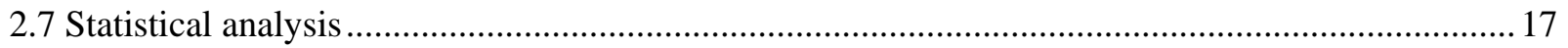

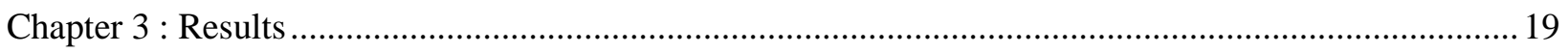

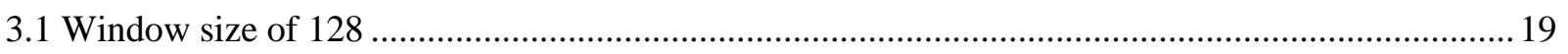

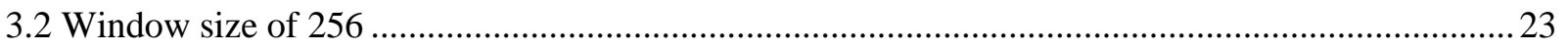

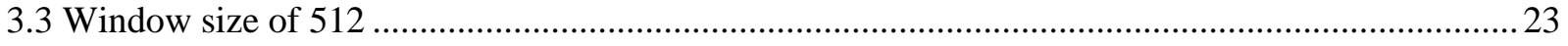

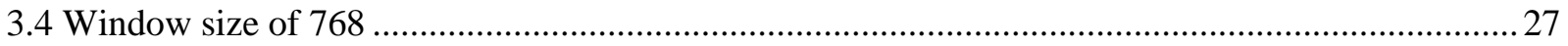

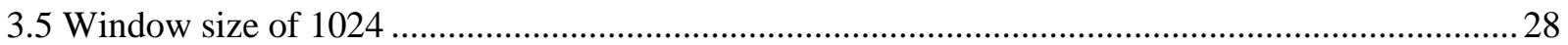

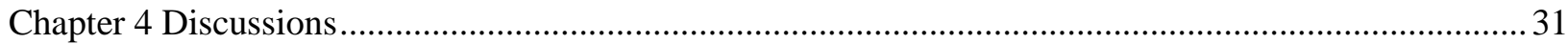

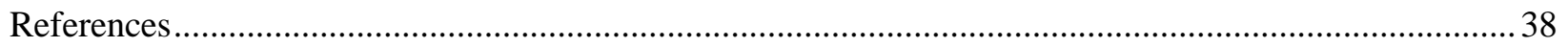

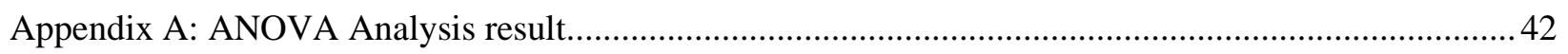

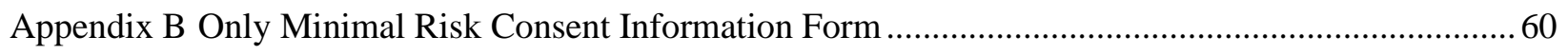




\section{List of Tables}

Table 2-1 Four-factor factorial design. .12

Table 2-2 Number of segments and sub-segments for various window sizes. .16

Table 3-1 Main effect of joint angle, plane, force level, and force direction on $\%$ stationarity data estimated using a window size of 128 . For each muscle mean (standard deviation) data and the pvalue (p-val) for the main effect are provided in the table along with the variation (Var) based on MSE. Statistically significant p-values are bolded. 20

Table 3-2 Main effect of joint angle, plane, force level, and force direction on $\%$ stationarity data estimated using a window size of 256. For each muscle mean (standard deviation) data and the pvalue (p-val) for the main effect are provided in the table along with the variation (Var) based on MSE. Statistically significant p-values are bolded. 20

Table 3-3 Main effect of joint angle, plane, force level, and force direction on $\%$ stationarity data estimated using a window size of 512. For each muscle mean (standard deviation) data and the pvalue (p-val) for the main effect are provided in the table along with the variation (Var) based on MSE. Statistically significant $\mathrm{p}$-values are bolded. .24

Table 3-4 Main effect of joint angle, plane, force level, and force direction on $\%$ stationarity data estimated using a window size of 768 . For each muscle mean (standard deviation) data and the pvalue (p-val) for the main effect are provided in the table along with the variation (Var) based on MSE. Statistically significant $\mathrm{p}$-values are bolded. .24

Table 3-5 Main effect of joint angle, plane, force level, and force direction on $\%$ stationarity data estimated using a window size of 1024. For each muscle mean (standard deviation) data and the p-value (p-val) for the main effect are provided in the table along with the variation (Var) based on MSE. Statistically significant p-values are bolded. 


\section{List of Figures}

Figure 1-1 An example of shoulder pain symptoms and causes (Mayo Clinic, 2018)................ 1

Figure 2-1: Force exertion device with a height adjustable bar-handle assembly .................... 10

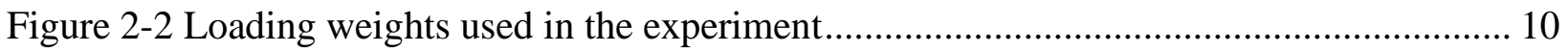

Figure 2-3 Parts of the Bagnoli -16 EMG system - (a) EMG sensor, (b) main amplifier (desktop) unit, (c) input models, (d) Input module cable, and (e) power supply (Chowdhury, 2016) ........ 11

Figure 2-4 The locations of measuring electrodes and reference electrode............................. 12

Figure 2-5 Four work related factors schematic diagram .............................................. 13

Figure 2-6 User interface of workflow environment pro................................................... 15

Figure 2-7 Divide filtered SEMG data into 72 segments with a window size of $128 \mathrm{~ms}$........... 17

Figure 3-1 Mean \% stationarity data (window size =128) for the shoulder muscles during the exertions performed in pull back (PB), pull down (PD), pull left (PL), pull right (PR), and pull up (PU) directions, using weights of 0, 2.5 and $5 \mathrm{lbs}$. in sagittal and scapular planes at $60^{\circ}$ and $120^{\circ}$ shoulder angles. Error bars represent 95\% confidence interval............................................. 21

Figure 3-2 Mean \% stationarity data (window size =256) for the shoulder muscles during the exertions performed in pull back (PB), pull down (PD), pull left (PL), pull right (PR), and pull up (PU) directions, using weights of $0,2.5$ and $5 \mathrm{lbs}$. in sagittal and scapular planes at $60^{\circ}$ and $120^{\circ}$ shoulder angles. Error bars represent $95 \%$ confidence interval. 22 Figure 3-3: Mean \% stationarity data (window size =512) for the shoulder muscles during the exertions performed in pull back (PB), pull down (PD), pull left (PL), pull right (PR), and pull up (PU) directions, using weights of 0, 2.5 and $5 \mathrm{lbs}$. in sagittal and scapular planes at $60^{\circ}$ and $120^{\circ}$ shoulder angles. Error bars represent $95 \%$ confidence interval. 25 
Figure 3-4: Mean \% stationarity data (window size =768) for the shoulder muscles during the exertions performed in pull back (PB), pull down (PD), pull left (PL), pull right (PR), and pull up (PU) directions, using weights of 0, 2.5 and $5 \mathrm{lbs}$. in sagittal and scapular planes at $60^{\circ}$ and $120^{\circ}$

shoulder angles. Error bars represent $95 \%$ confidence interval............................................ 26

Figure 3-5: Mean \% stationarity data (window size =1024) for the shoulder muscles during the exertions performed in pull back (PB), pull down (PD), pull left (PL), pull right (PR), and pull up (PU) directions, using weights of 0, 2.5 and $5 \mathrm{lbs}$. in sagittal and scapular planes at $60^{\circ}$ and $120^{\circ}$ shoulder angles. Error bars represent $95 \%$ confidence interval............................................ 30 


\section{Chapter 1: Introduction}

Musculoskeletal Disorders or MSDs are the injuries of soft tissues, muscles, ligaments, nerves, and tendons. The most common symptoms of MSDs include pain and discomfort of shoulders, neck, and lower back. Clinical syndromes of MSDs include tendon inflammations, osteoarthrosis, and nerve compression disorders (Punnett \& Wegman, 2004). Work-related MSDs (WMSDs) are common in modern workplaces. Some work environments and/or conditions put the workers at a higher risk of WMSD than others. For example, work environments characterized by heavy and sustained physical work, high psychosocial demands, longer work hours, overexertion, repetitive motion (bending, climbing, crawling, reaching, twisting, etc.) are frequently associated with the development of WMSDs (Costa \& Vieira, 2010). At any point in time, about $18-26 \%$ of adults suffer from shoulder WMSDs that negatively impact their work and daily lives (Linaker \& Walker-Bone, 2015). Most common shoulder WMSDs that cause pain and discomfort include, impingement, rotator cuff tears, tendonitis and osteoarthritis (Figure 1-1).

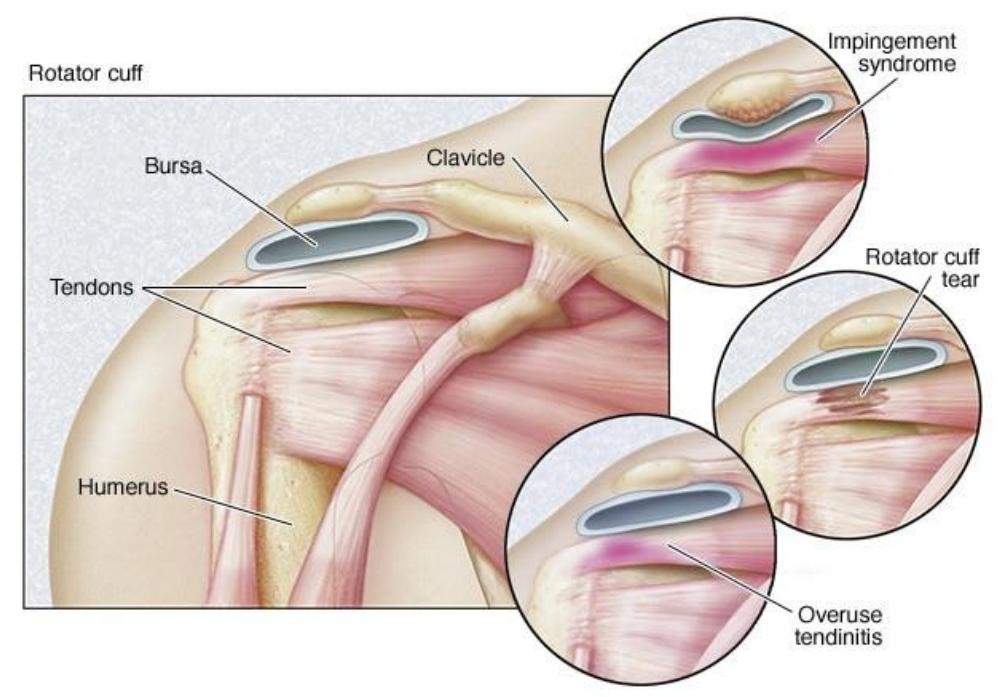

Figure 1-1 An example of shoulder pain symptoms and causes (Mayo Clinic, 2018) 


\subsection{Impact of WMSDs}

Based on the 2019 edition report of "Death on the Job: The Toll of Neglect" by American Federation of Labor and Congress of Industrial Organizations or AFL-CIO (AFL-CIO, 2019), for the years 1995 through 2017 the percent of cases involving WMSDs in private industry were in the range of $29 \%$ to $35 \%$. The total number of WMSD cases were in the range of 0.88 to 2.22 million per year. For the year 2017, the WMSD incidence rate was around 158 cases per 10,000 workers in air transportation industry. WMSDs are usually followed by several days away from work. The median number of days away from work due to WMSDs was 11 compared to 8 for all occupational injury cases (Bhattacharya, 2014).

WMSDs put significant socioeconomic burden on both employees and employers. In the economic aspect, the direct costs of WMSDs can be as high as $\$ 20$ billion a year including workers compensation payment, medical payments and legal expenses and the indirect costs including training replacement employees, accident investigation, lost productivity, repairs of damaged equipment and property and cost associated with lower employee morale and absenteeism. The indirect cost due to lost productivity, product defects, etc., can be up to five times of the direct costs (Ergo-plus, 2019). Due to the social or peer pressure, only $10.6 \%$ of the cases were reported to have filed for workers' compensation and only $21 \%$ of the individuals typically get approved for workers' compensation (Morse, 2013). The low percentage of the compensation may result in serious economic consequences from WMSDs, losing homes, incurring large out-of-pocket expenses, being divorced, and facing economic insecurity. Some WMSDs may result in the employee being unable to return to the same job or completely lose the work ability which generate a huge burden for their family. Particularly, shoulder WMSD is one of the three major MSDs based on a recent survey of 400,000 WMSD cases (Ergo-plus, 2019). It accounted for $14.6 \%$ of the total 
cases after lower back WMSD (45.4\%) and followed by leg WMSD (7.2 \%). In recent years, it has also become a major cause of morbidity and pain for employees in many working environments (Linaker \& Walker-Bone, 2015).

\subsection{WMSDs and muscle fatigue}

WMSDs are associated with many physical factors such as intense, repeated, or sustained exertions, awkward or extreme postures of the body, insufficient recovery time, vibration, and cold temperatures. Some of these physical factors lead to localized muscle fatigue (LMF). There are two main causes of LMF: 1) the limitations of a nerve's ability to generate a sustained signal (neural fatigue); and 2) the reduced ability of the muscle fiber to contract (metabolic fatigue). When fatigue outruns the body's recovery system, a musculoskeletal imbalance is developed and may lead to WMSDs over time. Vitro studies and animal tissue experiments provide evidence that the WMSDs might be the results of a fatigue failure process in musculoskeletal tissues (Gallagher \& Jr, 2017). Therefore, study of LMF development and recovery process is important to reduce the incidences of WMSD and to improve overall performance and productivity in the work environment. A good example of such effort is the European project, ConText, which aims at developing a wearable tool for continuous monitoring of LMF to prevent WMSD (Taelman et al., 2006). The key components in this wearable tool are textile integrated contactless electromyography (EMG) sensors.

\subsection{LMF estimation using SEMG}

The Surface Electromyography (SEMG) system is capable of direct measurement of electrical signals from the surface of muscles. These signals are controlled by the nervous system and produced during muscle contraction. Muscle fatigue influences several characteristics of 
(SEMG) signals, such as frequency, amplitude, and stationarity. Thus, the SEMG signals can be used to estimate muscle fatigue by reflecting the functions of the nerves and muscles.

In 1923, Cobb and Forbes (Cobb \& Forbes, 1923) reported an increase in the signal amplitude as one of the manifestations of LMF during the static contraction. Kogi and Hakamad (Kogi \& Hakamada, 1962) found that LMF produces a shift in the SEMG power spectrum toward lower frequencies using frequency analysis. Bonato et al. (Bonato et al., 2001) used the percentage drop of SEMG instantaneous median frequency to assess muscle fatigue during a repetitive squat exercise. Wang (Wang, Ren, Li, \& Wang, 2007) proposed a multifractal analysis method by calculating the area of the multifractal spectrum of the SEMG signals. They found that the spectrum area significantly increased during muscle fatigue. They also observed a higher sensitivity of the spectrum area method, compared with widely used median frequency method. Dimitrov et al. (Dimitrov et al., 2006) proposed that the ratios between different spectral moments calculated over the power spectral density can be used as indices for the assessment of muscle fatigue irrespective of SEMG signal variability caused by dynamic muscle contractions. Chowdhury et al. (Chowdhury, Nimbarte, Jaridi, \& Creese, 2013) assessed the fatigue of neck and shoulder muscles using Discrete Wavelet Transform (DWT) analysis of SEMG. They found that the spectral changes calculated with power of wavelet coefficients in the $12-23 \mathrm{~Hz}$ frequency have the highest sensitivity to fatigue induced by the dynamic repetitive exertions.

Cifrek et al. (Cifrek, Medved, Tonković, \& Ostojić, 2009) reviewed recent research on SEMG based muscle fatigue evaluation in biomechanics. They summarized classical and modern signal processing methods and techniques applied to SEMG signals in fatigue-inducing situations relevant to the broad field of biomechanics. González-Izal et al. (González-Izal, Malanda, Gorostiaga, \& Izquierdo, 2012) summarized current electromyographic models developed to 
assess muscle fatigue. These models are based on SEMG amplitude-based parameters such as the averaged rectified value (ARV) and the root mean squared value (RMS), spectral parameters such as mean and median frequency, time-frequency parameters such as instantaneous mean frequency and wavelet spectral parameters or non-linear parameters such as entropy and recurrence quantification analysis. Hussain et al. (Hussain et al., 2018) published a review on fatigue analysis in triceps brachii using surface electromyography. Based on the reviewed publications, it was reported that the SEMG RMS value is usually decreased when sustained isometric contractions are performed at the maximum voluntary contraction (MVC).

\subsection{LMF and stationarity of SEMG signal}

As summarized in the previous section, LMF can influence the SEMG signals in several ways, i.e., increase of amplitude, decrease of mean or median frequencies, shift in the power of low and high frequency components. These SEMG characteristics are calculated with a stationary assumption (Bilodeau, Cincera, Arsenault, \& Gravel, 1997). A SEMG signal is said to be stationary if the average, variance, and frequency contents of the signal do not alter over time (Blanco, Garcia, Quiroga, Romanelli, \& Rosso, 1995). However, muscle fatigue may reduce the stationarity of SEMG signals since it is a measurement of electric potentials when muscle cells are electrically or neurologically activated. At the onset of LMF, the nerve's ability to generate a sustained signal is limited and the contraction ability of the muscle fibers are significantly reduced. These changes can be captured by directly comparing the stationarity of SEMG signals under fatigue and non-fatigue conditions.

The research on signal stationarity to estimate LMF is limited. Mananas et al. (Mananas, Guillen, Fiz, Morera, \& Caminal, 2000) investigated the stationarity of EMG and vibromyographic (VMG) signals during respiratory cycles. They found that high levels of ventilation 
and the respiratory muscle fatigue reduced the stationarity of both EMG and VMG signals especially during the transition between inspiration and expiration intervals. In some participants the EMG stationary percentage was reduced from $80 \%$ in the initial stage to $20 \%$ at the end of the inspiration period. Chowdhury and Nimbarte (Chowdhury \& Nimbarte, 2017) conducted a study to quantify LMF using SEMG stationarity under both static and dynamic conditions. It was found that the muscle fatigue reduced the stationarity of the SEMG signals in both static and dynamic conditions. Specifically, the percent stationarity of SEMG signals was reduced from $80.25 \%$ to 71.91\% using a modified Reverse Arrangement Test when a window size of 512 millisecond (ms) was used.

\subsection{Estimation of Stationarity}

There are three tests that are commonly used in the literature to estimate stationarity of SEMG data - Runs Test, Reverse Arrangements Test, and modified Reverse Arrangements Test. Beck et al.(Beck et al., 2006) compared Runs Test, Reverse Arrangements Test, and modified Reverse Arrangements Test for assessing surface EMG signal stationarity. They tested six stationary signals including sine waves, sums of sine waves, sums of sine waves and random noise, and a stationary SEMG signal. Several signals generated using LabVIEW, SEMG signal downloaded from the SENIAM project database, and a real SEMG signal recorded from the biceps brachii during a concentric isokinetic muscle action of the forearm flexors were tested. They defined if the test classified stationary as nonstationary that generate false positive error. If the test incorrectly classified nonstationary as stationary that generate false negative error. After analysis, they found the Runs Test inaccurately classified stationary as nonstationary and produce false positive error. Reverse Arrangements Test and modified Reverse Arrangements Test can generate both false positive and false negative error. Thus, they concluded all three tests were not accurate 
tests for examining signal stationarity. Cho and Kim (Cho \& Kim, 2012) compared Reverse Arrangements Test, and modified Reverse Arrangements Test for assessing the effects of load, motions (flexion, twisting) and window size on the stationarity of trunk muscle SEMG signals. Their results suggested that modified Reverse Arrangement Test was a more conservative method in judging SEMG signal stationarity. Bilodeau et al.(Bilodeau et al., 1997) investigated normality and stationarity of EMG signals of elbow flexor muscles. The researchers used the Reverse Arrangement Test to evaluate the stationarity of the data. The author stated that this (nonparametric) test was justified because there was not enough evidence to indicate a Gaussian distribution at the 0.05 level of significance for the majority of the EMG segments tested. They estimated the test statistic, A, by counting the total number of reverse arrangements and recommended that the values of A, between 38 and 81, indicate stationarity of the EMG signal, whereas values outside this range are associated with nonstationary EMG signal.

Apart from the test method, the estimation of stationarity is also influenced by the window size. Cho and Kim (Cho \& Kim, 2012) compared the influence of different window sizes on the stationarity level of the SEMG signal. A higher stationary level at a window size of 750 ms was observed compared to the window sizes of 250, 500, 1000 and $2000 \mathrm{~ms}$. Waly et al. (Waly, Asfour, \& Khalil, 2003) also tested seven different window sizes $(64,128,256,512,1024,2048$, and 4096 ms) and found that the window size had a significant effect on the frequencies of the power spectrum. The minimum window size that can be used to estimate the power spectrum was found to be 0.5 seconds.

\subsection{Research objective and study hypotheses}

In summary, the previous studies indicate that the stationarity of the SEMG signal is affected by LMF. A reduction in the percentage of stationarity with respect to initial, or under non- 
fatigue conditions can be used to predict muscle fatigue. However, quantifying such change relies on the assumption that stationarity, without fatigue present, can serve as an appropriate reference within the functional ability of a joint. This assumption is even more critical when evaluating shortterm exertions performed under varying task demands for a region such as the shoulder, with a range of motion covering nearly $65 \%$ of a sphere. Recently, Alasim and Nimbarte (Alasim \& Nimbarte, 2019) conducted a study to quantify variability in the mean and median frequencies of the EMG power spectrum for shoulder muscles. They concluded that the mean and median frequencies can change/vary due to factors other than muscle fatigue and that changes within $\pm 6 \%$ of the initial value cannot be regarded as clinically significant. Previously, Öberg et al. (Öberg, Sandsjö, \& Kadefors, 1990) has also made a similar recommendation for a shoulder muscle.

To our knowledge, the assumption that stationarity of SEMG signals do not change due to factors other than fatigue has not been thoroughly tested. Therefore, the objective in this study is to quantify the influence of work/task-related factors on the stationarity of SEMG signals under non-fatigued conditions. The SEMG data from seven shoulder muscles were studied to quantify the changes in the stationarity due to factors such as force levels, force directions, plane of exertion and joint angle. The following null hypotheses were tested:

H01: The work/task-related factors (force, direction, plane and joint angle) will have no effect on the stationarity of SEMG data recorded under non-fatigue condition.

The successful completion of this study is expected to improve the SEMG stationarity based LMF prediction methods/models. 


\section{Chapter 2: Methodology}

\subsection{Approach}

A laboratory-based study was conducted to investigate the effects of force levels, force directions, plane of exertion, and shoulder joint angles on the stationarity of SEMG signals collected from seven shoulder muscles - supraspinatus, infraspinatus, middle deltoid, anterior deltoid, posterior deltoid, biceps, and triceps under non-fatigue condition. The stationarity of the SEMG data have been quantified using modified Reverse Arrangement Test and the effect of work/task-related factors on the stationarity was analyzed using ANOVA.

\subsection{Participants}

A total of 12 participants were recruited for this research. All participants were righthanded dominant and free from any types of musculoskeletal, degenerative, or neurological disorders. They were asked to read and sign a consent form approved by the local Institutional Review Board (Appendix B (pg.60)). The average height for the participants was $169.33 \mathrm{~cm}$ with a standard deviation of $9.28 \mathrm{~cm}$. The average weight for the participants was $69.92 \mathrm{~kg}$ with a standard deviation of $13.94 \mathrm{~kg}$ and the average age for the participants was 28.5 years old with a standard deviation of 3.71 years.

\subsection{Equipment}

\subsubsection{Custom-made Force Exertion Device}

This study used a Lido workset II (Loredan Biological, Inc., CA, USA) device with a height-adjustable component attached to its column (Figure 2-1) to simulate various work/task conditions. This component was constructed with a set of perforated square ducts fitted with pulleys allowing force exertion in various directions. Its height was adjusted based on the 
participant's height to investigate the influence of different shoulder angles. A rope, weight and D-handle system (Figure 2-2) was used with the pulleys to control force levels and directions.

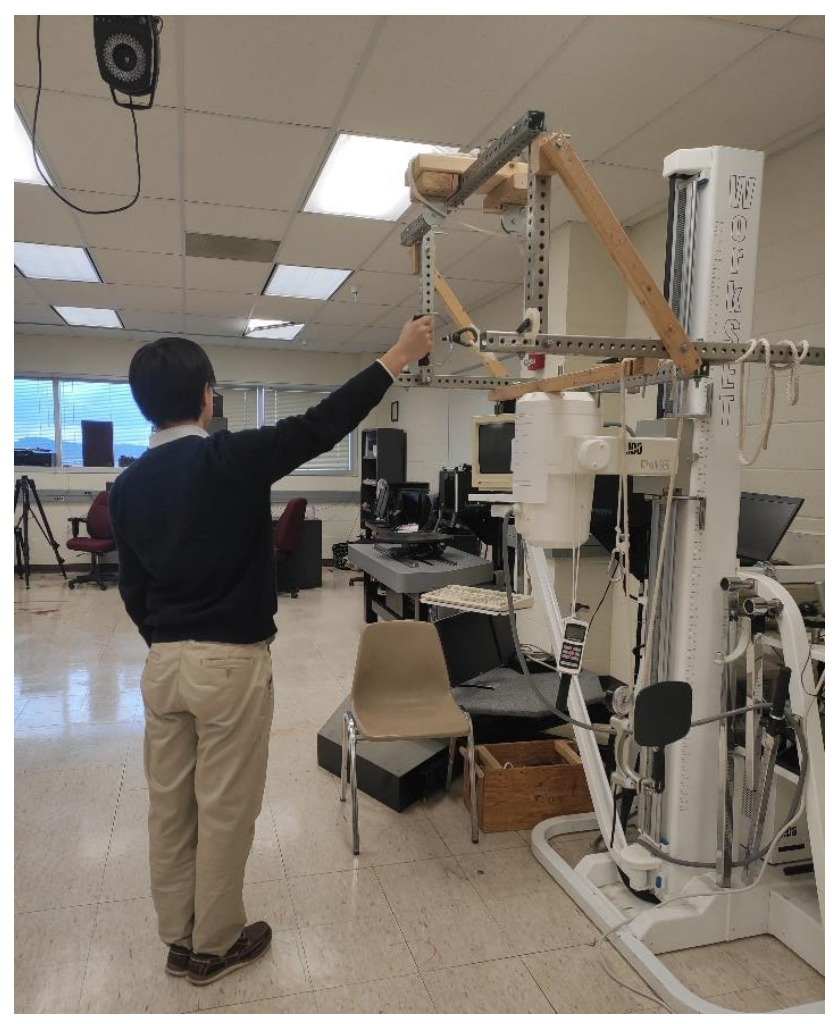

Figure 2-1: Force exertion device with a height adjustable bar-handle assembly

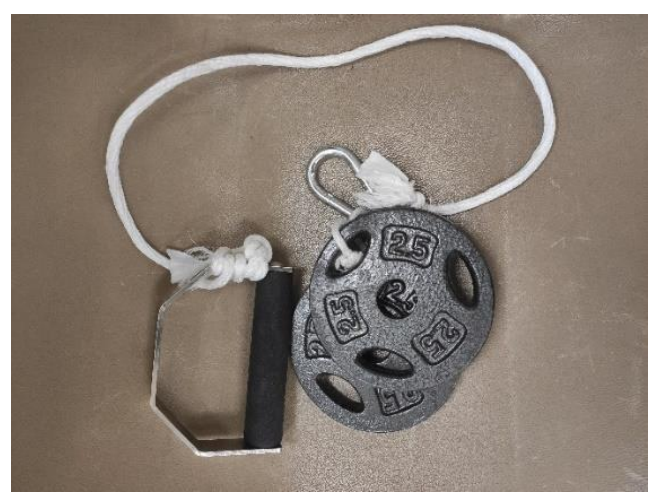

Figure 2-2 Weights and handle used in the experiment

\subsubsection{Electromyography (EMG) System}

A Bagnoli-16 desktop EMG system (Delsys Inc., Boston, USA) was used to collect SEMG data (Figure 2-3). It consists of EMG sensors (Figure 2-3 a), a main amplifier unit (Figure 2-3 b), 
input modules (Figure 2-3 c), input cable (Figure 2-3 d), power supply (Figure 2-3 e), and other peripheral cables.

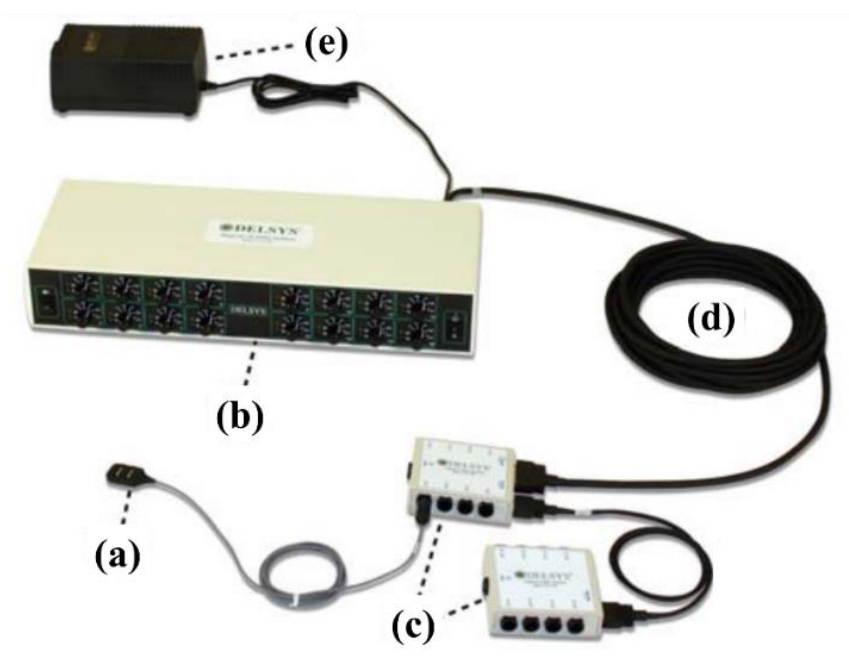

Figure 2-3 Parts of the Bagnoli -16 EMG system - (a) EMG sensor, (b) main amplifier (desktop) unit, (c) input models, (d) input module cable, and (e) power supply (Chowdhury, 2016)

The EMG sensors are parallel bar single differential surface electrodes (DE-2.1 EMG Sensors, Delsys Inc., Boston, USA). The seven measuring electrodes were attached to the surface/skin of the shoulder muscles while the reference electrode was attached to the participant's forehead. The SEMG signal is the potential difference between the measuring electrodes and the reference electrode (Figure 2-4). This signal is transmitted to the main amplifier unit which has a band pass filter of 20 to $450 \mathrm{~Hz}$ and a mechanism to check for excessive amounts of line interference. The data was collected at a frequency of $1000 \mathrm{~Hz}$ for 10 seconds for each experimental trial. 


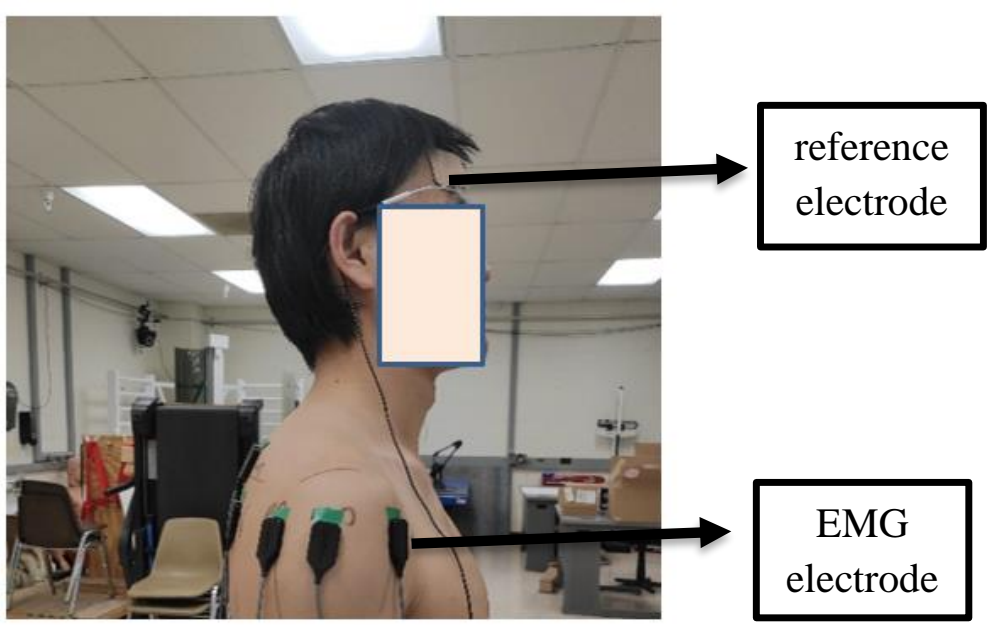

Figure 2-4 The locations of measuring electrodes and reference electrode

\subsection{Design of Experimental}

As summarized in Table 2-1, a four-factors factorial design was used in this research (Figure 2-5).

Table 2-1 Four-factor factorial design

\begin{tabular}{ll}
\hline Factors & Levels \\
\hline Force direction & 1) Pull back, 2) Pull down, 3) Pull left, 4) Pull right, 5) Pull up \\
Force level & 1) $0 \mathrm{lb}$, 2) $2.5 \mathrm{lb}, 3) 5 \mathrm{lb}$ \\
Plane of exertion & 1) Sagittal 2) Scapular \\
Arm-body angel & 1) $60^{\circ}$, 2) $120^{\circ}$ \\
\hline
\end{tabular}

Each trial was approximately 10 seconds long. Two replicates were collected for each experimental condition. A total of 120 experimental trials ( 5 force directions $\times 3$ force exertion levels $\times 2$ planes $\times 2$ angles $\times 2$ replications) have been collected from each individual participant and the trial orders were completely randomized. A rest period of 60 to 70 seconds was provided between different trials to mitigate fatigue. The approximate data collection time for an individual 
participant was around 3 to 4 hours including 20-25 minutes of forceful arm exertion, 120-140 minutes of rest period and 40-60 minutes of preparation time.

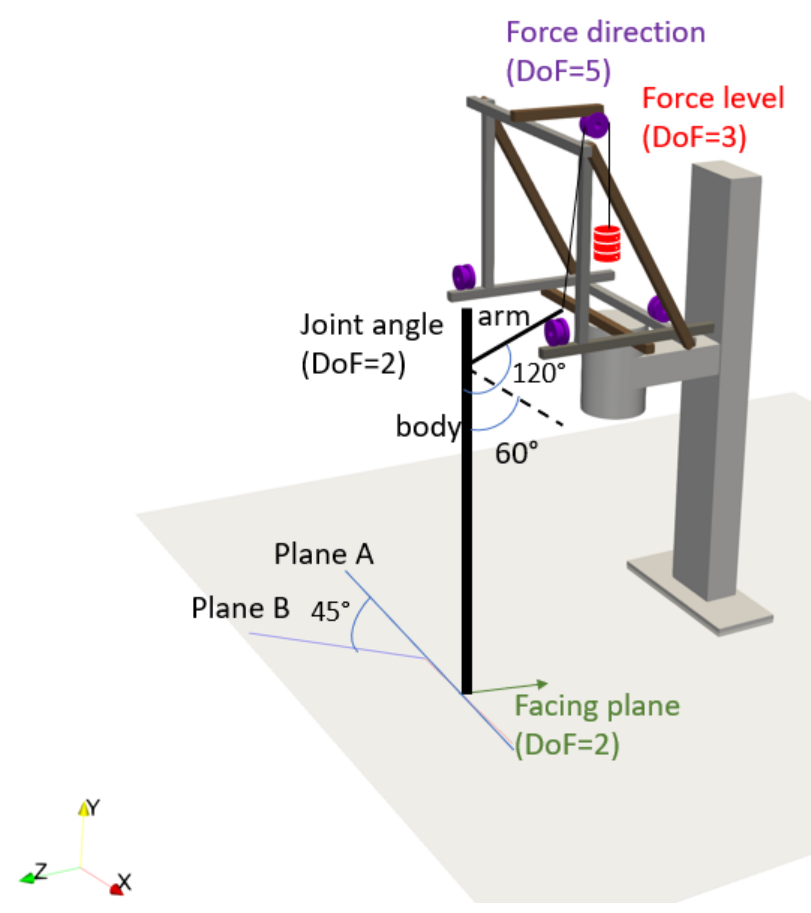

(a) Four-factors variation schematic diagram
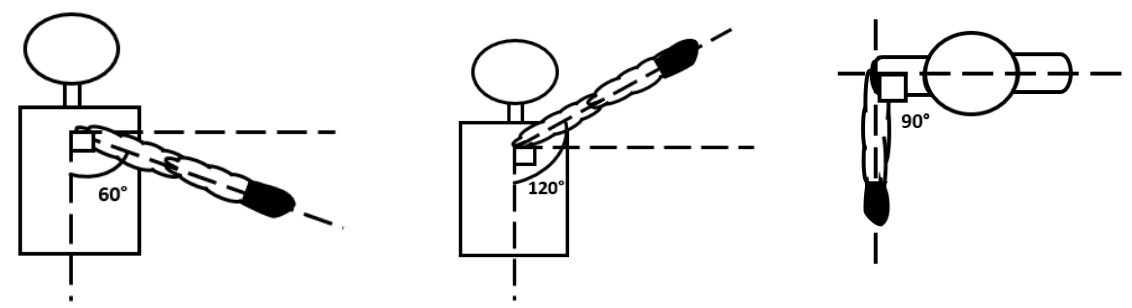

(b)Arm-Body angle $60^{\circ}$

(c) Arm-Body angle $120^{\circ}$

(d) Sagittal

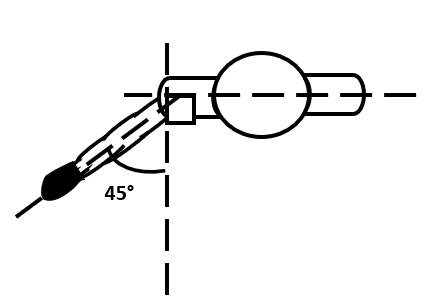

(e) Scapular

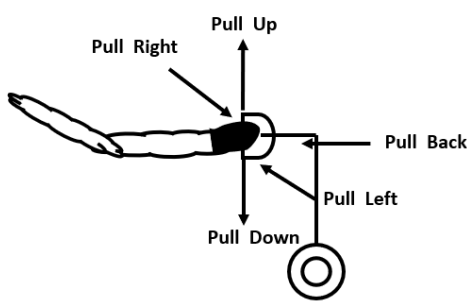

(f) Force direction

Figure 2-5 Four work related factors schematic diagram 


\subsection{Experiment Procedure}

The data collection procedure was explained to the participants upon their arrival at the laboratory. With their permission, a set of anthropometric measures such as height, weight, and age were recorded. Their signatures were obtained on a consent form approved by the local Institutional Review Board (Appendix A (pg.34)).

The surface/skin locations for the muscles were cleaned using $70 \%$ rubbing alcohol to ensure proper electric contact before attaching the electrodes. The SEMG electrode locations for the seven shoulder muscles are explained below:

1) Supraspinatus, which is at midpoint and two fingers-breadths anterior to the scapular spine;

2) Infraspinatus, which is at midpoint and two fingers-breadths below and parallel to the scapular spine;

3) Middle deltoid, which is at midline of the lateral surface of the arm, one fourth of the distance from the acromion to the elbow;

4) Anterior deltoid, which is at two to three fingers- breadths below the acromion process, over the muscle belly, in line with the fibers;

5) Posterior deltoid, which is at two fingers-widths behind the angle of the acromion, over the muscle belly, in line with the fibers;

6) Biceps, which is at midpoint between the acromioclavicular and elbow joint;

7) Triceps, which is at midpoint between acromion of the scapula and the ulna olecranon.

The reference location was placed on the right side of the participant's forehead. After attaching all the electrodes, the cables were plugged into the input module, which then were mounted onto the participant's waist belts or other articles of clothing using a clip attachment. 
Then, the connections of signal cables, power cables, and signal acquisition computer were made/checked.

The experimental trials began by adjusting the height of the custom-made force exertion device to meet the desired angle between the participant's arm and body. In the experiment, the participant resisted the pulling force using the D-handle, which was connected to weights through pulleys in different directions. To minimize the height adjustment of the custom assembly, the first 60 trials were conducted at 60-degree shoulder angle, while the remaining 60 trials were conducted at 120-degree shoulder angle. The sequencing of the other three parameters were randomized. After each trial, the participant was given a break of at least 1 minute.

\subsection{Data Collection and Processing}

The SEMG data were collected using the workflow environment Pro. 4.3.2 at a frequency of $1,000 \mathrm{~Hz}$ for $10 \mathrm{~s}$ (Figure 2-6). After data collection procedure, the Delsys File Utility was used to convert the stored EMGworks ${ }^{\circledR}$ data into Excels files. A total of 120 Excel files were generated for each participant.

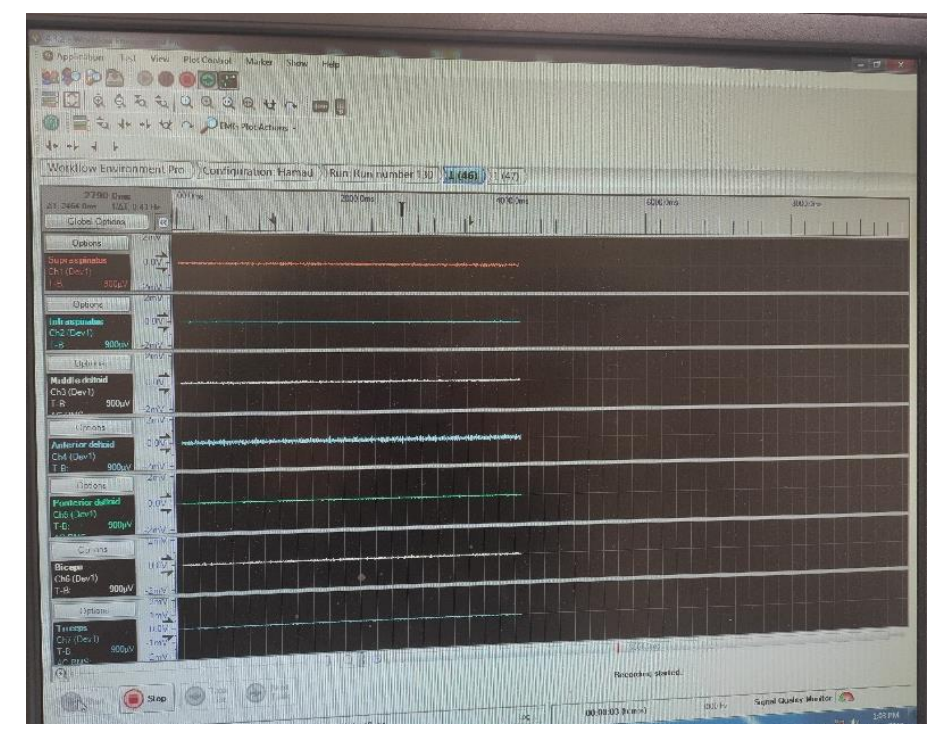

Figure 2-6 User interface of workflow environment pro. 
Based on the studies and recommendations by Cho and Kim (Cho \& Kim, 2012) and Chowdhury and Nimbarte (Chowdhury \& Nimbarte, 2017), the modified Reverse Arrangement Test was used to quantify stationarity of the SEMG data. The data were processed and analyzed using a custom-built MATLAB script (R2019a, The Math Works Inc.). As a first step, the SEMG data were filtered using bandpass $(10 \mathrm{~Hz}$ to $400 \mathrm{~Hz})$ and notch $(60 \mathrm{~Hz})$ filters. Then, the first 9,216 data points of the filtered SEMG signals were divided into segments using different window sizes of $128,256,512,768$, and $1024 \mathrm{~ms}$. As shown in Figure 2-7, a window size of 128 ms divides the data into 72 segments. Each segment was further divided into $M$ sub-segments with a fixed interval of $32 \mathrm{~ms}$. The number of segments and sub-segments for various window sizes are summarized in Table 2-2

Table 2-2 Number of segments and sub-segments for various window sizes

\begin{tabular}{ccc}
\hline Window Size & Number of Segments & Number of Sub-segments \\
\hline 128 & 72 & 4 \\
256 & 36 & 8 \\
512 & 18 & 16 \\
768 & 12 & 24 \\
1024 & 9 & 32 \\
\hline
\end{tabular}

The mean square value $(\mu)$ of each sub-segment was calculated. Then the number of reverse arrangements $(A \imath)$ in the sequence $\{\mu 1, \mu 2, \ldots, \mu M\}$ was calculated by counting the total number of inequalities: $\mu_{j}>\mu_{l}$ for $j<i$, where $j=1,2, \ldots, M-1 ; i=j+1,2, \ldots, M$. The total number of reverse arrangements of a sub-segment was calculated as:

$$
A=\sum_{i=1}^{M} A_{i}
$$


Finally, the stationarity of this segment was calculated using the z-score statistic test as shown in equation (2). When the absolute value of the z-score is less than 1.96, the segment is stationary at the 0.05 significance level.

$$
\mathrm{Z}=\frac{A-\left\{\frac{M(M-1)}{4}\right\}}{\sqrt{\frac{2 M^{3}+3 M^{2}-5 M}{72}}}
$$

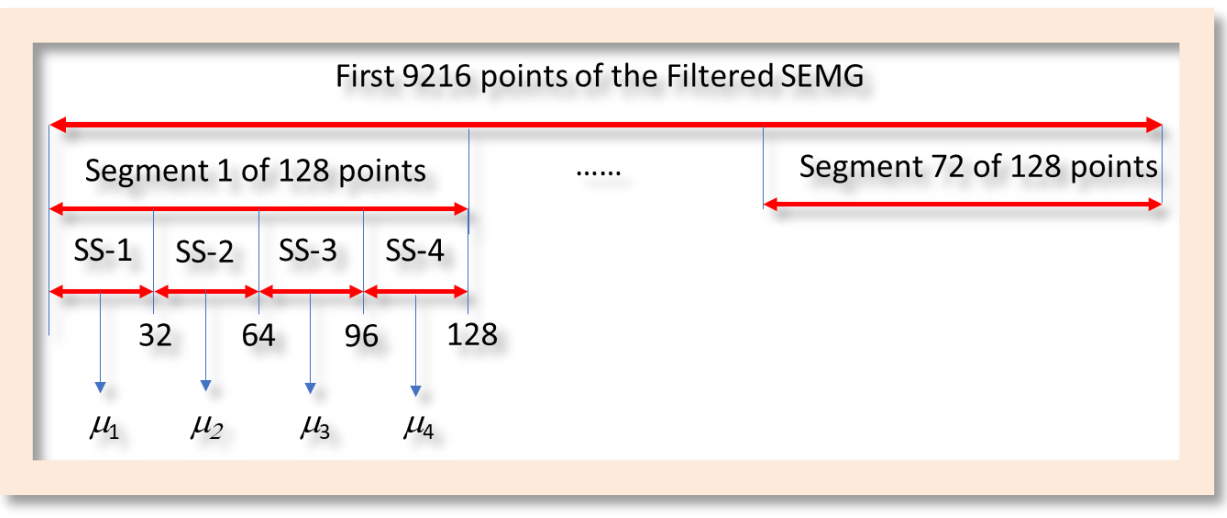

Figure 2-7 Divide filtered SEMG data into 72 segments with a window size of $128 \mathrm{~ms}$

The $\%$ stationarity of the signal was calculated as the number of stationary segments divide by the total number of segments.

$$
\% \text { stationarity }=\left(\frac{\text { Number of stationary segments }}{\text { Total number of segments }}\right) \times 100 \%
$$

\subsection{Statistical analysis}

Analysis of Variance (ANOVA) was performed to test the main and interaction effects of the independent variables on the dependent variables. The independent variables - joint angle, shoulder plane, force level, and force direction factors - were treated as fixed factors, and participants were treated as a random factor. Additionally, the variability in $\%$ stationarity values were estimated by using the square root of MSE $(\sqrt{M S E})$ found in ANOVA table. Normality of 
residuals (Quantile-Quantile plots) and equality of variances were assessed as the assumptions for ANOVA (Appendix A (pg.42)). The statistical significance was set as $\alpha=0.05$. The normality of residuals and equality of variances were assessed using $R$ statistical analysis software. MATLAB was used for the ANOVA analysis. 


\section{Chapter 3 : Results}

There were 10,080 SEMG data files (120 trials $\times 12$ participants $\times 7$ muscles). For each data file, the stationarity calculations were performed using five window sizes. An ANOVA analysis was performed for a muscle and a window size combination. Thus, a total of thirty-five (5 window sizes $\times 7$ muscles) ANOVA analyses were performed. The results are summarized below using different window sizes.

\subsection{Window size of 128}

The main effects of joint angle, plane, force level and force direction on $\%$ stationarity were statistically insignificant $(p>0.05)$ for the shoulder muscles except for the effects of joint angle on supraspinatus and posterior deltoid, plane on middle deltoid, posterior deltoid and triceps, force level on triceps and force direction on infraspinatus, anterior deltoid and triceps (Error!

\section{Reference source not found.).}

The $\%$ stationarity increased with an increase in the joint angle for supraspinatus and posterior deltoid. Higher \% stationarity was observed in the scapular plane compared to the sagittal plane for middle deltoid, posterior deltoid and triceps. The $\%$ stationarity increased with an increase in the force level for triceps. For the infraspinatus the ascending order of force directions in terms of \% stationarity was PD, PB, PU, PL and PR. For the anterior deltoid the ascending order was PU, PB, PR, PL, and PD. For the triceps the ascending order was PL, PU, PR, PB, and PD. (Error! Reference source not found.). 
Table 3-3 Main effect of joint angle, plane, force level, and force direction on \% stationarity data estimated using a window size of 128 . For each muscle mean (standard deviation) stationarity data and the $p$-value ( $p$-val) for the main effect are provided in the table along with the variation (Var) based on

$\sqrt{M S E}$. Statistically significant $p$-values are bolded.

\begin{tabular}{|c|c|c|c|c|c|c|c|c|c|c|c|c|c|c|c|c|c|}
\hline \multirow[b]{2}{*}{ Levels } & \multicolumn{3}{|c|}{ Joint angle } & \multicolumn{3}{|c|}{ Plane } & \multicolumn{4}{|c|}{ Force level } & \multicolumn{6}{|c|}{ Force direction } & \multirow{2}{*}{$\begin{array}{l}\text { Var } \\
(\%)\end{array}$} \\
\hline & $60^{\circ}$ & $120^{\circ}$ & $p$-val & Sagittal & Scapular & $p$-val & o lb. & $2.5 \mathrm{lb}$. & $5 \mathrm{lb}$. & $p$-val & PB & PD & PL & PR & PU & $p$-val & \\
\hline Supra & $\begin{array}{c}0.916 \\
(0.034)\end{array}$ & $\begin{array}{c}0.921 \\
(0.033)\end{array}$ & 0.008 & $\begin{array}{c}0.917 \\
(0.034)\end{array}$ & $\begin{array}{c}0.92 \\
(0.033)\end{array}$ & 0.140 & $\begin{array}{c}0.916 \\
(0.034)\end{array}$ & $\begin{array}{c}0.92 \\
(0.033) \\
\end{array}$ & $\begin{array}{c}0.919 \\
(0.034)\end{array}$ & 0.321 & $\begin{array}{c}0.917 \\
(0.033)\end{array}$ & $\begin{array}{c}0.916 \\
(0.035)\end{array}$ & $\begin{array}{c}0.921 \\
(0.032)\end{array}$ & $\begin{array}{c}0.919 \\
(0.035)\end{array}$ & $\begin{array}{c}0.919 \\
(0.034)\end{array}$ & 0.405 & 3.36 \\
\hline Infra & $\begin{array}{c}0.918 \\
(0.033)\end{array}$ & $\begin{array}{c}0.919 \\
(0.033)\end{array}$ & 0.443 & $\begin{array}{c}0.918 \\
(0.033)\end{array}$ & $\begin{array}{c}0.918 \\
(0.033)\end{array}$ & 0.295 & $\begin{array}{c}0.92 \\
(0.032)\end{array}$ & $\begin{array}{c}0.918 \\
(0.033)\end{array}$ & $\begin{array}{c}0.917 \\
(0.035)\end{array}$ & 0.119 & $\begin{array}{c}0.917 \\
(0.031)\end{array}$ & $\begin{array}{c}0.914 \\
(0.036)\end{array}$ & $\begin{array}{c}0.92 \\
(0.033)\end{array}$ & $\begin{array}{c}0.921 \\
(0.032)\end{array}$ & $\begin{array}{c}0.918 \\
(0.034)\end{array}$ & 0.047 & 3.31 \\
\hline Mdel & $\begin{array}{c}0.92 \\
(0.032)\end{array}$ & $\begin{array}{c}0.923 \\
(0.031)\end{array}$ & 0.108 & $\begin{array}{c}0.919 \\
(0.033)\end{array}$ & $\begin{array}{l}0.924 \\
(0.03)\end{array}$ & 0.024 & $\begin{array}{c}0.923 \\
(0.032)\end{array}$ & $\begin{array}{c}0.921 \\
(0.032)\end{array}$ & $\begin{array}{l}0.921 \\
(0.03)\end{array}$ & 0.199 & $\begin{array}{l}0.921 \\
(0.03)\end{array}$ & $\begin{array}{c}0.922 \\
(0.033)\end{array}$ & $\begin{array}{c}0.925 \\
(0.031)\end{array}$ & $\begin{array}{c}0.921 \\
(0.032)\end{array}$ & $\begin{array}{c}0.919 \\
(0.032)\end{array}$ & 0.967 & 3.15 \\
\hline Adel & $\begin{array}{c}0.923 \\
(0.034)\end{array}$ & $\begin{array}{c}0.92 \\
(0.033)\end{array}$ & 0.151 & $\begin{array}{c}0.921 \\
(0.034)\end{array}$ & $\begin{array}{c}0.922 \\
(0.033)\end{array}$ & 0.794 & $\begin{array}{c}0.922 \\
(0.035)\end{array}$ & $\begin{array}{c}0.922 \\
(0.033) \\
\end{array}$ & $\begin{array}{c}0.92 \\
(0.033)\end{array}$ & 0.353 & $\begin{array}{c}0.923 \\
(0.035)\end{array}$ & $\begin{array}{c}0.916 \\
(0.037)\end{array}$ & $\begin{array}{c}0.921 \\
(0.031)\end{array}$ & $\begin{array}{c}0.922 \\
(0.034)\end{array}$ & $\begin{array}{c}0.924 \\
(0.031)\end{array}$ & 0.005 & 3.35 \\
\hline Pdel & $\begin{array}{c}0.915 \\
(0.034)\end{array}$ & $\begin{array}{c}0.921 \\
(0.033)\end{array}$ & 0.001 & $\begin{array}{c}0.916 \\
(0.034)\end{array}$ & $\begin{array}{c}0.92 \\
(0.033)\end{array}$ & 0.012 & $\begin{array}{c}0.92 \\
(0.033)\end{array}$ & $\begin{array}{c}0.917 \\
(0.034)\end{array}$ & $\begin{array}{c}0.918 \\
(0.034)\end{array}$ & 0.913 & $\begin{array}{c}0.915 \\
(0.032)\end{array}$ & $\begin{array}{c}0.916 \\
(0.032)\end{array}$ & $\begin{array}{c}0.92 \\
(0.036)\end{array}$ & $\begin{array}{c}0.921 \\
(0.034)\end{array}$ & $\begin{array}{c}0.918 \\
(0.033)\end{array}$ & 0.307 & 3.34 \\
\hline Bic & $\begin{array}{c}0.922 \\
(0.033)\end{array}$ & $\begin{array}{c}0.921 \\
(0.034)\end{array}$ & 0.819 & $\begin{array}{c}0.921 \\
(0.033)\end{array}$ & $\begin{array}{c}0.921 \\
(0.034)\end{array}$ & 0.754 & $\begin{array}{c}0.925 \\
(0.034)\end{array}$ & $\begin{array}{c}0.918 \\
(0.033)\end{array}$ & $\begin{array}{c}0.92 \\
(0.033)\end{array}$ & 0.211 & $\begin{array}{c}0.921 \\
(0.034)\end{array}$ & $\begin{array}{c}0.923 \\
(0.033)\end{array}$ & $\begin{array}{c}0.924 \\
(0.033)\end{array}$ & $\begin{array}{c}0.919 \\
(0.033)\end{array}$ & $\begin{array}{c}0.92 \\
(0.036)\end{array}$ & 0.286 & 3.36 \\
\hline Tri & $\begin{array}{c}0.916 \\
(0.035)\end{array}$ & $\begin{array}{c}0.919 \\
(0.033)\end{array}$ & 0.224 & $\begin{array}{c}0.915 \\
(0.034)\end{array}$ & $\begin{array}{c}0.92 \\
(0.034)\end{array}$ & 0.017 & $\begin{array}{c}0.914 \\
(0.035)\end{array}$ & $\begin{array}{c}0.917 \\
(0.034)\end{array}$ & $\begin{array}{c}0.922 \\
(0.033)\end{array}$ & 0.000 & $\begin{array}{c}0.92 \\
(0.034)\end{array}$ & $\begin{array}{c}0.923 \\
(0.034)\end{array}$ & $\begin{array}{c}0.911 \\
(0.033)\end{array}$ & $\begin{array}{c}0.919 \\
(0.032)\end{array}$ & $\begin{array}{c}0.914 \\
(0.035)\end{array}$ & 0.002 & 3.35 \\
\hline
\end{tabular}

Table 3-4 Main effect of joint angle, plane, force level, and force direction on \% stationarity data estimated using a window size of 256 . For each muscle mean (standard deviation) stationarity data and the $p$-value ( $p$-val) for the main effect are provided in the table along with the variation (Var) based on $\sqrt{M S E}$. Statistically significant $p$-values are bolded.

\begin{tabular}{|c|c|c|c|c|c|c|c|c|c|c|c|c|c|c|c|c|c|}
\hline \multirow[b]{2}{*}{ Levels } & \multicolumn{3}{|c|}{ Joint angle } & \multicolumn{3}{|c|}{ Plane } & \multicolumn{4}{|c|}{ Force level } & \multicolumn{6}{|c|}{ Force direction } & \multirow[t]{2}{*}{$\begin{array}{l}\text { Var } \\
(\%)\end{array}$} \\
\hline & $60^{\circ}$ & $120^{\circ}$ & $p$-val & Sagittal & Scapular & $p$-val & O lb. & $2.5 \mathrm{lb}$. & $5 \mathrm{lb}$. & $p$-val & PB & PD & $\mathbf{P L}$ & PR & PU & $p$-val & \\
\hline Supra & $\begin{array}{c}0.925 \\
(0.048) \\
\end{array}$ & $\begin{array}{c}0.934 \\
(0.042)\end{array}$ & 0.000 & $\begin{array}{c}0.929 \\
(0.045) \\
\end{array}$ & $\begin{array}{c}0.93 \\
(0.045)\end{array}$ & 0.090 & $\begin{array}{c}0.931 \\
(0.045) \\
\end{array}$ & $\begin{array}{c}0.93 \\
(0.045)\end{array}$ & $\begin{array}{c}0.928 \\
(0.046)\end{array}$ & 0.151 & $\begin{array}{c}0.932 \\
(0.042)\end{array}$ & $\begin{array}{c}0.926 \\
(0.049) \\
\end{array}$ & $\begin{array}{c}0.93 \\
(0.046) \\
\end{array}$ & $\begin{array}{c}0.93 \\
(0.043)\end{array}$ & $\begin{array}{c}0.93 \\
(0.045) \\
\end{array}$ & 0.247 & 4.49 \\
\hline Infra & $\begin{array}{c}0.932 \\
(0.044)\end{array}$ & $\begin{array}{c}0.932 \\
(0.042)\end{array}$ & 0.953 & $\begin{array}{c}0.931 \\
(0.043) \\
\end{array}$ & $\begin{array}{c}0.933 \\
(0.043)\end{array}$ & 0.834 & $\begin{array}{c}0.936 \\
(0.041) \\
\end{array}$ & $\begin{array}{c}0.934 \\
(0.043)\end{array}$ & $\begin{array}{c}0.926 \\
(0.043) \\
\end{array}$ & 0.004 & $\begin{array}{c}0.93 \\
(0.045) \\
\end{array}$ & $\begin{array}{c}0.927 \\
(0.046) \\
\end{array}$ & $\begin{array}{l}0.936 \\
(0.04) \\
\end{array}$ & $\begin{array}{c}0.936 \\
(0.041) \\
\end{array}$ & $\begin{array}{c}0.932 \\
(0.042) \\
\end{array}$ & 0.034 & 4.27 \\
\hline Mdel & $\begin{array}{l}0.936 \\
(0.04)\end{array}$ & $\begin{array}{l}0.938 \\
(0.04)\end{array}$ & 0.630 & $\begin{array}{l}0.935 \\
(0.04)\end{array}$ & $\begin{array}{c}0.939 \\
(0.041)\end{array}$ & 0.497 & $\begin{array}{c}0.938 \\
(0.042)\end{array}$ & $\begin{array}{l}0.939 \\
(0.04)\end{array}$ & $\begin{array}{l}0.934 \\
(0.04)\end{array}$ & 0.057 & $\begin{array}{c}0.934 \\
(0.041)\end{array}$ & $\begin{array}{c}0.933 \\
(0.044)\end{array}$ & $\begin{array}{c}0.94 \\
(0.042)\end{array}$ & $\begin{array}{c}0.939 \\
(0.038)\end{array}$ & $\begin{array}{c}0.939 \\
(0.037)\end{array}$ & 0.130 & 4.00 \\
\hline Adel & $\begin{array}{c}0.939 \\
(0.042) \\
\end{array}$ & $\begin{array}{c}0.937 \\
(0.041)\end{array}$ & 0.218 & $\begin{array}{c}0.941 \\
(0.039) \\
\end{array}$ & $\begin{array}{c}0.935 \\
(0.043) \\
\end{array}$ & 0.007 & $\begin{array}{c}0.943 \\
(0.039)\end{array}$ & $\begin{array}{l}0.939 \\
(0.04) \\
\end{array}$ & $\begin{array}{c}0.933 \\
(0.044)\end{array}$ & 0.001 & $\begin{array}{c}0.937 \\
(0.045) \\
\end{array}$ & $\begin{array}{c}0.933 \\
(0.042)\end{array}$ & $\begin{array}{c}0.942 \\
(0.042)\end{array}$ & $\begin{array}{l}0.938 \\
(0.04)\end{array}$ & $\begin{array}{c}0.941 \\
(0.038)\end{array}$ & 0.054 & 4.12 \\
\hline Pdel & $\begin{array}{c}0.93 \\
(0.041) \\
\end{array}$ & $\begin{array}{c}0.939 \\
(0.044)\end{array}$ & 0.000 & $\begin{array}{c}0.933 \\
(0.043) \\
\end{array}$ & $\begin{array}{c}0.937 \\
(0.042)\end{array}$ & 0.326 & $\begin{array}{c}0.936 \\
(0.042) \\
\end{array}$ & $\begin{array}{c}0.934 \\
(0.043)\end{array}$ & $\begin{array}{c}0.934 \\
(0.043)\end{array}$ & 0.533 & $\begin{array}{c}0.934 \\
(0.042)\end{array}$ & $\begin{array}{c}0.932 \\
(0.043)\end{array}$ & $\begin{array}{c}0.933 \\
(0.045)\end{array}$ & $\begin{array}{c}0.937 \\
(0.042)\end{array}$ & $\begin{array}{c}0.938 \\
(0.042)\end{array}$ & 0.280 & 4.25 \\
\hline Bic & $\begin{array}{c}0.939 \\
(0.041)\end{array}$ & $\begin{array}{c}0.938 \\
(0.041)\end{array}$ & 0.924 & $\begin{array}{c}0.939 \\
(0.042) \\
\end{array}$ & $\begin{array}{c}0.939 \\
(0.041)\end{array}$ & 0.427 & $\begin{array}{l}0.944 \\
(0.04)\end{array}$ & $\begin{array}{c}0.936 \\
(0.043)\end{array}$ & $\begin{array}{l}0.936 \\
(0.04)\end{array}$ & 0.039 & $\begin{array}{c}0.937 \\
(0.043)\end{array}$ & $\begin{array}{c}0.94 \\
(0.041)\end{array}$ & $\begin{array}{c}0.935 \\
(0.042)\end{array}$ & $\begin{array}{c}0.943 \\
(0.039)\end{array}$ & $\begin{array}{c}0.939 \\
(0.041)\end{array}$ & 0.067 & 4.09 \\
\hline Tri & $\begin{array}{c}0.931 \\
(0.044) \\
\end{array}$ & $\begin{array}{c}0.933 \\
(0.045) \\
\end{array}$ & 0.827 & $\begin{array}{c}0.931 \\
(0.046) \\
\end{array}$ & $\begin{array}{c}0.933 \\
(0.043) \\
\end{array}$ & 0.981 & $\begin{array}{c}0.931 \\
(0.045) \\
\end{array}$ & $\begin{array}{c}0.933 \\
(0.043) \\
\end{array}$ & $\begin{array}{c}0.932 \\
(0.045) \\
\end{array}$ & 0.110 & $\begin{array}{c}0.932 \\
(0.042) \\
\end{array}$ & $\begin{array}{c}0.936 \\
(0.042) \\
\end{array}$ & $\begin{array}{c}0.925 \\
(0.048) \\
\end{array}$ & $\begin{array}{c}0.939 \\
(0.042) \\
\end{array}$ & $\begin{array}{c}0.929 \\
(0.047) \\
\end{array}$ & 0.001 & 4.41 \\
\hline
\end{tabular}




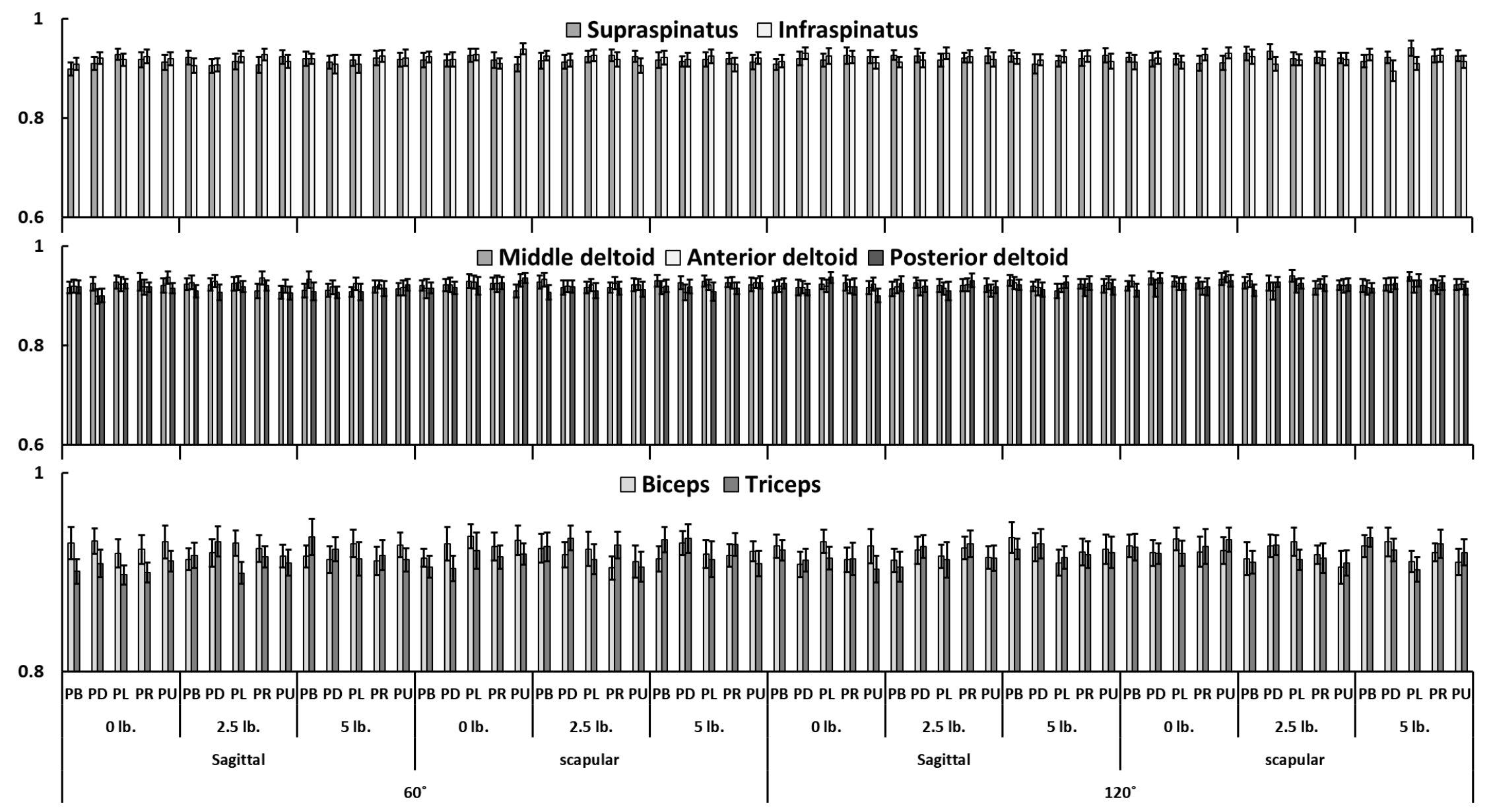

Figure 3-1 Mean stationarity data (window size =128) for the shoulder muscles during the exertions performed in pull back (PB), pull down (PD), pull left (PL), pull right (PR), and pull up (PU) directions, using weights of $0,2.5$ and $5 \mathrm{lbs}$. in sagittal and scapular planes at $60^{\circ}$ and $120^{\circ}$ shoulder angles. Error bars represent $95 \%$ confidence interval. 

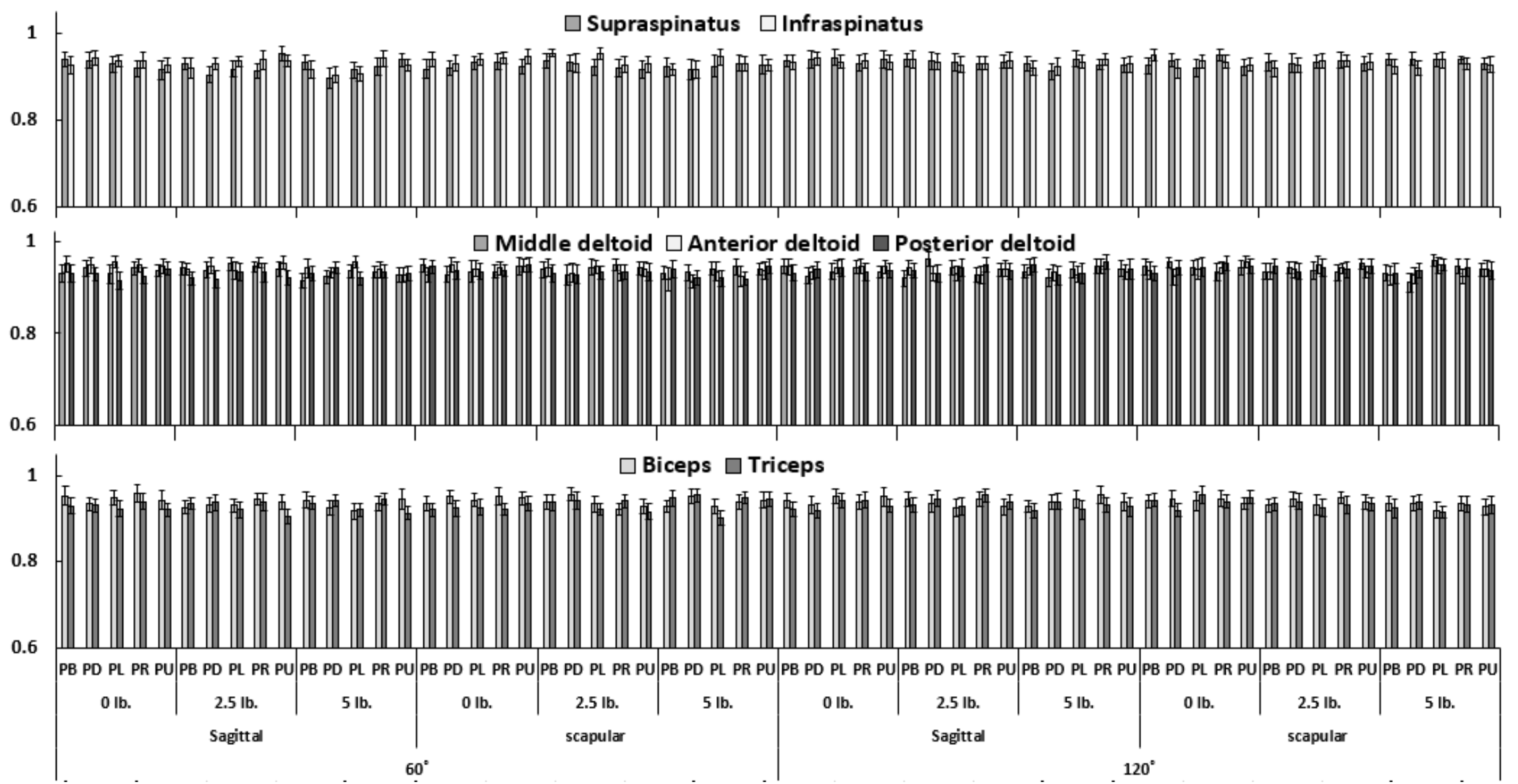

Figure 3-2 Mean stationarity data (window size =256) for the shoulder muscles during the exertions performed in pull back (PB), pull down (PD), pull left (PL), pull right (PR), and pull up (PU) directions, using weights of $0,2.5$ and 5 lbs. in sagittal and scapular planes at $60^{\circ}$ and $120^{\circ}$ shoulder angles. Error bars represent $95 \%$ confidence interval. 
The largest \% stationarity variation was observed in the supraspinatus and biceps $(3.36 \%)$ and the smallest \% stationarity variation was observed in the middle deltoid (3.15\%). Similar variation of 3.35\% was observed for anterior deltoid and triceps (Error! Reference source not found.).

\subsection{Window size of 256}

The main effects of joint angle, plane, force level and force direction on \% stationarity were statistically insignificant $(p>0.05)$ for the shoulder muscles except for the effects of joint angle on supraspinatus and posterior deltoid, plane on anterior deltoid, force level on infraspinatus, anterior deltoid and biceps and force direction on infraspinatus, and triceps (Error! Reference source not found.).

The $\%$ stationarity increased with an increase in the joint angle for supraspinatus and posterior deltoid. Higher \% stationarity was observed in the sagittal plane compared to the scapular plane for anterior deltoid. The $\%$ stationarity decreased with an increase of force level for infraspinatus, anterior deltoid and biceps. For the infraspinatus the ascending order of force directions in terms of $\%$ stationarity was PD, PB, PU, PL, and PR. For the triceps the ascending order was PL, PU, PB, PD, and PR. (Error! Reference source not found.).

The largest \% stationarity variation was observed in the supraspinatus (4.49\%) and the smallest \% stationarity variation was observed in the middle deltoid (4.00\%). Similar variation of 4.27\% was observed for infraspinatus and posterior deltoid (Table 3-4).

\subsection{Window size of 512}

The main effects of joint angle and plane on \% stationarity was statistically insignificant $(p>0.05)$ for the shoulder muscles except for the effects of joint angle on anterior deltoid, plane on supraspinatus and posterior deltoid. The main effects of force level and force direction on $\%$ stationarity were statistically significant $(p<0.05)$ for the shoulder muscles except for the effects 
of force level on supraspinatus, posterior deltoid and triceps, and force direction on infraspinatus and posterior deltoid (Table 3-5 
Table 3-5 Main effect of joint angle, plane, force level, and force direction on \% stationarity data estimated using a window size of 512. For each muscle mean (standard deviation) stationarity data and the $p$-value ( $p$-val) for the main effect are provided in the table along with the variation (Var) based on $\sqrt{M S E}$. Statistically significant $p$-values are bolded.

\begin{tabular}{|c|c|c|c|c|c|c|c|c|c|c|c|c|c|c|c|c|c|}
\hline & \multicolumn{3}{|c|}{ Joint angle } & \multicolumn{3}{|c|}{ Plane } & \multicolumn{4}{|c|}{ Force level } & \multicolumn{6}{|c|}{ Force direction } & \multirow{2}{*}{$\begin{array}{l}\text { Var } \\
(\%)\end{array}$} \\
\hline Levels & $60^{\circ}$ & $120^{\circ}$ & $p$-val & Sagittal & Scapular & $p-v a l$ & 0 lb. & $2.5 \mathrm{lb}$. & $5 \mathrm{lb}$. & $p$-val & PB & PD & PL & PR & PU & $p$-val & \\
\hline Supra & $\begin{array}{c}0.929 \\
(0.066)\end{array}$ & $\begin{array}{c}0.93 \\
(0.062)\end{array}$ & 0.462 & $\begin{array}{c}0.925 \\
(0.066)\end{array}$ & $\begin{array}{c}0.934 \\
(0.062)\end{array}$ & 0.012 & $\begin{array}{c}0.935 \\
(0.059)\end{array}$ & $\begin{array}{c}0.928 \\
(0.066)\end{array}$ & $\begin{array}{c}0.925 \\
(0.065)\end{array}$ & 0.015 & $\begin{array}{c}0.934 \\
(0.058)\end{array}$ & $\begin{array}{c}0.92 \\
(0.071)\end{array}$ & $\begin{array}{c}0.927 \\
(0.067)\end{array}$ & $\begin{array}{c}0.937 \\
(0.056)\end{array}$ & $\begin{array}{c}0.928 \\
(0.064)\end{array}$ & 0.005 & 6.31 \\
\hline Infra & $\begin{array}{c}0.935 \\
(0.061)\end{array}$ & $\begin{array}{c}0.932 \\
(0.061)\end{array}$ & 0.796 & $\begin{array}{c}0.933 \\
(0.061)\end{array}$ & $\begin{array}{c}0.934 \\
(0.061)\end{array}$ & 0.689 & $\begin{array}{c}0.94 \\
(0.058)\end{array}$ & $\begin{array}{c}0.934 \\
(0.061)\end{array}$ & $\begin{array}{c}0.927 \\
(0.063)\end{array}$ & 0.003 & $\begin{array}{c}0.937 \\
(0.059)\end{array}$ & $\begin{array}{c}0.926 \\
(0.068)\end{array}$ & $\begin{array}{l}0.935 \\
(0.06)\end{array}$ & $\begin{array}{c}0.933 \\
(0.058) \\
\end{array}$ & $\begin{array}{c}0.936 \\
(0.059)\end{array}$ & 0.059 & 6.08 \\
\hline Mdel & $\begin{array}{c}0.937 \\
(0.061)\end{array}$ & $\begin{array}{c}0.938 \\
(0.061)\end{array}$ & 0.739 & $\begin{array}{c}0.94 \\
(0.06)\end{array}$ & $\begin{array}{c}0.936 \\
(0.062) \\
\end{array}$ & 0.475 & $\begin{array}{c}0.949 \\
(0.055)\end{array}$ & $\begin{array}{c}0.937 \\
(0.059)\end{array}$ & $\begin{array}{c}0.927 \\
(0.066)\end{array}$ & 0.000 & $\begin{array}{l}0.939 \\
(0.06)\end{array}$ & $\begin{array}{l}0.928 \\
(0.07) \\
\end{array}$ & $\begin{array}{c}0.944 \\
(0.057)\end{array}$ & $\begin{array}{c}0.943 \\
(0.054)\end{array}$ & $\begin{array}{c}0.934 \\
(0.062) \\
\end{array}$ & 0.008 & 6.00 \\
\hline Adel & $\begin{array}{c}0.941 \\
(0.061)\end{array}$ & $\begin{array}{c}0.932 \\
(0.062)\end{array}$ & 0.031 & $\begin{array}{c}0.937 \\
(0.061)\end{array}$ & $\begin{array}{c}0.936 \\
(0.063)\end{array}$ & 0.944 & $\begin{array}{c}0.947 \\
(0.053)\end{array}$ & $\begin{array}{c}0.935 \\
(0.063)\end{array}$ & $\begin{array}{c}0.928 \\
(0.068)\end{array}$ & 0.000 & $\begin{array}{l}0.942 \\
(0.06)\end{array}$ & $\begin{array}{c}0.922 \\
(0.072)\end{array}$ & $\begin{array}{c}0.941 \\
(0.057)\end{array}$ & $\begin{array}{c}0.936 \\
(0.063) \\
\end{array}$ & $\begin{array}{c}0.942 \\
(0.055)\end{array}$ & 0.000 & 6.09 \\
\hline Pdel & $\begin{array}{c}0.934 \\
(0.058) \\
\end{array}$ & $\begin{array}{c}0.938 \\
(0.058) \\
\end{array}$ & 0.172 & $\begin{array}{l}0.932 \\
(0.06)\end{array}$ & $\begin{array}{c}0.94 \\
(0.056) \\
\end{array}$ & 0.028 & $\begin{array}{c}0.942 \\
(0.056) \\
\end{array}$ & $\begin{array}{c}0.933 \\
(0.061) \\
\end{array}$ & $\begin{array}{c}0.933 \\
(0.058) \\
\end{array}$ & 0.060 & $\begin{array}{l}0.935 \\
(0.06) \\
\end{array}$ & $\begin{array}{c}0.931 \\
(0.062) \\
\end{array}$ & $\begin{array}{c}0.939 \\
(0.055) \\
\end{array}$ & $\begin{array}{c}0.937 \\
(0.056) \\
\end{array}$ & $\begin{array}{c}0.937 \\
(0.058) \\
\end{array}$ & 0.323 & 5.81 \\
\hline Bic & $\begin{array}{c}0.936 \\
(0.059) \\
\end{array}$ & $\begin{array}{c}0.939 \\
(0.061)\end{array}$ & 0.613 & $\begin{array}{l}0.937 \\
(0.06) \\
\end{array}$ & $\begin{array}{l}0.938 \\
(0.06) \\
\end{array}$ & 0.613 & $\begin{array}{c}0.944 \\
(0.057)\end{array}$ & $\begin{array}{c}0.938 \\
(0.06) \\
\end{array}$ & $\begin{array}{c}0.929 \\
(0.062)\end{array}$ & 0.000 & $\begin{array}{c}0.938 \\
(0.059)\end{array}$ & $\begin{array}{c}0.933 \\
(0.063) \\
\end{array}$ & $\begin{array}{c}0.937 \\
(0.058)\end{array}$ & $\begin{array}{c}0.945 \\
(0.057) \\
\end{array}$ & $\begin{array}{c}0.933 \\
(0.061) \\
\end{array}$ & 0.048 & 5.92 \\
\hline Tri & $\begin{array}{c}0.928 \\
(0.063)\end{array}$ & $\begin{array}{c}0.928 \\
(0.061)\end{array}$ & 0.619 & $\begin{array}{l}0.928 \\
(0.06) \\
\end{array}$ & $\begin{array}{c}0.927 \\
(0.065)\end{array}$ & 0.790 & $\begin{array}{l}0.927 \\
(0.06) \\
\end{array}$ & $\begin{array}{c}0.931 \\
(0.059)\end{array}$ & $\begin{array}{c}0.925 \\
(0.067)\end{array}$ & 0.363 & $\begin{array}{c}0.928 \\
(0.061)\end{array}$ & $\begin{array}{l}0.933 \\
(0.06) \\
\end{array}$ & $\begin{array}{c}0.915 \\
(0.067)\end{array}$ & $\begin{array}{c}0.938 \\
(0.057)\end{array}$ & $\begin{array}{c}0.925 \\
(0.063)\end{array}$ & 0.000 & 6.17 \\
\hline
\end{tabular}

Table 3-6 Main effect of joint angle, plane, force level, and force direction on \% stationarity data estimated using a window size of 768. For each muscle mean (standard deviation) stationarity data and the $p$-value ( $p$-val) for the main effect are provided in the table along with the variation (Var) based on $\sqrt{M S E}$. Statistically significant $p$-values are bolded.

\begin{tabular}{|c|c|c|c|c|c|c|c|c|c|c|c|c|c|c|c|c|c|}
\hline \multirow[b]{2}{*}{ Levels } & \multicolumn{3}{|c|}{ Joint angle } & \multicolumn{3}{|c|}{ Plane } & \multicolumn{4}{|c|}{ Force level } & \multicolumn{6}{|c|}{ Force direction } & \multirow{2}{*}{$\begin{array}{l}\text { Var } \\
(\%)\end{array}$} \\
\hline & $60^{\circ}$ & $120^{\circ}$ & $p$-val & Sagittal & Scapular & $p$-val & 0 lb. & $2.5 \mathrm{lb}$ & $5 \mathrm{lb}$. & $p-v a l$ & PB & PD & PL & PR & PU & $p$-val & \\
\hline Supra & $\begin{array}{c}0.92 \\
(0.085)\end{array}$ & $\begin{array}{l}0.921 \\
(0.08)\end{array}$ & 0.225 & $\begin{array}{c}0.918 \\
(0.085)\end{array}$ & $\begin{array}{c}0.923 \\
(0.079)\end{array}$ & 0.355 & $\begin{array}{c}0.931 \\
(0.074)\end{array}$ & $\begin{array}{c}0.92 \\
(0.081)\end{array}$ & $\begin{array}{c}0.91 \\
(0.09)\end{array}$ & 0.000 & $\begin{array}{c}0.927 \\
(0.077)\end{array}$ & $\begin{array}{c}0.91 \\
(0.087)\end{array}$ & $\begin{array}{c}0.923 \\
(0.082)\end{array}$ & $\begin{array}{c}0.918 \\
(0.087)\end{array}$ & $\begin{array}{c}0.924 \\
(0.078)\end{array}$ & 0.024 & 8.11 \\
\hline Infra & $\begin{array}{c}0.927 \\
(0.075)\end{array}$ & $\begin{array}{l}0.925 \\
(0.08) \\
\end{array}$ & 0.600 & $\begin{array}{c}0.925 \\
(0.079) \\
\end{array}$ & $\begin{array}{c}0.926 \\
(0.076)\end{array}$ & 1.000 & $\begin{array}{c}0.932 \\
(0.076)\end{array}$ & $\begin{array}{c}0.924 \\
(0.077)\end{array}$ & $\begin{array}{c}0.92 \\
(0.08)\end{array}$ & 0.030 & $\begin{array}{c}0.926 \\
(0.078)\end{array}$ & $\begin{array}{c}0.923 \\
(0.078)\end{array}$ & $\begin{array}{c}0.932 \\
(0.076)\end{array}$ & $\begin{array}{c}0.92 \\
(0.082)\end{array}$ & $\begin{array}{c}0.926 \\
(0.073)\end{array}$ & 0.304 & 7.77 \\
\hline Mdel & $\begin{array}{c}0.93 \\
(0.073)\end{array}$ & $\begin{array}{l}0.922 \\
(0.08)\end{array}$ & 0.121 & $\begin{array}{c}0.926 \\
(0.078)\end{array}$ & $\begin{array}{c}0.926 \\
(0.076)\end{array}$ & 0.822 & $\begin{array}{c}0.937 \\
(0.069)\end{array}$ & $\begin{array}{c}0.927 \\
(0.074)\end{array}$ & $\begin{array}{c}0.914 \\
(0.086)\end{array}$ & 0.000 & $\begin{array}{c}0.927 \\
(0.073)\end{array}$ & $\begin{array}{c}0.913 \\
(0.088)\end{array}$ & $\begin{array}{c}0.929 \\
(0.078)\end{array}$ & $\begin{array}{c}0.934 \\
(0.066)\end{array}$ & $\begin{array}{c}0.928 \\
(0.078)\end{array}$ & 0.003 & 7.61 \\
\hline Adel & $\begin{array}{c}0.925 \\
(0.082)\end{array}$ & $\begin{array}{c}0.922 \\
(0.085)\end{array}$ & 0.906 & $\begin{array}{c}0.923 \\
(0.083)\end{array}$ & $\begin{array}{c}0.924 \\
(0.085)\end{array}$ & 0.927 & $\begin{array}{l}0.937 \\
(0.07)\end{array}$ & $\begin{array}{c}0.926 \\
(0.084)\end{array}$ & $\begin{array}{c}0.908 \\
(0.093)\end{array}$ & 0.000 & $\begin{array}{c}0.925 \\
(0.079)\end{array}$ & $\begin{array}{c}0.898 \\
(0.098)\end{array}$ & $\begin{array}{c}0.93 \\
(0.08) \\
\end{array}$ & $\begin{array}{c}0.929 \\
(0.082)\end{array}$ & $\begin{array}{c}0.936 \\
(0.073)\end{array}$ & 0.000 & 8.16 \\
\hline Pdel & $\begin{array}{c}0.924 \\
(0.078)\end{array}$ & $\begin{array}{c}0.925 \\
(0.077)\end{array}$ & 0.945 & $\begin{array}{c}0.922 \\
(0.079)\end{array}$ & $\begin{array}{c}0.927 \\
(0.076)\end{array}$ & 0.177 & $\begin{array}{c}0.93 \\
(0.076)\end{array}$ & $\begin{array}{c}0.925 \\
(0.074)\end{array}$ & $\begin{array}{c}0.919 \\
(0.082)\end{array}$ & 0.077 & $\begin{array}{c}0.933 \\
(0.073)\end{array}$ & $\begin{array}{c}0.911 \\
(0.084)\end{array}$ & $\begin{array}{c}0.924 \\
(0.083)\end{array}$ & $\begin{array}{c}0.924 \\
(0.073)\end{array}$ & $\begin{array}{c}0.93 \\
(0.073)\end{array}$ & 0.002 & 7.70 \\
\hline Bic & $\begin{array}{c}0.93 \\
(0.076)\end{array}$ & $\begin{array}{c}0.927 \\
(0.077)\end{array}$ & 0.202 & $\begin{array}{c}0.93 \\
(0.077)\end{array}$ & $\begin{array}{c}0.927 \\
(0.076)\end{array}$ & 0.022 & $\begin{array}{l}0.942 \\
(0.07)\end{array}$ & $\begin{array}{c}0.926 \\
(0.079)\end{array}$ & $\begin{array}{c}0.917 \\
(0.078)\end{array}$ & 0.000 & $\begin{array}{c}0.928 \\
(0.078)\end{array}$ & $\begin{array}{c}0.926 \\
(0.079)\end{array}$ & $\begin{array}{l}0.922 \\
(0.08)\end{array}$ & $\begin{array}{l}0.933 \\
(0.07)\end{array}$ & $\begin{array}{c}0.932 \\
(0.075)\end{array}$ & 0.430 & 7.55 \\
\hline Tri & $\begin{array}{c}0.914 \\
(0.088)\end{array}$ & $\begin{array}{c}0.918 \\
(0.084)\end{array}$ & 0.516 & $\begin{array}{c}0.915 \\
(0.084)\end{array}$ & $\begin{array}{c}0.918 \\
(0.088)\end{array}$ & 0.549 & $\begin{array}{c}0.917 \\
(0.083)\end{array}$ & $\begin{array}{c}0.918 \\
(0.084)\end{array}$ & $\begin{array}{c}0.914 \\
(0.091)\end{array}$ & 0.940 & $\begin{array}{c}0.916 \\
(0.086)\end{array}$ & $\begin{array}{c}0.924 \\
(0.083)\end{array}$ & $\begin{array}{c}0.906 \\
(0.095)\end{array}$ & $\begin{array}{c}0.926 \\
(0.075)\end{array}$ & $\begin{array}{c}0.909 \\
(0.088)\end{array}$ & 0.006 & 8.58 \\
\hline
\end{tabular}




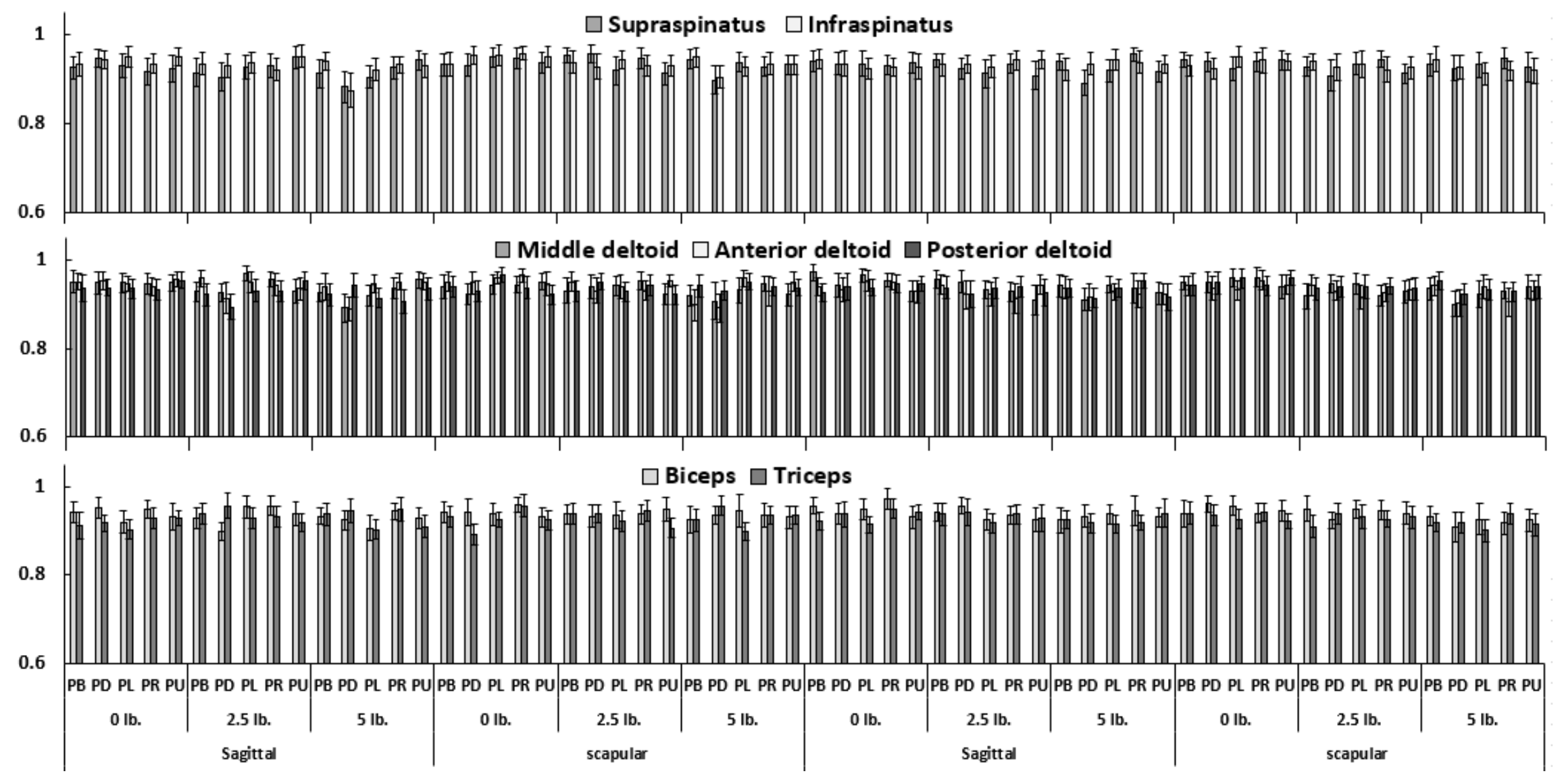

Figure 3-3: Mean stationarity data (window size =512) for the shoulder muscles during the exertions performed in pull back $(\mathrm{PB})$, pull down $(\mathrm{PD})$, pull left (PL), pull right (PR), and pull up (PU) directions, using weights of $0,2.5$ and $5 \mathrm{lbs}$. in sagittal and scapular planes at $60^{\circ}$ and $120^{\circ}$ shoulder angles. Error bars represent $95 \%$ confidence interval. 


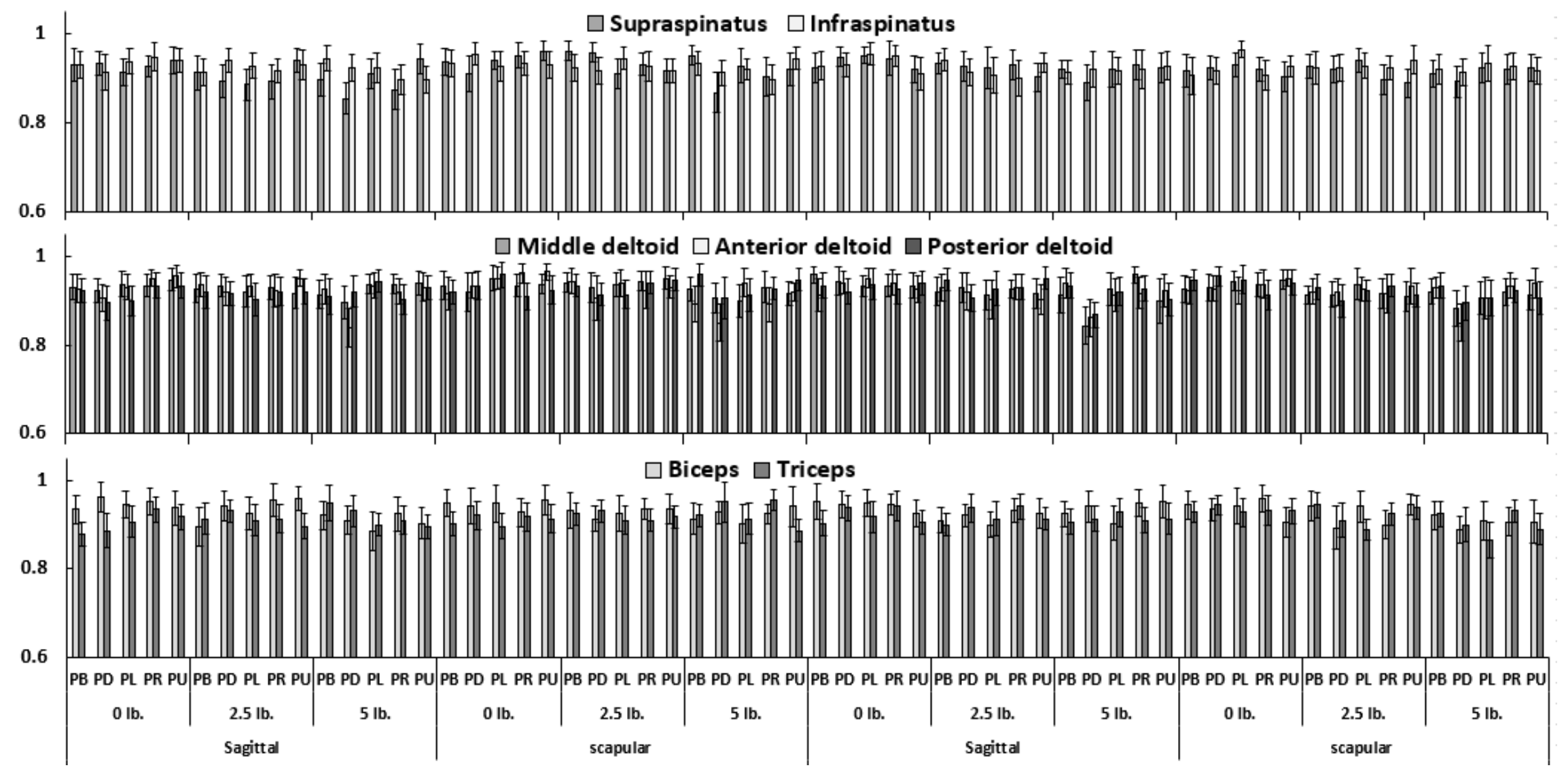

Figure 3-4: Mean stationarity data (window size $=768$ ) for the shoulder muscles during the exertions performed in pull back $(\mathrm{PB})$, pull down $(\mathrm{PD})$, pull left (PL), pull right (PR), and pull up (PU) directions, using weights of $0,2.5$ and $5 \mathrm{lbs}$. in sagittal and scapular planes at $60^{\circ}$ and $120^{\circ}$ shoulder angles. Error bars represent $95 \%$ confidence interval. 
The $\%$ stationarity decreased with an increase in the joint angle for anterior deltoid. Higher $\%$ stationarity was observed in the scapular plane compared to the sagittal plane for supraspinatus and posterior deltoid. The $\%$ stationarity decreased with an increase of force level for infraspinatus, anterior deltoid, middle deltoid and biceps. For the supraspinatus the ascending order of force directions in terms of \% stationarity was PD, PL, PU, PB and PR. For the anterior deltoid the ascending order of force directions in terms of \% stationarity was PD, PR, PL, PB and PU. For the middle deltoid the ascending order of force directions in terms of \% stationarity was PD, PU, PB, PR and PL. For the biceps the ascending order was PU, PD, PL, PB and PR, and for triceps the ascending order was PL, PU, PB, PD, and PR. (Figure 3-3).

The largest $\%$ stationarity variation was observed in the supraspinatus (6.31\%) and the smallest \% stationarity variation was observed in the posterior deltoid (5.81\%). Similar variation of $6.09 \%$ was observed for infraspinatus and anterior deltoid (Table 3-5).

\subsection{Window size of $\mathbf{7 6 8}$}

The main effects of joint angle and plane on $\%$ stationarity was statistically insignificant $(p>0.05)$ for the shoulder muscles except for the effects of plane on biceps. The main effects of force level and force direction on $\%$ stationarity were statistically significant $(p<0.05)$ for the shoulder muscles except for force level on posterior deltoid and triceps, and force direction on infraspinatus and biceps (

Table 3-6).

The $\%$ stationarity decreased with an increase of force level for supraspinatus, infraspinatus, anterior deltoid, middle deltoid and biceps. Higher $\%$ stationarity was observed in the sagittal plane compared to the scapular plane for biceps. For the supraspinatus the ascending order of force directions in terms of \% stationarity was PD, PR, PL, PU and PB. For the anterior 
deltoid the ascending order of force directions in terms of \% stationarity was PD, PB, PU, PL and PR. For the middle deltoid the ascending order of force directions in terms of $\%$ stationarity was PD, PB, PR, PL and PU. For the posterior deltoid the ascending order was PD, PR, PL, PU and $\mathrm{PB}$, and for the triceps the ascending order was PL, PU, PB, PD, and PR. (Figure 3-4).

The largest \% stationarity variation was observed in the triceps $(8.58 \%)$ and the smallest $\%$ stationarity variation was observed in the biceps $(7.55 \%)$. (

Table 3-6).

\subsection{Window size of 1024}

The main effects of joint angle and plane on \% stationarity was statistically insignificant $(p>0.05)$ for the shoulder muscles except for the effects of joint angle on middle deltoid and anterior deltoid. The main effects of force level and force direction on $\%$ stationarity were statistically significant $(p<0.05)$ for the shoulder muscles except for the effects of force level on triceps, and force direction on supraspinatus, infraspinatus and biceps (Table 3-7).

The $\%$ stationarity decreased with an increase in the joint angle for middle deltoid and anterior deltoid. The $\%$ stationarity decreased with an increase of force level for supraspinatus, infraspinatus, anterior deltoid, middle deltoid, posterior deltoid and biceps. For the anterior deltoid the ascending order of force directions in terms of $\%$ stationarity was PD, PU, PL, PB and PR. For the middle deltoid the ascending order of force directions in terms of \% stationarity was PD, PR, PU, PB and PL. For the posterior deltoid the ascending order was PD, PL, PB, PU and PR. For the triceps the ascending order was PL, PD, PU, PB, and PR. (Figure 3-5).

The largest \% stationarity variation was observed in the triceps (10.61\%) and the smallest $\%$ stationarity variation was observed in the middle deltoid and biceps (9.62\%). Similar variation of $9.92 \%$ was observed for posterior deltoid and anterior deltoid (Table 3-7). 
Table 3-7 Main effect of joint angle, plane, force level, and force direction on \% stationarity data estimated using a window size of 1024. For each muscle mean (standard deviation) stationarity data and the $p$-value (p-val) for the main effect are provided in the table along with the variation (Var) based on $\sqrt{M S E}$. Statistically significant $p$-values are bolded.

\begin{tabular}{|c|c|c|c|c|c|c|c|c|c|c|c|c|c|c|c|c|c|}
\hline \multirow[b]{2}{*}{ Levels } & \multicolumn{3}{|c|}{ Joint angle } & \multicolumn{3}{|c|}{ Plane } & \multicolumn{4}{|c|}{ Force level } & \multicolumn{6}{|c|}{ Force direction } & \multirow{2}{*}{$\begin{array}{l}\text { Var } \\
(\%)\end{array}$} \\
\hline & $60^{\circ}$ & $120^{\circ}$ & $p$-val & Sagittal & Scapular & $p$-val & 0 lb. & $2.5 \mathrm{lb}$ & $5 \mathrm{lb}$. & $p$-val & PB & PD & PL & PR & $\mathbf{P U}$ & $p$-val & \\
\hline Supra & $\begin{array}{c}0.91 \\
(0.102)\end{array}$ & $\begin{array}{c}0.906 \\
(0.106)\end{array}$ & 0.792 & $\begin{array}{c}0.907 \\
(0.106)\end{array}$ & $\begin{array}{c}0.909 \\
(0.102)\end{array}$ & 0.814 & $\begin{array}{c}0.92 \\
(0.095)\end{array}$ & $\begin{array}{c}0.906 \\
(0.106)\end{array}$ & $\begin{array}{c}0.898 \\
(0.109)\end{array}$ & 0.003 & $\begin{array}{c}0.917 \\
(0.105)\end{array}$ & $\begin{array}{c}0.897 \\
(0.101)\end{array}$ & $\begin{array}{c}0.907 \\
(0.108)\end{array}$ & $\begin{array}{c}0.912 \\
(0.096)\end{array}$ & $\begin{array}{c}0.907 \\
(0.107)\end{array}$ & 0.139 & 10.31 \\
\hline Infra & $\begin{array}{c}0.917 \\
(0.096)\end{array}$ & $\begin{array}{c}0.915 \\
(0.099)\end{array}$ & 0.965 & $\begin{array}{c}0.919 \\
(0.094)\end{array}$ & $\begin{array}{c}0.913 \\
(0.101)\end{array}$ & 0.054 & $\begin{array}{c}0.924 \\
(0.094)\end{array}$ & $\begin{array}{c}0.915 \\
(0.097)\end{array}$ & $\begin{array}{c}0.909 \\
(0.1)\end{array}$ & 0.000 & $\begin{array}{c}0.924 \\
(0.095)\end{array}$ & $\begin{array}{c}0.913 \\
(0.103)\end{array}$ & $\begin{array}{c}0.907 \\
(0.1) \\
\end{array}$ & $\begin{array}{c}0.918 \\
(0.091)\end{array}$ & $\begin{array}{c}0.917 \\
(0.097)\end{array}$ & 0.844 & 9.69 \\
\hline Mdel & $\begin{array}{c}0.923 \\
(0.089)\end{array}$ & $\begin{array}{c}0.902 \\
(0.107)\end{array}$ & 0.003 & $\begin{array}{c}0.913 \\
(0.099)\end{array}$ & $\begin{array}{c}0.913 \\
(0.099)\end{array}$ & 0.373 & $\begin{array}{c}0.931 \\
(0.086)\end{array}$ & $\begin{array}{c}0.909 \\
(0.098)\end{array}$ & $\begin{array}{c}0.897 \\
(0.108)\end{array}$ & 0.000 & $\begin{array}{l}0.922 \\
(0.09)\end{array}$ & $\begin{array}{l}0.895 \\
(0.11)\end{array}$ & $\begin{array}{c}0.913 \\
(0.098) \\
\end{array}$ & $\begin{array}{c}0.926 \\
(0.088)\end{array}$ & $\begin{array}{c}0.906 \\
(0.105)\end{array}$ & 0.001 & 9.62 \\
\hline Adel & $\begin{array}{c}0.913 \\
(0.097)\end{array}$ & $\begin{array}{c}0.902 \\
(0.107)\end{array}$ & 0.046 & $\begin{array}{c}0.91 \\
(0.101)\end{array}$ & $\begin{array}{c}0.904 \\
(0.105)\end{array}$ & 0.154 & $\begin{array}{c}0.927 \\
(0.085)\end{array}$ & $\begin{array}{c}0.913 \\
(0.099)\end{array}$ & $\begin{array}{c}0.883 \\
(0.117)\end{array}$ & 0.000 & $\begin{array}{c}0.916 \\
(0.094)\end{array}$ & $\begin{array}{c}0.878 \\
(0.121)\end{array}$ & $\begin{array}{c}0.926 \\
(0.087) \\
\end{array}$ & $\begin{array}{c}0.905 \\
(0.108)\end{array}$ & $\begin{array}{c}0.913 \\
(0.094)\end{array}$ & 0.000 & 9.92 \\
\hline Pdel & $\begin{array}{c}0.91 \\
(0.098) \\
\end{array}$ & $\begin{array}{c}0.907 \\
(0.102) \\
\end{array}$ & 0.818 & $\begin{array}{c}0.907 \\
(0.098)\end{array}$ & $\begin{array}{c}0.909 \\
(0.103) \\
\end{array}$ & 0.645 & $\begin{array}{c}0.923 \\
(0.093) \\
\end{array}$ & $\begin{array}{c}0.905 \\
(0.102) \\
\end{array}$ & $\begin{array}{c}0.897 \\
(0.104)\end{array}$ & 0.000 & $\begin{array}{c}0.912 \\
(0.102)\end{array}$ & $\begin{array}{c}0.894 \\
(0.104) \\
\end{array}$ & $\begin{array}{c}0.904 \\
(0.103) \\
\end{array}$ & $\begin{array}{c}0.917 \\
(0.093) \\
\end{array}$ & $\begin{array}{c}0.915 \\
(0.097) \\
\end{array}$ & 0.016 & 9.92 \\
\hline Bic & $\begin{array}{c}0.914 \\
(0.095) \\
\end{array}$ & $\begin{array}{c}0.913 \\
(0.098) \\
\end{array}$ & 0.733 & $\begin{array}{c}0.915 \\
(0.095)\end{array}$ & $\begin{array}{c}0.912 \\
(0.098) \\
\end{array}$ & 0.504 & $\begin{array}{c}0.926 \\
(0.088) \\
\end{array}$ & $\begin{array}{c}0.911 \\
(0.103) \\
\end{array}$ & $\begin{array}{c}0.903 \\
(0.096) \\
\end{array}$ & 0.002 & $\begin{array}{c}0.913 \\
(0.1)\end{array}$ & $\begin{array}{c}0.91 \\
(0.101) \\
\end{array}$ & $\begin{array}{c}0.91 \\
(0.098) \\
\end{array}$ & $\begin{array}{c}0.924 \\
(0.089) \\
\end{array}$ & $\begin{array}{c}0.909 \\
(0.094) \\
\end{array}$ & 0.100 & 9.62 \\
\hline Tri & $\begin{array}{c}0.899 \\
(0.105)\end{array}$ & $\begin{array}{c}0.897 \\
(0.108)\end{array}$ & 0.618 & $\begin{array}{c}0.901 \\
(0.103)\end{array}$ & $\begin{array}{l}0.895 \\
(0.11)\end{array}$ & 0.158 & $\begin{array}{c}0.896 \\
(0.105)\end{array}$ & $\begin{array}{c}0.9 \\
(0.106)\end{array}$ & $\begin{array}{l}0.897 \\
(0.11)\end{array}$ & 0.857 & $\begin{array}{c}0.899 \\
(0.099)\end{array}$ & $\begin{array}{c}0.893 \\
(0.107)\end{array}$ & $\begin{array}{c}0.89 \\
(0.113)\end{array}$ & $\begin{array}{c}0.912 \\
(0.102)\end{array}$ & $\begin{array}{l}0.895 \\
(0.11)\end{array}$ & 0.034 & 10.61 \\
\hline
\end{tabular}




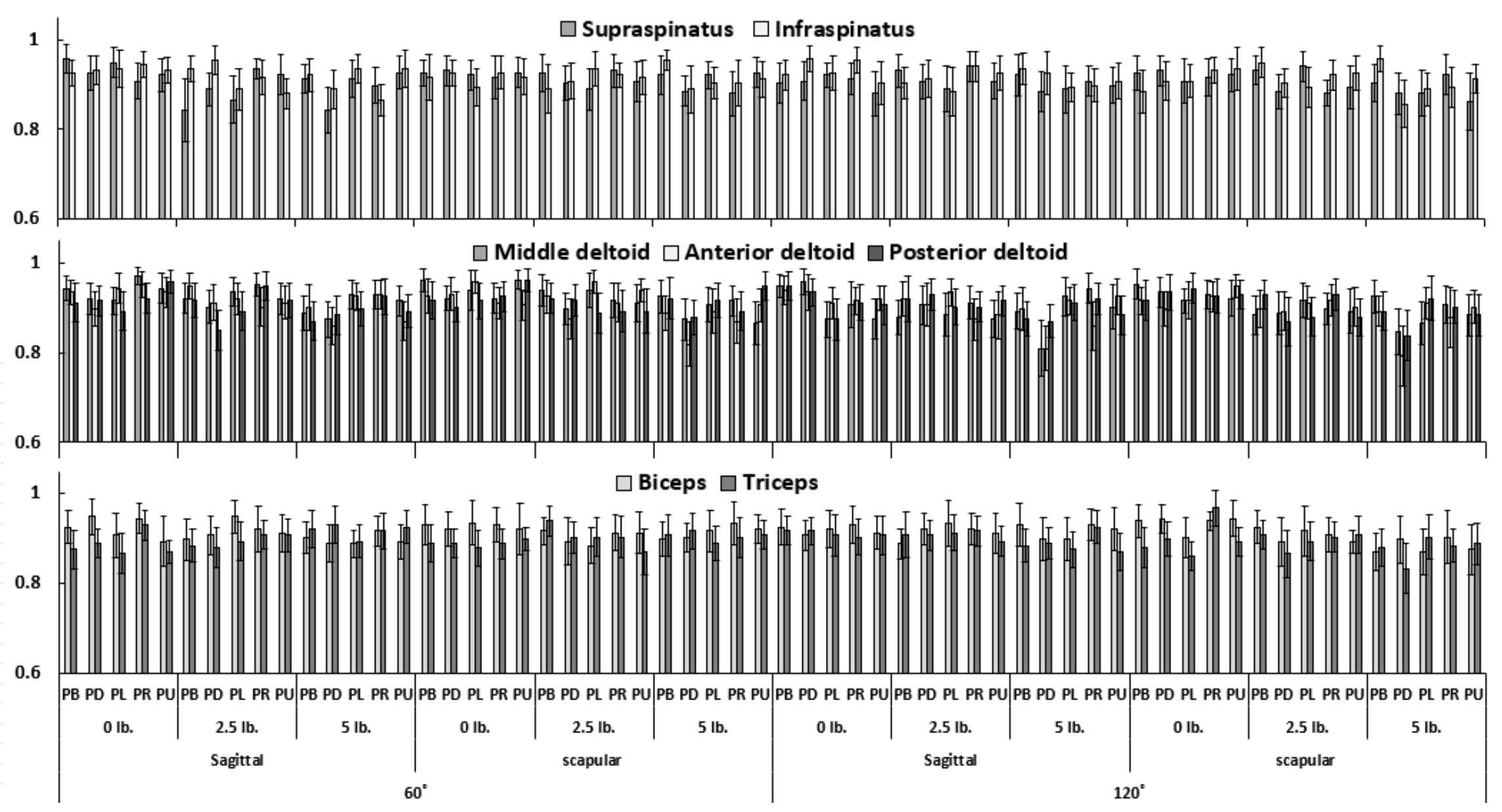

Figure 3-5: Mean stationarity data (window size =1024) for the shoulder muscles during the exertions performed in pull back (PB), pull down (PD), pull left (PL), pull right (PR), and pull up (PU) directions, using weights of $0,2.5$ and 5 lbs. in sagittal and scapular planes at $60^{\circ}$ and $120^{\circ}$ shoulder angles. Error bars represent $95 \%$ confidence interval. 


\section{Chapter 4 Discussions}

In this study the effects of various occupationally relevant factors such as joint angle, plane, force level, and force direction on SEMG signal stationarity were examined. This study also analyzed the stationarity of SEMG signal using five different window sizes. It was hypothesized that the occupationally relevant factors will have no effect on \% stationarity of the SEMG data acquired from non-fatigued shoulder muscles. For several muscles, the $\%$ stationarity was significantly affected by the occupational factors and their interactions, thus the data rejected the null hypothesis.

The mean $\%$ stationarity values observed in this study ranged from $87.8 \%$ to $94.9 \%$. For the window sizes of $128,256,512,768,1024 \mathrm{~ms}$, the mean stationarity values were $91.9 \%(91.1 \%$ to $92.5 \%$ ), $93.5 \%$ (92.5\% to $94.4 \%$ ), $93.4 \%$ (91.5\% to $94.9 \%), 92.4 \%$ (89.8\% to $94.2 \%$ ), $90.9 \%$ ( $87.8 \%$ to $93.1 \%)$, respectively. The lowest mean $\%$ stationarity was observed for a window size of $1024 \mathrm{~ms}$. The highest mean \% stationarity was observed for a window size of $512 \mathrm{~ms}$. The stationarity values observed in the previous studies are summarized in Table 4-1. Bilodeau et al., ( 1997) reported stationarity of $92 \%$ for the elbow flexor muscle using a window size of $512 \mathrm{~ms}$ and the \% stationarity was estimated using Reverse Arrangement Test. The mean \% stationarity observed in our study is very close to that reported by Bilodeau et al., ( 1997). In another study by Schwartz \& Nascimento (2011), the authors used the test method of Kwiatkowiski, Phillips, Schmidt, and Shin (KPSS) to compute the signal stationarity. The numbers reported by them were also very similar to the numbers obtained in our study (a differential of 3\%-4\%). Nazmi et al., (2017) investigated signal stationarity using different window sizes and reported a decrease in the stationarities with an increase in the window size. The \% stationarity reported by Nazmi et al., 
(2017) were much smaller than our study. In their study, the participants performed a task of walking on a treadmill for $5 \mathrm{~s}$ with a constant speed. Thus, the stationarities were investigated using dynamic contractions. In our study static contractions were used. Unlike static contractions during which the muscle length is constant, the muscle length changes continuously during dynamic contractions. Such change in the muscle length may reduce the \% stationarity. Another study investigated changes in the SEMG stationarity due to fatigue under static as well as dynamic conditions (Chowdhury \& Nimbarte, 2017). In this study, a reduction in the stationarity was observed due to the fatigue. The \% stationarity data reported by Chowdhury \& Nimbarte (2017) under no-fatigue static conditions are comparable with our study. Chowdhury \& Nimbarte (2017) also reported a reduction in the \% stationarity during dynamic contractions when compared with static contractions. Similar to our study, Chowdhury \& Nimbarte (2017) also reported the highest $\%$ stationarity under no-fatigue conditions at a window size of $512 \mathrm{~ms}$. In general, the \% stationarity observed in our study is quite comparable with the previous studies.

Table 4-1 Typical SEMG stationarity values reported in the literature

\begin{tabular}{|l|l|l|l|}
\hline Study & Muscle & $\begin{array}{l}\text { Calculation method and } \\
\text { window size }\end{array}$ & Stationarity \\
\hline $\begin{array}{l}\text { Bilodeau et al., } \\
1997\end{array}$ & Elbow flexor & $\begin{array}{l}\text { Reverse Arrangement } \\
\text { Test, 512 }\end{array}$ & $92 \%$ \\
\hline $\begin{array}{l}\text { Schwartz and } \\
\text { Nascimento, } \\
2011\end{array}$ & Vastus lateralis & KPSS test, N.A. & $93 \%$ to 97\% \\
\hline $\begin{array}{l}\text { Nazmi et al., } \\
2017\end{array}$ & $\begin{array}{l}\text { Gastrocnemius } \\
\text { medialis }\end{array}$ & $\begin{array}{l}\text { Reverse Arrangement, } \\
100,200,500,1000\end{array}$ & $\begin{array}{l}88.21 \%, 88.57 \%, \\
50 \%, 35.71 \%\end{array}$ \\
\cline { 3 - 4 } & $\begin{array}{l}\text { Modified Reverse } \\
\text { Arrangement, 100, 200, } \\
500,1000\end{array}$ & $\begin{array}{l}87.86 \%, 88.57 \%, \\
51.89 \%, 39.29 \%\end{array}$ \\
\hline $\begin{array}{l}\text { Chowdhury and } \\
\text { Nimbarte, 2017 }\end{array}$ & $\begin{array}{l}\text { Upper } \\
\text { trapezius }\end{array}$ & $\begin{array}{l}\text { Modified Reverse } \\
\text { Arrangement, 128, 256, } \\
512,768 \text { and } 1024\end{array}$ & $42.83 \%$ to 92.59\% \\
\hline
\end{tabular}


Four work-related factors - joint angle, plane exertion, force level, force direction - were examined in this study. In general, the factors such as the joint angle and the plane of exertion affected the \% stationarity in fewer instances compared to the factors such as the force level and the force direction. Out of the thirty-five (5 window sizes $\times 7$ muscles) ANOVA analyses, statistical significance was observed in 7 (20\%) cases for the joint angle as well as for the plane of exertion. For the force level and the force direction, statistical significance was observed in 19 (54.3\%) cases, each. The significant effect of joint angle and plane of exertion was generally observed for small window sizes of 128 and $256 \mathrm{~ms}$ and for the force level and the force direction the effect was generally observed at the window sizes of $512 \mathrm{~ms}$ or larger. For the joint angle and the plane of exertion, the mean $\%$ stationarity varied by $2.21 \%$ and $0.89 \%$, respectively. For the force level and the force direction, the mean $\%$ stationarity varied by $4.70 \%$ and $5.45 \%$, respectively.

In general, an inverse relationship was observed between \% stationarity and muscle activation. The exertions that produced higher activation (SEMG amplitude) resulted in lower \% stationarity. Such effect was observed more frequently at larger window (512 ms and above) sizes compared to lower window sizes. The \% stationarity decreased with an increase of force level in most of the tested muscles - supraspinatus, infraspinatus, middle deltoid, anterior deltoid, and biceps. An increase in the joint angle from $60^{\circ}$ to $120^{\circ}$ resulted in a decrease in SEMG stationarities for anterior deltoid and middle deltoid. With an increase in the force level as well as with an increase in the joint angle, the force demand for the muscles increases. Increased force demand augments the muscle fibers recruitment and conduction velocity, further inducing higher time-dependent variation in the amplitude of the SEMG signal resulting in larger reverse arrangements and thus reduced stationarity (Chowdhury \& Nimbarte, 2017). For biceps and 
triceps, the exertions performed in the PL direction produced the smallest \% stationarity. Alasim et al., (Alasim \& Nimbarte, 2019) reported that biceps exhibited higher muscle activity when performing exertions in PL direction compared to the other directions.

Seven shoulder muscles were investigated in this study. For infraspinatus, the \% stationarity was affected in $6(30 \%)$ out of 20 cases (4 factors x 5 window sizes). For posterior deltoid, biceps and triceps, the \% stationarity was affected in 7 (35\%) out of 20 cases. For supraspinatus and middle deltoid, the \% stationarity was affected in $8(40 \%)$ out of 20 cases and for anterior deltoid, the \% stationarity was affected in $10(50 \%)$ out of 20 cases, respectively. Thus, deltoid muscles showed a slightly higher sensitivity to stationarity compared to the other shoulder muscles during occupational exertions. anterior deltoid, middle deltoid, posterior deltoid are nonrotator cuff muscles. These muscles serve as the primary movers for the shoulder joint and are perhaps more sensitive to occupational factors. On the other hand, supraspinatus and infraspinatus are the rotator cuff muscles and mainly work to stabilize the glenohumeral joint. The main function of supraspinatus is to pull the head of the humerus medially towards the glenoid cavity and the main function of infraspinatus is to externally rotate the humerus and stabilize the shoulder joint.

The variability in \% stationarity values showed an increasing trend with respect to the window size. As summarized in Figure 4-1, the variability increased from about 3.3\% to $10.0 \%$ when the window size was increased from $128 \mathrm{~ms}$ to $1024 \mathrm{~ms}$. A large window size reduces the number of segments but increases the number of sub-segments. For example, a window size of $128 \mathrm{~ms}$ results into 72 segments but only 4 sub-segments (per segment) and a window size of 1024 ms results into only 9 segments but 32 sub-segments (per segment). The reverse arrangements are estimated using multiple comparisons of means of the sub-segments. Lower number of segments for a larger window size seem to increase the overall variability and reduces the overall stationarity 
values. Furthermore, the range of variability in the \% stationarity was slightly higher at the larger window sizes compared to the smaller window sizes when the shoulder muscles are compared. At a window size of $1024 \mathrm{~ms}$, the variability range was 9.62 to $10.61 \%$ (range $=0.99 \%$ ). The corresponding values for the window sizes of $786 \mathrm{~ms}, 512 \mathrm{~ms}, 256 \mathrm{~ms}$, and $128 \mathrm{~ms}$ were 7.55 to $8.58 \%($ range $=1.03 \%), 5.81$ to $6.31 \%($ range $=0.5 \%), 4.0$ to $4.49 \%($ range $=0.49 \%), 3.15$ to $3.36 \%($ range $=0.21 \%)$, respectively .

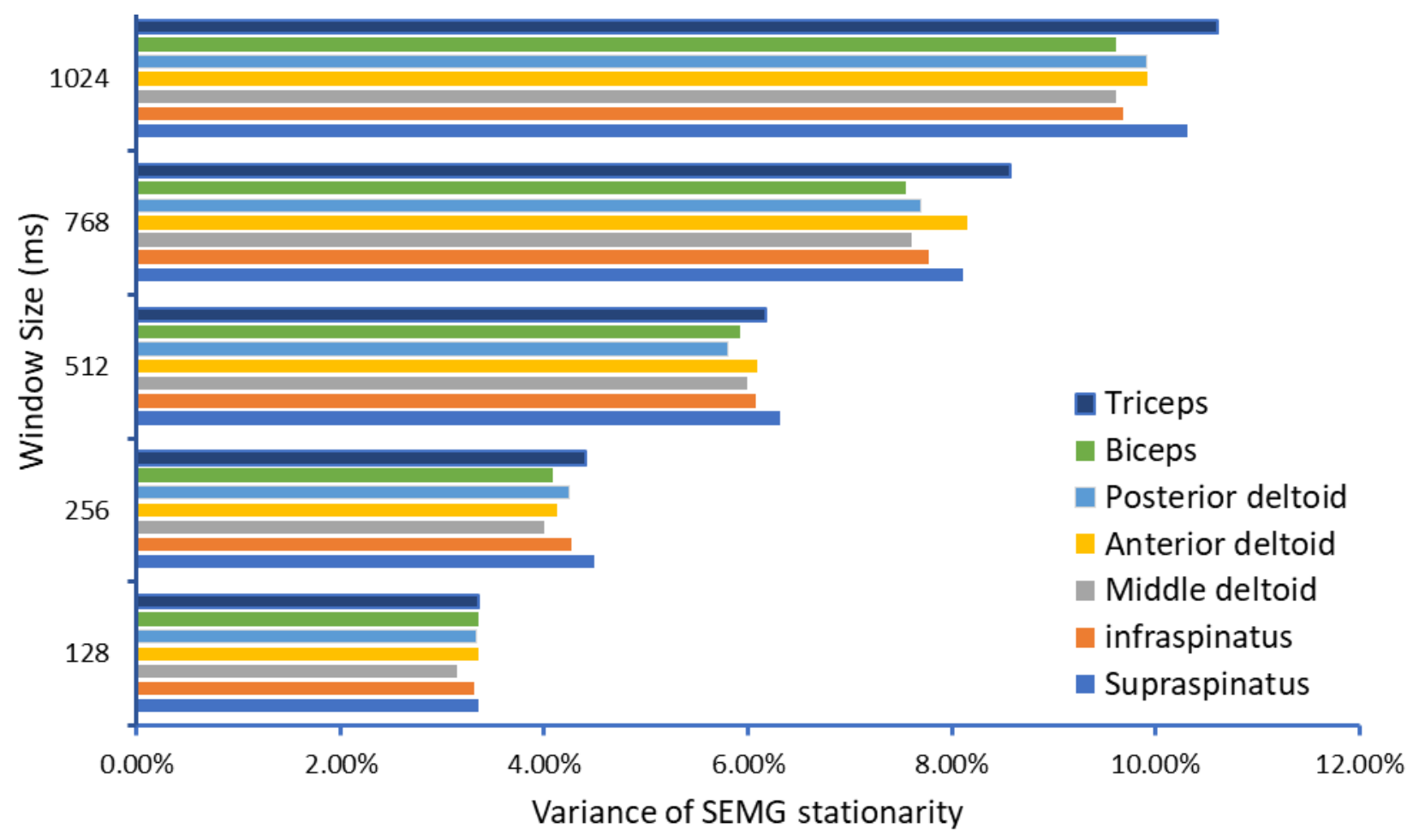

Figure 4-1 Variance in \% stationarity of non-fatigued shoulder muscles for different window sizes

Accurate estimation and/or prediction of localized muscle fatigue is essential to prevent the incidences of WMSDs. Previous studies have reported that the \% stationarity of SEMG signal reduces with the development of muscle fatigue. Results of this study indicate that factors other than muscle fatigue can also change/vary/reduce the \% stationarity of SEMG signal. During a 
physical exertion, the muscles in human body develop fatigue continuously. Using the findings from this study the process to identify a point in the continuous fatigue development process at which the risk level has risen above baseline can be improved. For example, the variability in $\%$ stationarity due to various work-related factors for a window size of 512 is $6.31 \%$. Thus, for the shoulder muscles a change in \% stationarity (estimated using a window size of 512) smaller than $6.31 \%$, cannot be regarded as a sign of muscle fatigue.

With the recent advancement in wireless technologies, the SEMG system and sensors can be easily deployed in the workplace to continuously monitor muscle activation. Real-time \% stationarity values and a relative change in these values could be used to determine the fatigue status of the workers and accordingly appropriate interventions (rest time, change in schedule, assistive devices, etc.) can be implemented to reduce the probability of muscle fatigue induced WMSDs. Such real-time fatigue prediction and/or WMSDs reduction methods could be the possible practical implications of the current study.

The following study limitations should be considered while interpreting the findings of this study:

a) This research only investigated seven shoulder muscles. The results cannot be generalized for other (low back, lower extremity) muscles.

b) The participants were graduate students in the ages of 22 to 30 s with limited manual material handling experience. Experienced workers in the higher age groups may exhibit different trends in the \% stationarity values.

c) This research only investigated static exertion, but the occupational tasks are static as well as dynamic. Future studies can investigate dynamic tasks. 
d) Only the dominant hand muscles were tested. Future studies can evaluate non-dominant hand muscles

This study concludes that various work-related factors such as force levels, force directions, plane of exertion, and joint angle can influence the \% stationarity of SEMG signals. Therefore, if reduction in the \% stationarity values is used as a surrogate measure of muscle fatigue, then the variability in the $\%$ stationarity values due to work/task related factors must be considered. The variability data provided in this study could be useful in improving muscle fatigue detection methods based on the relative change in $\%$ stationarity values with respect to the initial or fresh condition for the shoulder muscles. 


\section{References}

AFL-CIO. (2019). Death on the Job: The Toll of Neglect. Retrieved March 22, 2020, from https://aflcio.org/reports/death-job-toll-neglect-2019

Alasim, H. N., \& Nimbarte, A. D. (2019). Variability of Electromyographic Spectral Measures in Nonfatigued Shoulder Muscles and Implications for Assessing Muscle Fatigue. IISE Transactions on Occupational Ergonomics and Human Factors, 7, 119-131.

Beck, T. W., Housh, T. J., Weir, J. P., Cramer, J. T., Vardaxis, V., Johnson, G. O., ... Mielke, M. (2006). An examination of the Runs Test, Reverse Arrangements Test, and modified Reverse Arrangements Test for assessing surface EMG signal stationarity. Journal of Neuroscience Methods, 156, 242-248.

Bhattacharya, A. (2014). Costs of occupational musculoskeletal disorders (MSDs) in the United States. International Journal of Industrial Ergonomics, 44, 448-454.

Bilodeau, M., Cincera, M., Arsenault, A. B., \& Gravel, D. (1997). Normality and stationarity of EMG signals of elbow flexor muscles during ramp and step isometric contractions. Journal of Electromyography and Kinesiology: Official Journal of the International Society of Electrophysiological Kinesiology, 7, 87-96.

Blanco, S., Garcia, H., Quiroga, R. Q., Romanelli, L., \& Rosso, O. A. (1995). Stationarity of the EEG series. IEEE Engineering in Medicine and Biology Magazine, 14, 395-399.

Bonato, P., Heng, M. S. S., Gonzalez-Cueto, J., Leardini, A., O’Connor, J., \& Roy, S. H. (2001). EMGbased measures of fatigue during a repetitive squat exercise. IEEE Engineering in Medicine and Biology Magazine, 20, 133-143.

Cho, Y. J., \& Kim, J. Y. (2012). The effects of load, flexion, twisting and window size on the stationarity of trunk muscle EMG signals. International Journal of Industrial Ergonomics, 42, 287-292. 
Chowdhury, S. K. (2016). Evaluation of Concavity Compression Mechanism as a Possible Predictor of Shoulder Muscle Fatigue. Graduate Theses, Dissertations, and Problem Reports. https://doi.org/10.33915/etd.5364

Chowdhury, S. K., \& Nimbarte, A. D. (2017). Effect of fatigue on the stationarity of surface electromyography signals. International Journal of Industrial Ergonomics, 61, 120-125.

Chowdhury, S. K., Nimbarte, A. D., Jaridi, M., \& Creese, R. C. (2013). Discrete wavelet transform analysis of surface electromyography for the fatigue assessment of neck and shoulder muscles. Journal of Electromyography and Kinesiology, 23, 995-1003.

Cifrek, M., Medved, V., Tonković, S., \& Ostojić, S. (2009). Surface EMG based muscle fatigue evaluation in biomechanics. Clinical Biomechanics, 24, 327-340.

Cobb, S., \& Forbes, A. (1923). Electromyographic studies of muscular fatigue in man. American Journal of Physiology-Legacy Content, 65, 234-251.

Costa, B. R. da, \& Vieira, E. R. (2010). Risk factors for work-related musculoskeletal disorders: A systematic review of recent longitudinal studies. American Journal of Industrial Medicine, 53, $285-323$.

Dimitrov, G. V., Arabadzhiev, T. I., Mileva, K. N., Bowtell, J. L., Crichton, N., \& Dimitrova, N. A. (2006). Muscle Fatigue during Dynamic Contractions Assessed by New Spectral Indices. Medicine \& Science in Sports \& Exercise, 38, 1971-1979.

Ergo-plus. (2019). The Cost of Musculoskeletal Disorders. Retrieved March 21, 2020, from https://ergoplus.com/cost-of-musculoskeletal-disorders-infographic/

Escamilla, R. F., Yamashiro, K., Paulos, L., \& Andrews, J. R. (2009). Shoulder Muscle Activity and Function in Common Shoulder Rehabilitation Exercises. Sports Medicine, 39, 663-685.

F. P. Schwartz, \& F. A. O. Nascimento. (2011). Stationarity of surface electromyographic signals on isokinetic knee extension test. 2011 Pan American Health Care Exchanges, 49-49.

Gallagher, S., \& Jr, M. C. S. (2017). Musculoskeletal disorders as a fatigue failure process: Evidence, implications and research needs. Ergonomics, 60, 255-269. 
González-Izal, M., Malanda, A., Gorostiaga, E., \& Izquierdo, M. (2012). Electromyographic models to assess muscle fatigue. Journal of Electromyography and Kinesiology, 22, 501-512.

Hussain, J., Sundaraj, K., Low, Y. F., Kiang, L. C., Sundaraj, S., \& Ali, Md. A. (2018). A systematic review on fatigue analysis in triceps brachii using surface electromyography. Biomedical Signal Processing and Control, 40, 396-414.

Kogi, K., \& Hakamada, T. (1962). [Frequency analysis of the surface electromyogram in muscle fatigue]. Rodo Kagaku. The Journal of Science of Labour, 38, 519-528.

Linaker, C., \& Walker-Bone, K. (2015). SHOULDER DISORDERS AND OCCUPATION. Best Practice \& Research. Clinical Rheumatology, 29, 405-423.

Mananas, M. A., Guillen, M., Fiz, J. A., Morera, J., \& Caminal, P. (2000). Analysis of stationarity and statistical changes in myographic signals from respiratory muscles. Proceedings of the 22nd Annual International Conference of the IEEE Engineering in Medicine and Biology Society (Cat. No.00CH37143), 2, 1337-1340 vol.2.

Mayo Clinic. (2018). Rotator cuff injury_-Symptoms and causes. Retrieved March 21, 2020, from https://www.mayoclinic.org/diseases-conditions/rotator-cuff-injury/symptoms-causes/syc20350225

Morse, T. F. (2013). The Economic and Social Consequences of Work-related Musculoskeletal Disorders: The Connecticut Upper-extremity Surveillance Project (CUSP): International Journal of Occupational and Environmental Health: Vol 4, No 4. Retrieved April 4, 2020, from https://www.tandfonline.com/doi/abs/10.1179/oeh.1998.4.4.209

Nazmi, N., Abdul Rahman, M. A., Yamamoto, S., Ahmad, S. A., Malarvili, M. B., Mazlan, S. A., \& Zamzuri, H. (2017). Assessment on Stationarity of EMG Signals with Different Windows Size During Isotonic Contractions. Applied Sciences, 7, 1050.

Öberg, T., Sandsjö, L., \& Kadefors, R. (1990). Electromyogram mean power frequency in non-fatigued trapezius muscle. European Journal of Applied Physiology and Occupational Physiology, 61, 362-369. 
Punnett, L., \& Wegman, D. H. (2004). Work-related musculoskeletal disorders: The epidemiologic evidence and the debate. Journal of Electromyography and Kinesiology, 14, 13-23.

Sporrong, H., Palmerud, G., \& Herberts, P. (1995). Influences of handgrip on shoulder muscle activity. European Journal of Applied Physiology and Occupational Physiology, 71, 485-492.

Taelman, J., Adriaensen, T., Spaepen, A., Langereis, G. R., Gourmelon, L., \& Van Huffel, S. (2006). Contactless emg sensors for continuous monitoring of muscle activity to prevent musculoskeletal disorders. Proceedings of the First Annual Symposium of the IEEE-EMBS Benelux Chapter, 223226.

Waly, S. M., Asfour, S. S., \& Khalil, T. M. (2003). Effects of window size and load on estimated myoelectric signal power spectrum. Computers \& Industrial Engineering, 44, 595-610.

Wang, G., Ren, X., Li, L., \& Wang, Z. (2007). Multifractal analysis of surface EMG signals for assessing muscle fatigue during static contractions. Journal of Zhejiang University-SCIENCE A, 8, 910915. 


\section{Appendix A: ANOVA Analysis result}

\begin{tabular}{|c|c|c|c|c|c|c|}
\hline \multicolumn{7}{|c|}{ Analysis of Variance } \\
\hline Source & Sum Sq. & d.f. & Mean Sq. & F & Prob $>F$ & $\wedge$ \\
\hline Angle & 0.00804 & 1 & 0.00804 & 7.11 & 0.0078 & \\
\hline Plane & 0.00246 & 1 & 0.00246 & 2.18 & 0.1401 & \\
\hline Weight & 0.00257 & 2 & 0.00129 & 1.14 & 0.3211 & \\
\hline Direction & 0.00204 & 2 & 0.00102 & 0.9 & 0.4055 & \\
\hline Angle*Plane & 0.00041 & 1 & 0.00041 & 0.37 & 0.5451 & \\
\hline Angle*Weight & 0.00241 & 2 & 0.00121 & 1.07 & 0.3444 & \\
\hline Angle*Direction & 0.00211 & 2 & 0.00106 & 0.93 & 0.3935 & \\
\hline Plane*Weight & 0.00294 & 2 & 0.00147 & 1.3 & 0.2726 & \\
\hline Plane*Direction & 0.00106 & 2 & 0.00053 & 0.47 & 0.6271 & \\
\hline Weight*Direction & 0.00223 & 4 & 0.00056 & 0.49 & 0.7408 & \\
\hline Angle*Plane*Weight & 0.0037 & 2 & 0.00185 & 1.64 & 0.1951 & \\
\hline Angle*Plane*Direction & 0.00137 & 2 & 0.00068 & 0.6 & 0.5463 & \\
\hline Angle*Weight*Direction & 0.00491 & 4 & 0.00123 & 1.08 & 0.3624 & \\
\hline Plane*Weight*Direction & 0.00403 & 4 & 0.00101 & 0.89 & 0.4684 & \\
\hline Angle*Plane*Weight*Direction & 0.00095 & 4 & 0.00024 & 0.21 & 0.9334 & \\
\hline Error & 1.5882 & 1404 & 0.00113 & & & \\
\hline Total & 1.62837 & 1439 & & & & \\
\hline
\end{tabular}

Supraspinatus, $128 \mathrm{~ms}$ 
Analysis of Variance

\begin{tabular}{|c|c|c|c|c|c|c|}
\hline Source & Sum Sq. & d.f. & Mean Sq. & $\mathrm{F}$ & Prob $>F$ & $\hat{\wedge}$ \\
\hline ---------- & --------- & ----- & --------- & ------ & ------- & \\
\hline Angle & 0.03463 & 1 & 0.03463 & 17.2 & 0 & \\
\hline Plane & 0.00579 & 1 & 0.00579 & 2.87 & 0.0902 & \\
\hline Weight & 0.00763 & 2 & 0.00381 & 1.89 & 0.1509 & \\
\hline Direction & 0.00564 & 2 & 0.00282 & 1.4 & 0.2469 & \\
\hline Angle*Plane & 0.00004 & 1 & 0.00004 & 0.02 & 0.8924 & \\
\hline Angle*Direction & 0.00575 & 2 & 0.00287 & 1.43 & 0.2403 & \\
\hline Plane*Weight & 0.00711 & 2 & 0.00356 & 1.77 & 0.1714 & \\
\hline Plane*Direction & 0.01947 & 2 & 0.00974 & 4.83 & 0.0081 & \\
\hline Weight*Direction & 0.01622 & 4 & 0.00405 & 2.01 & 0.0903 & \\
\hline Angle*Plane*Weight & 0.00316 & 2 & 0.00158 & 0.79 & 0.456 & \\
\hline Error & 2.82728 & 1404 & 0.00201 & & & \\
\hline Total & 2.94326 & 1439 & & & & \\
\hline
\end{tabular}

Constrained (Type III) sums of squares.

\section{Supraspinatus, 256ms}

\begin{tabular}{|c|c|c|c|c|c|c|}
\hline \multicolumn{7}{|c|}{ Analysis of Variance } \\
\hline Source & Sum Sq. & d.f. & Mean Sq. & $\mathrm{F}$ & Prob $>F$ & ヘ \\
\hline Angle & 0.00216 & 1 & 0.00216 & 0.54 & 0.462 & \\
\hline Plane & 0.02492 & 1 & 0.02492 & 6.26 & 0.0125 & \\
\hline Weight & 0.0336 & 2 & 0.0168 & 4.22 & 0.0149 & \\
\hline Angle*Plane & 0.00723 & 1 & 0.00723 & 1.81 & 0.1782 & \\
\hline Angle*Weight & 0.01992 & 2 & 0.00996 & 2.5 & 0.0824 & \\
\hline Angle*Direction & 0.00657 & 2 & 0.00329 & 0.83 & 0.4383 & \\
\hline Plane*Weight & 0.00108 & 2 & 0.00054 & 0.14 & 0.8733 & \\
\hline Plane*Direction & 0.00206 & 2 & 0.00103 & 0.26 & 0.7718 & \\
\hline Angle*Weight*Direction & 0.01204 & 4 & 0.00301 & 0.76 & 0.5539 & \\
\hline Plane*Weight*Direction & 0.02149 & 4 & 0.00537 & 1.35 & 0.2495 & \\
\hline Angle*Plane*Weight*Direction & 0.03637 & 4 & 0.00909 & 2.28 & 0.0584 & \\
\hline Error & 5.59126 & 1404 & 0.00398 & & & \\
\hline Total & 5.85159 & 1439 & & & & \\
\hline
\end{tabular}

Constrained (Type III) sums of squares.

Supraspinatus, $512 \mathrm{~ms}$ 
Analysis of Variance

\begin{tabular}{lcrrrr|}
\hline Source & Sum Sq. & d.f. & Mean Sq. & F & Prob $>F$ \\
\hline Angle & 0.00972 & 1 & 0.00972 & 1.48 & 0.2245 \\
Plane & 0.00563 & 1 & 0.00563 & 0.85 & 0.3554 \\
Weight & 0.16785 & 2 & 0.08393 & 12.75 & 0 \\
Direction & 0.04905 & 2 & 0.02452 & 3.73 & 0.0243 \\
Angle*Plane & 0.08371 & 1 & 0.08371 & 12.72 & 0.0004 \\
Angle*Weight & 0.02943 & 2 & 0.01472 & 2.24 & 0.1073 \\
Angle*Direction & 0.03068 & 2 & 0.01534 & 2.33 & 0.0976 \\
Plane*Weight & 0.02115 & 2 & 0.01058 & 1.61 & 0.2009 \\
Plane*Direction & 0.00021 & 2 & 0.0001 & 0.02 & 0.9845 \\
Weight*Direction & 0.11837 & 4 & 0.02959 & 4.5 & 0.0013 \\
Angle*Plane*Weight & 0.01373 & 2 & 0.00687 & 1.04 & 0.3527 \\
Angle*Plane*Direction & 0.01235 & 2 & 0.00617 & 0.94 & 0.3917 \\
Angle*Weight*Direction & 0.0242 & 4 & 0.00605 & 0.92 & 0.452 \\
Plane*Wight*Direction & 0.02368 & 4 & 0.00592 & 0.9 & 0.4636 \\
Angle*Plane*Weight*Direction & 0.02014 & 4 & 0.00503 & 0.76 & 0.5481 \\
Error & 9.24171 & 1404 & 0.00658 & & \\
Total & 9.75802 & 1439 & & & \\
& & & & & \\
\hline
\end{tabular}

Constrained (Type III) sums of squares.

Supraspinatus, $768 \mathrm{~ms}$

\section{Analysis of Variance}

\begin{tabular}{|c|c|c|c|c|c|c|}
\hline Source & Sum Sq. & d.f. & Mean Sq. & F & Prob $>F$ & $\hat{\wedge}$ \\
\hline-- & & & -------- & ---- & ------- & \\
\hline Angle & 0.0007 & 1 & 0.00074 & 0.07 & 0.7923 & \\
\hline Plane & 0.0006 & 1 & 0.00059 & 0.06 & 0.8138 & \\
\hline Weight & 0.1262 & 2 & 0.06311 & 5.94 & 0.0027 & \\
\hline Direction & 0.042 & 2 & 0.02101 & 1.98 & 0.1389 & \\
\hline Angle*Plane & 0.0092 & 1 & 0.00916 & 0.86 & 0.3533 & \\
\hline Angle*Weight & 0.0118 & 2 & 0.00588 & 0.55 & 0.5751 & \\
\hline Angle*Direction & 0.0122 & 2 & 0.00609 & 0.57 & 0.5639 & \\
\hline Plane*Weight & 0.0067 & 2 & 0.00337 & 0.32 & 0.7283 & \\
\hline Plane*Direction & 0.014 & 2 & 0.007 & 0.66 & 0.5178 & \\
\hline Weight*Direction & 0.079 & 4 & 0.01974 & 1.86 & 0.1154 & \\
\hline Angle*Plane*Weight & 0.0333 & 2 & 0.01666 & 1.57 & 0.2089 & \\
\hline Angle*Plane*Direction & 0.0044 & 2 & 0.0022 & 0.21 & 0.8132 & \\
\hline Angle*Weight*Direction & 0.1145 & 4 & 0.02863 & 2.69 & 0.0296 & \\
\hline Plane*Weight*Direction & 0.0582 & 4 & 0.01456 & 1.37 & 0.2422 & \\
\hline Angle*Plane*Weight*Direction & 0.0314 & 4 & 0.00784 & 0.74 & 0.566 & \\
\hline Error & 14.921 & 1404 & 0.01063 & & & \\
\hline Total & 15.5055 & 1439 & & & & \\
\hline
\end{tabular}

Constrained (Type III) sums of squares.

Supraspinatus, 1024ms 
2)

Analysis of Variance

\begin{tabular}{llrlll|}
\hline Source & Sum Sq. & d.f. & Mean Sq. & F & Prob $>F$ \\
\hline Angle & 0.00064 & 1 & 0.00064 & 0.59 & 0.4432 \\
Plane & 0.0012 & 1 & 0.0012 & 1.1 & 0.2948 \\
Weight & 0.00466 & 2 & 0.00233 & 2.13 & 0.1191 \\
Direction & 0.00668 & 2 & 0.00334 & 3.05 & 0.0474 \\
Angle*Plane & 0.00123 & 1 & 0.00123 & 1.12 & 0.2899 \\
Angle*Weight & 0.00043 & 2 & 0.00022 & 0.2 & 0.8212 \\
Angle*Direction & 0.00231 & 2 & 0.00116 & 1.06 & 0.3471 \\
Plane*Weight & 0.00057 & 2 & 0.00029 & 0.26 & 0.77 \\
Plane*Direction & 0.00741 & 2 & 0.00371 & 3.39 & 0.0339 \\
Weight*Direction & 0.00647 & 4 & 0.00162 & 1.48 & 0.2059 \\
Angle*Plane*Weight & 0.00059 & 2 & 0.00029 & 0.27 & 0.7643 \\
Angle*Plane*Direction & 0.01068 & 2 & 0.00534 & 4.89 & 0.0077 \\
Angle*Weight*Direction & 0.00584 & 4 & 0.00146 & 1.34 & 0.2541 \\
Plane*Weight*Direction & 0.00157 & 4 & 0.00039 & 0.36 & 0.8382 \\
Angle*Plane*Weight*Direction & 0.00289 & 4 & 0.00072 & 0.66 & 0.6198 \\
Error & 1.53459 & 1404 & 0.00109 & & \\
Total & 1.58688 & 1439 & & & \\
& & & & &
\end{tabular}

Constrained (Type III) sums of squares.

Infraspinatus, $128 \mathrm{~ms}$

\begin{tabular}{|c|c|c|c|c|c|c|}
\hline \multicolumn{7}{|c|}{ Analysis of Variance } \\
\hline Source & Sum sq. & d.f. & Mean Sq. & F & Prob $>F$ & $\wedge$ \\
\hline Angle & 0.00001 & 1 & 0.00001 & 0 & 0.9533 & \\
\hline Plane & 0.00008 & 1 & 0.00008 & 0.04 & 0.8343 & \\
\hline Weight & 0.02058 & 2 & 0.01029 & 5.65 & 0.0036 & \\
\hline Direction & 0.01241 & 2 & 0.0062 & 3.4 & 0.0335 & \\
\hline Angle*Plane & 0.00356 & 1 & 0.00356 & 1.95 & 0.1625 & \\
\hline Angle*Weight & 0.0044 & 2 & 0.0022 & 1.21 & 0.2996 & \\
\hline Angle*Direction & 0.00026 & 2 & 0.00013 & 0.07 & 0.9301 & \\
\hline Plane*Weight & 0.00038 & 2 & 0.00019 & 0.1 & 0.9018 & \\
\hline Plane*Direction & 0.01078 & 2 & 0.00539 & 2.96 & 0.0523 & \\
\hline Weight*Direction & 0.00916 & 4 & 0.00229 & 1.26 & 0.2849 & \\
\hline Angle*Plane*Weight & 0.00033 & 2 & 0.00017 & 0.09 & 0.9128 & \\
\hline Angle*Plane*Direction & 0.00471 & 2 & 0.00236 & 1.29 & 0.2749 & \\
\hline Angle*Weight*Direction & 0.00342 & 4 & 0.00085 & 0.47 & 0.7587 & \\
\hline Plane*Weight*Direction & 0.00816 & 4 & 0.00204 & 1.12 & 0.3458 & \\
\hline Angle*Plane*Weight*Direction & 0.00277 & 4 & 0.00069 & 0.38 & 0.8233 & \\
\hline Error & 2.55859 & 1404 & 0.00182 & & & \\
\hline Total & 2.65508 & 1439 & & & & \\
\hline
\end{tabular}

Constrained (Type III) sums of squares.

Infraspinatus, $256 \mathrm{~ms}$ 
Analysis of Variance

\begin{tabular}{|c|c|c|c|c|c|}
\hline Source & Sum Sq. & d.f. & Mean Sq. & $\mathrm{F}$ & Prob $>F$ \\
\hline \multicolumn{6}{|c|}{-------- - - - - - - - - - - - - - - - - - - - - - - - - - - - - - - - - - - - - - - - - - - - - - - - - - - - } \\
\hline Angle & 0.00025 & 1 & 0.00025 & 0.07 & 0.796 \\
\hline Plane & 0.00059 & 1 & 0.00059 & 0.16 & 0.6894 \\
\hline Weight & 0.04378 & 2 & 0.02189 & 5.93 & 0.0027 \\
\hline Direction & 0.02092 & 2 & 0.01046 & 2.83 & 0.0592 \\
\hline Angle*Plane & 0.01406 & 1 & 0.01406 & 3.81 & 0.0512 \\
\hline Angle*Weight & 0.02636 & 2 & 0.01318 & 3.57 & 0.0284 \\
\hline Angle*Direction & 0.01073 & 2 & 0.00537 & 1.45 & 0.2342 \\
\hline Plane*Weight & 0.00725 & 2 & 0.00362 & 0.98 & 0.3751 \\
\hline Plane*Direction & 0.00035 & 2 & 0.00017 & 0.05 & 0.9539 \\
\hline Weight*Direction & 0.01798 & 4 & 0.00449 & 1.22 & 0.3015 \\
\hline Angle*Plane*Weight & 0.00339 & 2 & 0.00169 & 0.46 & 0.6322 \\
\hline Angle*Plane*Direction & 0.00756 & 2 & 0.00378 & 1.02 & 0.3596 \\
\hline Angle*Weight*Direction & 0.03506 & 4 & 0.00876 & 2.37 & 0.0504 \\
\hline Plane*Weight*Direction & 0.01017 & 4 & 0.00254 & 0.69 & 0.5998 \\
\hline Angle*Plane*Weight*Direction & 0.00365 & 4 & 0.00091 & 0.25 & 0.9116 \\
\hline Error & 5.18407 & 1404 & 0.00369 & & \\
\hline Total & 5.369 & 1439 & & & \\
\hline
\end{tabular}

Constrained (Type III) sums of squares.

Infraspinatus, $512 \mathrm{~ms}$

\section{Analysis of Variance}

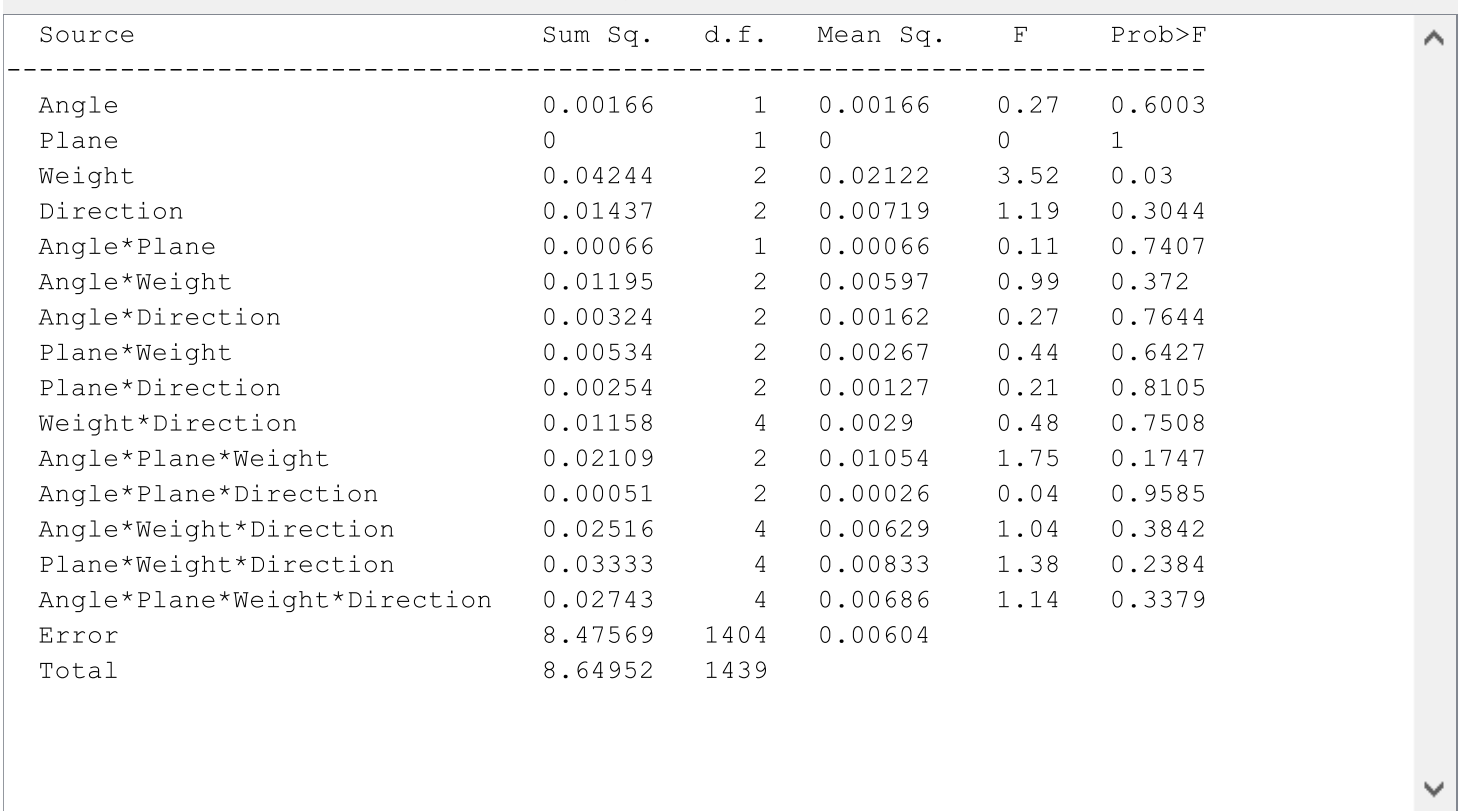

Constrained (Type III) sums of squares.

Infraspinatus, $768 \mathrm{~ms}$ 
Analysis of Variance

\begin{tabular}{|c|c|c|c|c|c|}
\hline Source & Sum Sq. & d.f. & Mean Sq. & $\mathrm{F}$ & Prob $>F$ \\
\hline-- & & -1 & -- & -- & ------- \\
\hline Angle & 0 & 1 & 0.00002 & 0 & 0.9647 \\
\hline Plane & 0.035 & 1 & 0.03503 & 3.73 & 0.0537 \\
\hline Weight & 0.1487 & 2 & 0.07436 & 7.92 & 0.0004 \\
\hline Direction & 0.0032 & 2 & 0.00159 & 0.17 & 0.8444 \\
\hline Angle*Plane & 0.0109 & 1 & 0.01088 & 1.16 & 0.282 \\
\hline Angle*Weight & 0.0006 & 2 & 0.0003 & 0.03 & 0.9686 \\
\hline Angle*Direction & 0.0119 & 2 & 0.00593 & 0.63 & 0.5318 \\
\hline Plane*Weight & 0.0135 & 2 & 0.00675 & 0.72 & 0.4875 \\
\hline Plane*Direction & 0.0504 & 2 & 0.02522 & 2.68 & 0.0686 \\
\hline Weight*Direction & 0.1677 & 4 & 0.04192 & 4.46 & 0.0014 \\
\hline Angle*Plane*Weight & 0.0172 & 2 & 0.00861 & 0.92 & 0.4 \\
\hline Angle*Plane*Direction & 0.0289 & 2 & 0.01445 & 1.54 & 0.2151 \\
\hline Angle*Weight*Direction & 0.0216 & 4 & 0.00539 & 0.57 & 0.6817 \\
\hline Plane*Weight*Direction & 0.0226 & 4 & 0.00565 & 0.6 & 0.6617 \\
\hline Angle*Plane*Weight*Direction & 0.0369 & 4 & 0.00923 & 0.98 & 0.4157 \\
\hline Error & 13.1864 & 1404 & 0.00939 & & \\
\hline Total & 13.6348 & 1439 & & & \\
\hline
\end{tabular}

Constrained (Type III) sums of squares.

Infraspinatus, $1024 \mathrm{~ms}$

3)

\section{Analysis of Variance}

\begin{tabular}{|c|c|c|c|c|c|c|}
\hline Source & Sum Sq. & d.f. & Mean Sq. & $\mathrm{F}$ & Prob $>F$ & ^ \\
\hline -------------- ----------- & -------- & ----- & --------- & ----- & ------- & \\
\hline Angle & 0.00257 & 1 & 0.00257 & 2.59 & 0.1079 & \\
\hline Weight & 0.00322 & 2 & 0.00161 & 1.62 & 0.1985 & \\
\hline Direction & 0.00007 & 2 & 0.00003 & 0.03 & 0.9671 & \\
\hline Angle*Plane & 0.00002 & 1 & 0.00002 & 0.02 & 0.8829 & \\
\hline Angle*Direction & 0.00028 & 2 & 0.00014 & 0.14 & 0.8668 & \\
\hline Plane*Weight & 0.00226 & 2 & 0.00113 & 1.14 & 0.3214 & \\
\hline Plane*Direction & 0.00249 & 2 & 0.00125 & 1.25 & 0.2859 & \\
\hline Weight*Direction & 0.00498 & 4 & 0.00124 & 1.25 & 0.2873 & \\
\hline Angle*Plane*Weight & 0.00566 & 2 & 0.00283 & 2.85 & 0.0583 & \\
\hline Angle*Plane*Weight*Direction & 0.00142 & 4 & 0.00035 & 0.36 & 0.8398 & \\
\hline Error & 1.39591 & 1404 & 0.00099 & & & \\
\hline Total & 1.43649 & 1439 & & & & \\
\hline
\end{tabular}

Constrained (Type III) sums of squares.

Middle deltoid, $128 \mathrm{~ms}$ 
Analysis of Variance

\begin{tabular}{lccccc|}
\hline Source & Sum Sq. & d.f. & Mean Sq. & F & Prob $>F$ \\
Angle & 0.00037 & 1 & 0.00037 & 0.23 & 0.6296 \\
Plane & 0.00074 & 1 & 0.00074 & 0.46 & 0.4973 \\
Weight & 0.00919 & 2 & 0.00459 & 2.87 & 0.0569 \\
Direction & 0.00653 & 2 & 0.00326 & 2.04 & 0.1302 \\
Angle*Plane & 0 & 1 & 0 & 0 & 0.9715 \\
Angle*Weight & 0.00056 & 2 & 0.00028 & 0.18 & 0.8393 \\
Angle*Direction & 0.00219 & 2 & 0.0011 & 0.69 & 0.5036 \\
Plane*Weight & 0.0027 & 2 & 0.00135 & 0.84 & 0.4303 \\
Plane*Direction & 0.00482 & 2 & 0.00241 & 1.51 & 0.2216 \\
Weight*Direction & 0.01652 & 4 & 0.00413 & 2.58 & 0.0356 \\
Angle*Plane*Weight & 0.00666 & 2 & 0.00333 & 2.08 & 0.1249 \\
Angle*Plane*Direction & 0.00091 & 2 & 0.00046 & 0.29 & 0.7513 \\
Angle*Weight*Direction & 0.02424 & 4 & 0.00606 & 3.79 & 0.0045 \\
Plane*Weight*Direction & 0.00803 & 4 & 0.00201 & 1.25 & 0.2859 \\
Angle*Plane*Weight*Direction & 0.01334 & 4 & 0.00334 & 2.09 & 0.0804 \\
Error & 2.24511 & 1404 & 0.0016 & & \\
Total & 2.34609 & 1439 & & & \\
& & & & & \\
\hline
\end{tabular}

Constrained (Type III) sums of squares.

Middle deltoid, 256ms

\section{Analysis of Variance}

\begin{tabular}{llrrrl|}
\hline Source & Sum Sq. & d.f. & Mean Sq. & F & Prob>F \\
Angle & 0.0004 & 1 & 0.0004 & 0.11 & 0.7388 \\
Plane & 0.00184 & 1 & 0.00184 & 0.51 & 0.475 \\
Weight & 0.10454 & 2 & 0.05227 & 14.53 & 0 \\
Direction & 0.03512 & 2 & 0.01756 & 4.88 & 0.0077 \\
Angle*Plane & 0.0002 & 1 & 0.0002 & 0.06 & 0.8118 \\
Angle*Weight & 0.01177 & 2 & 0.00589 & 1.64 & 0.1951 \\
Angle*Direction & 0.01463 & 2 & 0.00732 & 2.03 & 0.1312 \\
Plane*Weight & 0.00065 & 2 & 0.00032 & 0.09 & 0.9141 \\
Plane*Direction & 0.00252 & 2 & 0.00126 & 0.35 & 0.7045 \\
Weight*Direction & 0.05282 & 4 & 0.0132 & 3.67 & 0.0056 \\
Angle*Plane*Weight & 0.00767 & 2 & 0.00384 & 1.07 & 0.3445 \\
Angle*Plane*Direction & 0.00165 & 2 & 0.00083 & 0.23 & 0.7949 \\
Angle*Weight*Direction & 0.0173 & 4 & 0.00432 & 1.2 & 0.308 \\
Plane*Weight*Direction & 0.00421 & 4 & 0.00105 & 0.29 & 0.8827 \\
Angle*Plane*Weight*Direction & 0.0117 & 4 & 0.00293 & 0.81 & 0.5167 \\
Error & 5.05084 & 1404 & 0.0036 & & \\
Total & 5.3225 & 1439 & & & \\
& & & & & \\
\end{tabular}

Constrained (Type III) sums of squares.

\section{Middle deltoid, $512 \mathrm{~ms}$}


Analysis of Variance

\begin{tabular}{llrlll|}
\hline Source & Sum Sq. & d.f. & Mean Sq. & F & Prob $>F$ \\
\hline Angle & 0.01389 & 1 & 0.01389 & 2.4 & 0.1214 \\
Plane & 0.00029 & 1 & 0.00029 & 0.05 & 0.8217 \\
Weight & 0.10032 & 2 & 0.05016 & 8.67 & 0.0002 \\
Direction & 0.0696 & 2 & 0.0348 & 6.02 & 0.0025 \\
Angle*Plane & 0.00265 & 1 & 0.00265 & 0.46 & 0.499 \\
Angle*Weight & 0.02439 & 2 & 0.0122 & 2.11 & 0.1219 \\
Angle*Direction & 0.00238 & 2 & 0.00119 & 0.21 & 0.8144 \\
Plane*Weight & 0.00079 & 2 & 0.00039 & 0.07 & 0.9342 \\
Plane*Direction & 0.00365 & 2 & 0.00182 & 0.32 & 0.7296 \\
Weight*Direction & 0.0926 & 4 & 0.02315 & 4 & 0.0031 \\
Angle*Plane*Weight & 0.00639 & 2 & 0.00319 & 0.55 & 0.576 \\
Angle*Plane*Direction & 0.00381 & 2 & 0.0019 & 0.33 & 0.7195 \\
Angle*Weight*Direction & 0.02603 & 4 & 0.00651 & 1.12 & 0.3431 \\
Plane*Weight*Direction & 0.03685 & 4 & 0.00921 & 1.59 & 0.1738 \\
Angle*Plane*Weight*Direction & 0.00988 & 4 & 0.00247 & 0.43 & 0.7894 \\
Error & 8.12269 & 1404 & 0.00579 & & \\
Total & 8.55399 & 1439 & & & \\
& & & & & \\
\hline
\end{tabular}

Constrained (Type III) sums of squares.

Middle deltoid, $768 \mathrm{~ms}$

Analysis of Variance

\begin{tabular}{lcrrrl}
\hline Source & Sum Sq. & d.f. & Mean Sq. & F & Prob $>$ F \\
\hline Angle & 0.0817 & 1 & 0.08165 & 8.82 & 0.003 \\
Plane & 0.0073 & 1 & 0.00735 & 0.79 & 0.3732 \\
Weight & 0.2877 & 2 & 0.14385 & 15.54 & 0 \\
Direction & 0.141 & 2 & 0.07052 & 7.62 & 0.0005 \\
Angle*Plane & 0.0078 & 1 & 0.00785 & 0.85 & 0.3574 \\
Angle*Weight & 0.008 & 2 & 0.00399 & 0.43 & 0.6497 \\
Angle*Direction & 0.0168 & 2 & 0.00841 & 0.91 & 0.4033 \\
Plane*Weight & 0.0038 & 2 & 0.00189 & 0.2 & 0.8152 \\
Plane*Direction & 0.0466 & 2 & 0.02332 & 2.52 & 0.0809 \\
Weight*Direction & 0.1606 & 4 & 0.04014 & 4.34 & 0.0017 \\
Angle*Plane*Weight & 0.0036 & 2 & 0.00181 & 0.2 & 0.822 \\
Angle*Plane*Direction & 0.0061 & 2 & 0.00303 & 0.33 & 0.721 \\
Angle*Weight*Direction & 0.1016 & 4 & 0.02539 & 2.74 & 0.0273 \\
Plane*Wight*Direction & 0.0502 & 4 & 0.01254 & 1.35 & 0.2476 \\
Angle*Plane*Weight*Direction & 0.0402 & 4 & 0.01004 & 1.08 & 0.3626 \\
Error & 13.0003 & 1404 & 0.00926 & & \\
Total & 14.0614 & 1439 & & & \\
& & & & & \\
\end{tabular}

Constrained (Type III) sums of squares.

Middle deltoid, 1024 ms 
4)

Analysis of Variance

\begin{tabular}{|c|c|c|c|c|c|c|}
\hline Source & Sum Sq. & d.f. & Mean Sq. & F & Prob $>F$ & $\hat{\wedge}$ \\
\hline & & & & & & \\
\hline Angle & 0.00231 & 1 & 0.00231 & 2.06 & 0.1513 & \\
\hline Plane & 0.00008 & 1 & 0.00008 & 0.07 & 0.7937 & \\
\hline Weight & 0.00233 & 2 & 0.00117 & 1.04 & 0.3529 & \\
\hline Direction & 0.01179 & 2 & 0.0059 & 5.27 & 0.0053 & \\
\hline Angle*Plane & 0.00011 & 1 & 0.00011 & 0.1 & 0.7529 & \\
\hline Angle*Weight & 0.00424 & 2 & 0.00212 & 1.89 & 0.1513 & \\
\hline Angle*Direction & 0.00183 & 2 & 0.00092 & 0.82 & 0.4411 & \\
\hline Plane*Weight & 0.00337 & 2 & 0.00169 & 1.51 & 0.222 & \\
\hline Plane*Direction & 0.00046 & 2 & 0.00023 & 0.2 & 0.8155 & \\
\hline Weight*Direction & 0.00661 & 4 & 0.00165 & 1.47 & 0.2074 & \\
\hline Angle*Plane*Weight & 0.00332 & 2 & 0.00166 & 1.48 & 0.2275 & \\
\hline Angle*Plane*Direction & 0.00127 & 2 & 0.00064 & 0.57 & 0.5664 & \\
\hline Angle*Weight*Direction & 0.00274 & 4 & 0.00068 & 0.61 & 0.6545 & \\
\hline Plane*Weight*Direction & 0.0056 & 4 & 0.0014 & 1.25 & 0.2875 & \\
\hline Angle*Plane*Weight*Direction & 0.00738 & 4 & 0.00184 & 1.65 & 0.1598 & \\
\hline Error & 1.57212 & 1404 & 0.00112 & & & \\
\hline Total & 1.62236 & 1439 & & & & \\
\hline
\end{tabular}

Constrained (Type III) sums of squares.

Anterior deltoid, $128 \mathrm{~ms}$

\section{Analysis of Variance}

\begin{tabular}{|c|c|c|c|c|c|c|}
\hline Source & Sum Sq. & d.f. & Mean Sq. & $\mathrm{F}$ & Prob $>F$ & $\wedge$ \\
\hline & & & & & & \\
\hline Angle & 0.00257 & 1 & 0.00257 & 1.52 & 0.2182 & \\
\hline Plane & 0.01242 & 1 & 0.01242 & 7.33 & 0.0069 & \\
\hline Weight & 0.02264 & 2 & 0.01132 & 6.68 & 0.0013 & \\
\hline Direction & 0.00994 & 2 & 0.00497 & 2.93 & 0.0536 & \\
\hline Angle*Plane & 0.00652 & 1 & 0.00652 & 3.84 & 0.0501 & \\
\hline Angle*Weight & 0.00709 & 2 & 0.00355 & 2.09 & 0.1239 & \\
\hline Angle*Direction & 0.00142 & 2 & 0.00071 & 0.42 & 0.6576 & \\
\hline Plane*Weight & 0.00415 & 2 & 0.00208 & 1.23 & 0.294 & \\
\hline Plane*Direction & 0.0022 & 2 & 0.0011 & 0.65 & 0.5224 & \\
\hline Weight*Direction & 0.0018 & 4 & 0.00045 & 0.26 & 0.9006 & \\
\hline Angle*Plane*Weight & 0.00415 & 2 & 0.00208 & 1.22 & 0.2943 & \\
\hline Angle*Plane*Direction & 0.00003 & 2 & 0.00001 & 0.01 & 0.9917 & \\
\hline Angle*Weight*Direction & 0.00723 & 4 & 0.00181 & 1.07 & 0.3716 & \\
\hline Plane*Weight*Direction & 0.00309 & 4 & 0.00077 & 0.46 & 0.7683 & \\
\hline Angle*Plane*Weight*Direction & 0.01122 & 4 & 0.00281 & 1.66 & 0.1579 & \\
\hline Error & 2.37989 & 1404 & 0.0017 & & & \\
\hline Total & 2.47026 & 1439 & & & & \\
\hline
\end{tabular}

Constrained (Type III) sums of squares.

Anterior deltoid, 256ms 
Analysis of Variance

\begin{tabular}{lccccc|}
\hline Source & Sum Sq. & d.f. & Mean Sq. & F & Prob $>F$ \\
\hline Angle & 0.01728 & 1 & 0.01728 & 4.67 & 0.0309 \\
Plane & 0.00002 & 1 & 0.00002 & 0 & 0.9439 \\
Weight & 0.12513 & 2 & 0.06257 & 16.9 & 0 \\
Direction & 0.07887 & 2 & 0.03943 & 10.65 & 0 \\
Angle*Plane & 0 & 1 & 0 & 0 & 0.9813 \\
Angle*Weight & 0.00136 & 2 & 0.00068 & 0.18 & 0.8322 \\
Angle*Direction & 0.01265 & 2 & 0.00633 & 1.71 & 0.1816 \\
Plane*Weight & 0.0104 & 2 & 0.0052 & 1.4 & 0.2459 \\
Plane*Direction & 0.00081 & 2 & 0.0004 & 0.11 & 0.8969 \\
Weight*Direction & 0.05297 & 4 & 0.01324 & 3.58 & 0.0066 \\
Angle*Plane*Weight & 0.00121 & 2 & 0.0006 & 0.16 & 0.8496 \\
Angle*Plane*Direction & 0.00078 & 2 & 0.00039 & 0.1 & 0.9004 \\
Angle*Weight*Direction & 0.02391 & 4 & 0.00598 & 1.61 & 0.1682 \\
Plane*Wight*Direction & 0.01323 & 4 & 0.00331 & 0.89 & 0.4671 \\
Angle*Plane*Weight*Direction & 0.01373 & 4 & 0.00343 & 0.93 & 0.4472 \\
Error & 5.19925 & 1404 & 0.0037 & & \\
Total & 5.52365 & 1439 & & & \\
& & & & & \\
\hline
\end{tabular}

Constrained (Type III) sums of squares.

Anterior deltoid, 512ms

\section{Analysis of Variance}

\begin{tabular}{lcrrrl|}
\hline Source & Sum Sq. & d.f. & Mean Sq. & F & Prob>F \\
Angle & 0.0001 & 1 & 0.00009 & 0.01 & 0.906 \\
Plane & 0.0001 & 1 & 0.00006 & 0.01 & 0.9268 \\
Weight & 0.3046 & 2 & 0.1523 & 22.85 & 0 \\
Direction & 0.2348 & 2 & 0.11741 & 17.62 & 0 \\
Angle*Plane & 0 & 1 & 0.00003 & 0 & 0.9477 \\
Angle*Weight & 0.0134 & 2 & 0.00672 & 1.01 & 0.3651 \\
Angle*Direction & 0.0223 & 2 & 0.01115 & 1.67 & 0.1881 \\
Plane*Weight & 0.0042 & 2 & 0.00212 & 0.32 & 0.728 \\
Plane*Direction & 0.0011 & 2 & 0.00054 & 0.08 & 0.9226 \\
Weight*Direction & 0.2038 & 4 & 0.05096 & 7.65 & 0 \\
Angle*Plane*Weight & 0.0136 & 2 & 0.00679 & 1.02 & 0.3611 \\
Angle*Plane*Direction & 0.0084 & 2 & 0.0042 & 0.63 & 0.5325 \\
Angle*Weight*Direction & 0.0136 & 4 & 0.00341 & 0.51 & 0.7275 \\
Plane*Wight*Direction & 0.0049 & 4 & 0.00123 & 0.18 & 0.9466 \\
Angle*Plane*Wight*Direction & 0.0153 & 4 & 0.00383 & 0.57 & 0.6812 \\
Error & 9.3568 & 1404 & 0.00666 & & \\
Total & 10.103 & 1439 & & & \\
& & & & & \\
\end{tabular}

Constrained (Type III) sums of squares.

\section{Anterior deltoid,768ms}


Analysis of Variance

\begin{tabular}{lcrrrr|}
\hline Source & Sum Sq. & d.f. & Mean Sq. & F & Prob $>$ F \\
Angle & 0.0394 & 1 & 0.03944 & 4.01 & 0.0455 \\
Plane & 0.02 & 1 & 0.02001 & 2.03 & 0.1542 \\
Weight & 0.574 & 2 & 0.28702 & 29.16 & 0 \\
Direction & 0.3595 & 2 & 0.17974 & 18.26 & 0 \\
Angle*Plane & 0.0121 & 1 & 0.0121 & 1.23 & 0.2677 \\
Angle*Weight & 0.0094 & 2 & 0.00471 & 0.48 & 0.6198 \\
Angle*Direction & 0.0052 & 2 & 0.00258 & 0.26 & 0.7692 \\
Plane*Weight & 0.019 & 2 & 0.00948 & 0.96 & 0.382 \\
Plane*Direction & 0.016 & 2 & 0.00799 & 0.81 & 0.4443 \\
Weight*Direction & 0.2061 & 4 & 0.05154 & 5.24 & 0.0003 \\
Angle*Plane*Weight & 0.0135 & 2 & 0.00677 & 0.69 & 0.503 \\
Angle*Plane*Direction & 0.0535 & 2 & 0.02676 & 2.72 & 0.0663 \\
Angle*Weight*Direction & 0.0758 & 4 & 0.01896 & 1.93 & 0.1037 \\
Plane*Wight*Direction & 0.0299 & 4 & 0.00748 & 0.76 & 0.5517 \\
Angle*Plane*Weight*Direction & 0.0458 & 4 & 0.01145 & 1.16 & 0.3254 \\
Error & 13.8218 & 1404 & 0.00984 & & \\
Total & 15.1687 & 1439 & & & \\
& & & & & \\
\end{tabular}

Constrained (Type III) sums of squares.

Anterior deltoid, 1024ms

5)

\section{Analysis of Variance}

\begin{tabular}{llrlll|}
\hline Source & Sum Sq. & d.f. & Mean Sq. & F & Prob>F \\
\hline Angle & 0.01356 & 1 & 0.01356 & 12.13 & 0.0005 \\
Plane & 0.00711 & 1 & 0.00711 & 6.36 & 0.0118 \\
Weight & 0.0002 & 2 & 0.0001 & 0.09 & 0.9131 \\
Direction & 0.00264 & 2 & 0.00132 & 1.18 & 0.307 \\
Angle*Plane & 0.00013 & 1 & 0.00013 & 0.12 & 0.7325 \\
Angle*Weight & 0.00135 & 2 & 0.00067 & 0.6 & 0.547 \\
Angle*Direction & 0.00212 & 2 & 0.00106 & 0.95 & 0.3881 \\
Plane*Weight & 0.00258 & 2 & 0.00129 & 1.15 & 0.3161 \\
Plane*Direction & 0.00952 & 2 & 0.00476 & 4.26 & 0.0143 \\
Weight*Direction & 0.00561 & 4 & 0.0014 & 1.25 & 0.2859 \\
Angle*Plane*Weight & 0.00002 & 2 & 0.00001 & 0.01 & 0.9898 \\
Angle*Plane*Direction & 0.00026 & 2 & 0.00013 & 0.12 & 0.8907 \\
Angle*Weight*Direction & 0.00389 & 4 & 0.00097 & 0.87 & 0.4811 \\
Plane*Weight*Direction & 0.0009 & 4 & 0.00022 & 0.2 & 0.938 \\
Angle*Plane*Weight*Direction & 0.0012 & 4 & 0.0003 & 0.27 & 0.899 \\
Error & 1.56912 & 1404 & 0.00112 & & \\
Total & 1.62113 & 1439 & & & \\
& & & & & \\
\hline
\end{tabular}

Constrained (Type III) sums of squares.

Posterior deltoid, $128 \mathrm{~ms}$ 
Analysis of Variance

\begin{tabular}{llrrrr|}
\hline Source & Sum Sq. & d.f. & Mean Sq. & F & Prob>F \\
Angle & 0.02526 & 1 & 0.02526 & 13.97 & 0.0002 \\
Plane & 0.00175 & 1 & 0.00175 & 0.97 & 0.3259 \\
Weight & 0.00228 & 2 & 0.00114 & 0.63 & 0.5327 \\
Direction & 0.0046 & 2 & 0.0023 & 1.27 & 0.2803 \\
Angle*Plane & 0.00002 & 1 & 0.00002 & 0.01 & 0.9131 \\
Angle*Weight & 0.00075 & 2 & 0.00037 & 0.21 & 0.8136 \\
Angle*Direction & 0.00403 & 2 & 0.00202 & 1.12 & 0.3281 \\
Plane*Weight & 0.01141 & 2 & 0.00571 & 3.16 & 0.0429 \\
Plane*Direction & 0.00367 & 2 & 0.00184 & 1.02 & 0.3623 \\
Weight*Direction & 0.00291 & 4 & 0.00073 & 0.4 & 0.8073 \\
Angle*Plane*Weight & 0.00203 & 2 & 0.00101 & 0.56 & 0.5707 \\
Angle*Plane*Direction & 0.00286 & 2 & 0.00143 & 0.79 & 0.4541 \\
Angle*Weight*Direction & 0.00481 & 4 & 0.0012 & 0.66 & 0.6166 \\
Plane*Weight*Direction & 0.00678 & 4 & 0.0017 & 0.94 & 0.4409 \\
Angle*Plane*Weight*Direction & 0.0065 & 4 & 0.00162 & 0.9 & 0.4643 \\
Error & 2.53833 & 1404 & 0.00181 & & \\
Total & 2.62399 & 1439 & & & \\
& & & & &
\end{tabular}

Constrained (Type III) sums of squares.

Posterior deltoid, 256ms

\begin{tabular}{lccccc|}
\multicolumn{7}{c}{ Analysis of Variance } \\
\hline Source & Sum Sq. & d.f. & Mean Sq. & F & Prob>F \\
Angle & 0.00629 & 1 & 0.00629 & 1.86 & 0.1725 \\
Plane & 0.01635 & 1 & 0.01635 & 4.85 & 0.0279 \\
Weight & 0.01907 & 2 & 0.00954 & 2.83 & 0.0596 \\
Direction & 0.00763 & 2 & 0.00382 & 1.13 & 0.3231 \\
Angle*Plane & 0.00335 & 1 & 0.00335 & 0.99 & 0.3194 \\
Angle*Weight & 0.00231 & 2 & 0.00116 & 0.34 & 0.7097 \\
Angle*Direction & 0.00341 & 2 & 0.0017 & 0.5 & 0.6037 \\
Plane*Weight & 0.00503 & 2 & 0.00251 & 0.74 & 0.4751 \\
Plane*Direction & 0.00309 & 2 & 0.00154 & 0.46 & 0.633 \\
Weight*Direction & 0.00411 & 4 & 0.00103 & 0.3 & 0.8753 \\
Angle*Plane*Weight & 0.00775 & 2 & 0.00388 & 1.15 & 0.3174 \\
Angle*Plane*Direction & 0.01486 & 2 & 0.00743 & 2.2 & 0.111 \\
Angle*Weight*Direction & 0.0129 & 4 & 0.00322 & 0.96 & 0.431 \\
Plane*Weight*Direction & 0.03348 & 4 & 0.00837 & 2.48 & 0.0423 \\
Angle*Plane*Weight*Direction & 0.02135 & 4 & 0.00534 & 1.58 & 0.1767 \\
Error & 4.73804 & 1404 & 0.00337 & & \\
Total & 4.90458 & 1439 & & & \\
& & & & & \\
\end{tabular}

Constrained (Type III) sums of squares.

Posterior deltoid, 512ms 
Analysis of Variance

\begin{tabular}{llrlll|}
\hline Source & Sum Sq. & d.f. & Mean Sq. & F & Prob>F \\
Angle & 0.00003 & 1 & 0.00003 & 0 & 0.9445 \\
Plane & 0.0108 & 1 & 0.0108 & 1.82 & 0.1771 \\
Weight & 0.03043 & 2 & 0.01522 & 2.57 & 0.0771 \\
Direction & 0.07181 & 2 & 0.0359 & 6.06 & 0.0024 \\
Angle*Plane & 0.00299 & 1 & 0.00299 & 0.5 & 0.4779 \\
Angle*Weight & 0.02778 & 2 & 0.01389 & 2.34 & 0.0963 \\
Angle*Direction & 0.00546 & 2 & 0.00273 & 0.46 & 0.6308 \\
Plane*Weight & 0.00287 & 2 & 0.00143 & 0.24 & 0.7851 \\
Plane*Direction & 0.00521 & 2 & 0.00261 & 0.44 & 0.6443 \\
Weight*Direction & 0.02986 & 4 & 0.00747 & 1.26 & 0.2838 \\
Angle*Plane*Weight & 0.00563 & 2 & 0.00281 & 0.47 & 0.622 \\
Angle*Plane*Direction & 0.01318 & 2 & 0.00659 & 1.11 & 0.329 \\
Angle*Weight*Direction & 0.03259 & 4 & 0.00815 & 1.37 & 0.2404 \\
Plane*Weight*Direction & 0.03706 & 4 & 0.00927 & 1.56 & 0.1816 \\
Angle*Plane*Weight*Direction & 0.01181 & 4 & 0.00295 & 0.5 & 0.7372 \\
Error & 8.31935 & 1404 & 0.00593 & & \\
Total & 8.64128 & 1439 & & & \\
& & & & & \\
\hline
\end{tabular}

Constrained (Type III) sums of squares.

Posterior deltoid, 768ms

\begin{tabular}{|c|c|c|c|c|c|c|}
\hline \multicolumn{7}{|c|}{ Analysis of Variance } \\
\hline Source & Sum Sq. & d.f. & Mean Sq. & $\mathrm{F}$ & Prob $>F$ & $\wedge$ \\
\hline & & & & & - 0 & \\
\hline Angle & 0.0005 & 1 & 0.00052 & 0.05 & 0.8179 & \\
\hline Plane & 0.0021 & 1 & 0.00209 & 0.21 & 0.6451 & \\
\hline Weight & 0.1566 & 2 & 0.07828 & 7.95 & 0.0004 & \\
\hline Direction & 0.0814 & 2 & 0.04071 & 4.13 & 0.0162 & \\
\hline Angle*Plane & 0.0036 & 1 & 0.0036 & 0.37 & 0.5455 & \\
\hline Angle*Weight & 0.0184 & 2 & 0.00919 & 0.93 & 0.3937 & \\
\hline Angle*Direction & 0.0067 & 2 & 0.00336 & 0.34 & 0.7114 & \\
\hline Plane*Weight & 0.0106 & 2 & 0.00528 & 0.54 & 0.5851 & \\
\hline Plane*Direction & 0.0294 & 2 & 0.01471 & 1.49 & 0.2251 & \\
\hline Weight*Direction & 0.0581 & 4 & 0.01452 & 1.47 & 0.2075 & \\
\hline Angle*Plane*Weight & 0.0113 & 2 & 0.00564 & 0.57 & 0.5642 & \\
\hline Angle*Plane*Direction & 0.0608 & 2 & 0.03042 & 3.09 & 0.0459 & \\
\hline Angle*Weight*Direction & 0.0291 & 4 & 0.00728 & 0.74 & 0.5652 & \\
\hline Plane*Weight*Direction & 0.0494 & 4 & 0.01236 & 1.25 & 0.286 & \\
\hline Angle*Plane*Weight*Direction & 0.0803 & 4 & 0.02008 & 2.04 & 0.0867 & \\
\hline Error & 13.8296 & 1404 & 0.00985 & & & \\
\hline Total & 14.4679 & 1439 & & & & \\
\hline
\end{tabular}

Constrained (Type III) sums of squares.

Posterior deltoid, $1024 \mathrm{~ms}$

6) 
Analysis of Variance

\begin{tabular}{lcrrrr|}
\hline Source & Sum Sq. & d.f. & Mean Sq. & F & Prob $>F$ \\
Angle & 0.00006 & 1 & 0.00006 & 0.05 & 0.819 \\
Plane & 0.00011 & 1 & 0.00011 & 0.1 & 0.7536 \\
Weight & 0.00351 & 2 & 0.00175 & 1.56 & 0.2111 \\
Direction & 0.00282 & 2 & 0.00141 & 1.25 & 0.2861 \\
Angle*Plane & 0.00037 & 1 & 0.00037 & 0.32 & 0.5691 \\
Angle*Weight & 0.00767 & 2 & 0.00383 & 3.41 & 0.0335 \\
Angle*Direction & 0.00068 & 2 & 0.00034 & 0.3 & 0.741 \\
Plane*Weight & 0.0027 & 2 & 0.00135 & 1.2 & 0.3018 \\
Plane*Direction & 0.00295 & 2 & 0.00148 & 1.31 & 0.2696 \\
Weight*Direction & 0.00529 & 4 & 0.00132 & 1.17 & 0.3205 \\
Angle*Plane*Weight & 0.00235 & 2 & 0.00118 & 1.04 & 0.352 \\
Angle*Plane*Direction & 0.00028 & 2 & 0.00014 & 0.12 & 0.8849 \\
Angle*Weight*Direction & 0.01012 & 4 & 0.00253 & 2.25 & 0.0619 \\
Plane*Weight*Direction & 0.00743 & 4 & 0.00186 & 1.65 & 0.1591 \\
Angle*Plane*Weight*Direction & 0.00206 & 4 & 0.00052 & 0.46 & 0.7665 \\
Error & 1.58082 & 1404 & 0.00113 & & \\
Total & 1.62828 & 1439 & & & \\
& & & & & \\
\hline
\end{tabular}

Constrained (Type III) sums of squares.

Biceps, $128 \mathrm{~ms}$

\section{Analysis of Variance}

\begin{tabular}{llrlll|}
\hline Source & Sum Sq. & d.f. & Mean Sq. & F & Prob>F \\
Angle & 0.00002 & 1 & 0.00002 & 0.01 & 0.9235 \\
Plane & 0.00106 & 1 & 0.00106 & 0.63 & 0.4273 \\
Weight & 0.01092 & 2 & 0.00546 & 3.26 & 0.0387 \\
Direction & 0.0091 & 2 & 0.00455 & 2.72 & 0.0665 \\
Angle*Plane & 0.00101 & 1 & 0.00101 & 0.6 & 0.4375 \\
Angle*Weight & 0.00446 & 2 & 0.00223 & 1.33 & 0.2649 \\
Angle*Direction & 0.00154 & 2 & 0.00077 & 0.46 & 0.6308 \\
Plane*Weight & 0.00069 & 2 & 0.00034 & 0.2 & 0.8149 \\
Plane*Direction & 0.02162 & 2 & 0.01081 & 6.45 & 0.0016 \\
Weight*Direction & 0.00599 & 4 & 0.0015 & 0.89 & 0.4669 \\
Angle*Plane*Weight & 0.00946 & 2 & 0.00473 & 2.82 & 0.0598 \\
Angle*Plane*Direction & 0.00436 & 2 & 0.00218 & 1.3 & 0.2728 \\
Angle*Weight*Direction & 0.00725 & 4 & 0.00181 & 1.08 & 0.3637 \\
Plane*Weight*Direction & 0.00377 & 4 & 0.00094 & 0.56 & 0.6903 \\
Angle*Plane*Weight*Direction & 0.00573 & 4 & 0.00143 & 0.85 & 0.4908 \\
Error & 2.35244 & 1404 & 0.00168 & & \\
Total & 2.44579 & 1439 & & & \\
& & & & & \\
\end{tabular}

Constrained (Type III) sums of squares.

Biceps, 268ms 
Analysis of Variance

\begin{tabular}{llrlll|}
\hline Source & Sum Sq. & d.f. & Mean Sq. & F & Prob $>F$ \\
\hline Angle & 0.0009 & 1 & 0.0009 & 0.26 & 0.6126 \\
Plane & 0.0009 & 1 & 0.0009 & 0.26 & 0.6126 \\
Weight & 0.0606 & 2 & 0.0303 & 8.63 & 0.0002 \\
Direction & 0.02132 & 2 & 0.01066 & 3.04 & 0.0483 \\
Angle*Plane & 0.01 & 1 & 0.01 & 2.85 & 0.0916 \\
Angle*Weight & 0.00827 & 2 & 0.00413 & 1.18 & 0.3083 \\
Angle*Direction & 0.00445 & 2 & 0.00222 & 0.63 & 0.531 \\
Plane*Weight & 0.00387 & 2 & 0.00194 & 0.55 & 0.5763 \\
Plane*Direction & 0.0149 & 2 & 0.00745 & 2.12 & 0.12 \\
Weight*Direction & 0.016 & 4 & 0.004 & 1.14 & 0.3362 \\
Angle*Plane*Weight & 0.00483 & 2 & 0.00241 & 0.69 & 0.5027 \\
Angle*Plane*Direction & 0.00654 & 2 & 0.00327 & 0.93 & 0.3939 \\
Angle*Weight*Direction & 0.01558 & 4 & 0.00389 & 1.11 & 0.3503 \\
Plane*Wight*Direction & 0.00312 & 4 & 0.00078 & 0.22 & 0.9261 \\
Angle*Plane*Weight*Direction & 0.04796 & 4 & 0.01199 & 3.42 & 0.0086 \\
Error & 4.92738 & 1404 & 0.00351 & & \\
Total & 5.14029 & 1439 & & & \\
& & & & & \\
\end{tabular}

Constrained (Type III) sums of squares.

Biceps, 512ms

\begin{tabular}{lcrrrr}
\multicolumn{7}{c}{ Analysis of Variance } & & \\
\hline Source & Sum Sq. & d.f. & Mean Sq. & F & Prob $>$ F \\
\hline Angle & 0.0093 & 1 & 0.0093 & 1.63 & 0.2018 \\
Plane & 0.03013 & 1 & 0.03013 & 5.28 & 0.0217 \\
Weight & 0.12341 & 2 & 0.0617 & 10.82 & 0 \\
Direction & 0.00963 & 2 & 0.00481 & 0.84 & 0.4303 \\
Angle*Plane & 0.0081 & 1 & 0.0081 & 1.42 & 0.2335 \\
Angle*Weight & 0.01943 & 2 & 0.00972 & 1.7 & 0.1824 \\
Angle*Direction & 0.00731 & 2 & 0.00366 & 0.64 & 0.527 \\
Plane*Weight & 0.00187 & 2 & 0.00093 & 0.16 & 0.849 \\
Plane*Direction & 0.05505 & 2 & 0.02753 & 4.83 & 0.0081 \\
Weight*Direction & 0.01127 & 4 & 0.00282 & 0.49 & 0.7403 \\
Angle*Plane*Weight & 0.04577 & 2 & 0.02288 & 4.01 & 0.0183 \\
Angle*Plane*Direction & 0.00239 & 2 & 0.0012 & 0.21 & 0.8109 \\
Angle*Weight*Direction & 0.02193 & 4 & 0.00548 & 0.96 & 0.4277 \\
Plane*Weight*Direction & 0.01817 & 4 & 0.00454 & 0.8 & 0.5274 \\
Angle*Plane*Weight*Direction & 0.0305 & 4 & 0.00762 & 1.34 & 0.2541 \\
Error & 8.00752 & 1404 & 0.0057 & & \\
Total & 8.40044 & 1439 & & & \\
& & & & &
\end{tabular}

Constrained (Type III) sums of squares.

\section{Biceps, $768 \mathrm{~ms}$}


Analysis of Variance

\begin{tabular}{|c|c|c|c|c|c|}
\hline Source & Sum Sq. & d.f. & Mean Sq. & $\mathrm{F}$ & Prob $>F$ \\
\hline-- & - & -- & --- & ----- & ------- \\
\hline Angle & 0.0011 & 1 & 0.00108 & 0.12 & 0.7328 \\
\hline Plane & 0.0041 & 1 & 0.00413 & 0.45 & 0.5042 \\
\hline Weight & 0.1174 & 2 & 0.05868 & 6.34 & 0.0018 \\
\hline Direction & 0.0426 & 2 & 0.02132 & 2.3 & 0.1004 \\
\hline Angle*Plane & 0.002 & 1 & 0.00196 & 0.21 & 0.6454 \\
\hline Angle*Weight & 0.0022 & 2 & 0.00112 & 0.12 & 0.8864 \\
\hline Angle*Direction & 0.0009 & 2 & 0.00043 & 0.05 & 0.9545 \\
\hline Plane*Weight & 0.0168 & 2 & 0.00838 & 0.91 & 0.4047 \\
\hline Plane*Direction & 0.0008 & 2 & 0.0004 & 0.04 & 0.9574 \\
\hline Weight*Direction & 0.0224 & 4 & 0.00559 & 0.6 & 0.6602 \\
\hline Angle*Plane*Weight & 0.0516 & 2 & 0.0258 & 2.79 & 0.0621 \\
\hline Angle*Plane*Direction & 0.0133 & 2 & 0.00667 & 0.72 & 0.4867 \\
\hline Angle*Weight*Direction & 0.0071 & 4 & 0.00177 & 0.19 & 0.9432 \\
\hline Plane*Weight*Direction & 0.0163 & 4 & 0.00406 & 0.44 & 0.7807 \\
\hline Angle*Plane*Weight*Direction & 0.0285 & 4 & 0.00712 & 0.77 & 0.5457 \\
\hline Error & 13.0043 & 1404 & 0.00926 & & \\
\hline Total & 13.3868 & 1439 & & & \\
\hline
\end{tabular}

Constrained (Type III) sums of squares.

\section{Biceps, 1024ms}

7)

\begin{tabular}{|c|c|c|c|c|c|c|}
\hline \multicolumn{7}{|c|}{ Analysis of Variance } \\
\hline Source & Sum sq. & d.f. & Mean Sq. & F & Prob $>F$ & $\wedge$ \\
\hline Angle & 0.00166 & 1 & 0.00166 & 1.48 & 0.2243 & \\
\hline Plane & 0.00646 & 1 & 0.00646 & 5.76 & 0.0165 & \\
\hline Weight & 0.02085 & 2 & 0.01042 & 9.29 & 0.0001 & \\
\hline Direction & 0.01375 & 2 & 0.00688 & 6.13 & 0.0022 & \\
\hline Angle*Plane & 0.00141 & 1 & 0.00141 & 1.25 & 0.263 & \\
\hline Angle*Weight & 0.00901 & 2 & 0.00451 & 4.02 & 0.0182 & \\
\hline Angle*Direction & 0.00073 & 2 & 0.00036 & 0.32 & 0.7227 & \\
\hline Plane*Weight & 0.00267 & 2 & 0.00134 & 1.19 & 0.3042 & \\
\hline Plane*Direction & 0.00129 & 2 & 0.00065 & 0.58 & 0.5617 & \\
\hline Weight*Direction & 0.01847 & 4 & 0.00462 & 4.12 & 0.0026 & \\
\hline Angle*Plane*Weight & 0.00245 & 2 & 0.00123 & 1.09 & 0.3354 & \\
\hline Angle*Plane*Direction & 0.00108 & 2 & 0.00054 & 0.48 & 0.6182 & \\
\hline Angle*Weight*Direction & 0.00015 & 4 & 0.00004 & 0.03 & 0.998 & \\
\hline Plane*Weight*Direction & 0.00448 & 4 & 0.00112 & 1 & 0.4076 & \\
\hline Angle*Plane*Weight*Direction & 0.00386 & 4 & 0.00096 & 0.86 & 0.4872 & \\
\hline Error & 1.57491 & 1404 & 0.00112 & & & \\
\hline Total & 1.66418 & 1439 & & & & \\
\hline
\end{tabular}

Constrained (Type III) sums of squares.

\section{Triceps, $128 \mathrm{~ms}$}


Analysis of Variance

\begin{tabular}{llcccc|}
\hline Source & Sum Sq. & d.f. & Mean Sq. & F & Prob $>F$ \\
\hline Angle & 0.00009 & 1 & 0.00009 & 0.05 & 0.8269 \\
Plane & 0 & 1 & 0 & 0 & 0.9806 \\
Weight & 0.0086 & 2 & 0.0043 & 2.21 & 0.1099 \\
Direction & 0.02781 & 2 & 0.01391 & 7.15 & 0.0008 \\
Angle*Plane & 0.00051 & 1 & 0.00051 & 0.26 & 0.6099 \\
Angle*Weight & 0.01191 & 2 & 0.00596 & 3.06 & 0.047 \\
Angle*Direction & 0.00766 & 2 & 0.00383 & 1.97 & 0.1398 \\
Plane*Weight & 0.00294 & 2 & 0.00147 & 0.76 & 0.4695 \\
Plane*Direction & 0.00718 & 2 & 0.00359 & 1.85 & 0.1582 \\
Weight*Direction & 0.03399 & 4 & 0.0085 & 4.37 & 0.0016 \\
Angle*Plane*Weight & 0.00911 & 2 & 0.00455 & 2.34 & 0.0965 \\
Angle*Plane*Direction & 0.00062 & 2 & 0.00031 & 0.16 & 0.8528 \\
Angle*Weight*Direction & 0.00582 & 4 & 0.00146 & 0.75 & 0.5588 \\
Plane*Weight*Direction & 0.00393 & 4 & 0.00098 & 0.51 & 0.7315 \\
Angle*Plane*Weight*Direction & 0.00154 & 4 & 0.00038 & 0.2 & 0.9397 \\
Error & 2.72963 & 1404 & 0.00194 & & \\
Total & 2.85501 & 1439 & & & \\
& & & & & \\
\hline
\end{tabular}

Constrained (Type III) sums of squares.

\section{Triceps, 256ms}

\begin{tabular}{lccccc|}
\multicolumn{7}{c}{ Analysis of Variance } & \\
\hline Source & Sum Sq. & d.f. & Mean Sq. & F & Prob>F \\
Angle & 0.00094 & 1 & 0.00094 & 0.25 & 0.6189 \\
Plane & 0.00027 & 1 & 0.00027 & 0.07 & 0.7902 \\
Weight & 0.00773 & 2 & 0.00386 & 1.01 & 0.3632 \\
Direction & 0.06022 & 2 & 0.03011 & 7.9 & 0.0004 \\
Angle*Plane & 0.00043 & 1 & 0.00043 & 0.11 & 0.7373 \\
Angle*Weight & 0.04097 & 2 & 0.02049 & 5.37 & 0.0047 \\
Angle*Direction & 0.00482 & 2 & 0.00241 & 0.63 & 0.5313 \\
Plane*Weight & 0.00256 & 2 & 0.00128 & 0.34 & 0.7145 \\
Plane*Direction & 0.00366 & 2 & 0.00183 & 0.48 & 0.619 \\
Weight*Direction & 0.03065 & 4 & 0.00766 & 2.01 & 0.0908 \\
Angle*Plane*Wight & 0.00089 & 2 & 0.00044 & 0.12 & 0.8903 \\
Angle*Plane*Direction & 0.0038 & 2 & 0.0019 & 0.5 & 0.608 \\
Angle*Weight*Direction & 0.03183 & 4 & 0.00796 & 2.09 & 0.0802 \\
Plane*Weight*Direction & 0.01117 & 4 & 0.00279 & 0.73 & 0.5698 \\
Angle*Plane*Weight*Direction & 0.02214 & 4 & 0.00553 & 1.45 & 0.2147 \\
Error & 5.35258 & 1404 & 0.00381 & & \\
Total & 5.5642 & 1439 & & & \\
& & & & &
\end{tabular}

Constrained (Type III) sums of squares.

\section{Triceps, $512 \mathrm{~ms}$}


Analysis of Variance

\begin{tabular}{lcrrrr|}
\hline Source & Sum Sq. & d.f. & Mean Sq. & F & Prob $>F$ \\
\hline Angle & 0.0031 & 1 & 0.0031 & 0.42 & 0.5163 \\
Plane & 0.0026 & 1 & 0.00265 & 0.36 & 0.5491 \\
Weight & 0.0009 & 2 & 0.00046 & 0.06 & 0.9396 \\
Direction & 0.0763 & 2 & 0.03817 & 5.18 & 0.0057 \\
Angle*Plane & 0.0115 & 1 & 0.01148 & 1.56 & 0.212 \\
Angle*Weight & 0.0728 & 2 & 0.03639 & 4.94 & 0.0073 \\
Angle*Direction & 0.0025 & 2 & 0.00123 & 0.17 & 0.8461 \\
Plane*Weight & 0.0067 & 2 & 0.00336 & 0.46 & 0.6336 \\
Plane*Direction & 0 & 2 & 0.00001 & 0 & 0.9987 \\
Weight*Direction & 0.0078 & 4 & 0.00194 & 0.26 & 0.9015 \\
Angle*Plane*Weight & 0.0062 & 2 & 0.0031 & 0.42 & 0.6561 \\
Angle*Plane*Direction & 0.0141 & 2 & 0.00706 & 0.96 & 0.3839 \\
Angle*Weight*Direction & 0.0326 & 4 & 0.00815 & 1.11 & 0.3518 \\
Plane*Weight*Direction & 0.0778 & 4 & 0.01944 & 2.64 & 0.0324 \\
Angle*Plane*Weight*Direction & 0.0017 & 4 & 0.00042 & 0.06 & 0.9939 \\
Error & 10.3416 & 1404 & 0.00737 & & \\
Total & 10.6526 & 1439 & & & \\
& & & & & \\
\end{tabular}

Constrained (Type III) sums of squares.

\section{Triceps, $768 \mathrm{~ms}$}

\begin{tabular}{|c|c|c|c|c|c|c|}
\hline \multicolumn{7}{|c|}{ Analysis of Variance } \\
\hline Source & Sum Sq. & d.f. & Mean Sq. & $\mathrm{F}$ & Prob $>F$ & $\hat{\wedge}$ \\
\hline Angle & 0 ค ח 20 & 1 & 0000270 & 0 & 05100 & \\
\hline Plane & 0.0225 & 1 & 0.02251 & 2 & 0.1576 & \\
\hline Weight & 0.0035 & 2 & 0.00173 & 0.15 & 0.8573 & \\
\hline Direction & 0.0763 & 2 & 0.03813 & 3.39 & 0.0341 & \\
\hline Angle*Plane & 0.0071 & 1 & 0.00711 & 0.63 & 0.427 & \\
\hline Angle*Weight & 0.118 & 2 & 0.059 & 5.24 & 0.0054 & \\
\hline Angle*Direction & 0.0223 & 2 & 0.01116 & 0.99 & 0.3714 & \\
\hline Plane*Weight & 0.0191 & 2 & 0.00956 & 0.85 & 0.4279 & \\
\hline Plane*Direction & 0.0163 & 2 & 0.00813 & 0.72 & 0.4859 & \\
\hline Weight*Direction & 0.0458 & 4 & 0.01146 & 1.02 & 0.3967 & \\
\hline Angle*Plane*Weight & 0.0197 & 2 & 0.00987 & 0.88 & 0.4162 & \\
\hline Angle*Plane*Direction & 0.038 & 2 & 0.01898 & 1.69 & 0.1857 & \\
\hline Angle*Weight*Direction & 0.0241 & 4 & 0.00603 & 0.54 & 0.7092 & \\
\hline Plane*Weight*Direction & 0.0259 & 4 & 0.00648 & 0.58 & 0.6805 & \\
\hline Angle*Plane*Weight*Direction & 0.1153 & 4 & 0.02883 & 2.56 & 0.0369 & \\
\hline Error & 15.803 & 1404 & 0.01126 & & & \\
\hline Total & 16.3394 & 1439 & & & & \\
\hline
\end{tabular}

Constrained (Type III) sums of squares.

Triceps, $1024 \mathrm{~ms}$ 


\section{Appendix B}

\section{Only Minimal Risk \\ Consent Information Form (without HIPAA)}

Principal Investigator

Dr. Ashish Nimbarte

Department

ENGINEERING-Industrial and Management Systems Engineering

Protocol Number

1903485280

Study Title

FATIGUE EVALUATION PARAMETERS VARIABILITY IN NON-

FATIGUED SHOULDER MUSCLES

Co-Investigator(s) Hui Ci

Sponsor (if any) N/A

\section{Contact Persons}

In the event you experience any side effects or injury related to this research, you should contact Dr. Ashish Nimbarte at (304) 293-9473. If you have any questions, concerns, or complaints about this research, you can contact Dr. Ashish Nimbarte at (304) 293-9473.

For information regarding your rights as a research subject, to discuss problems, concerns, or suggestions related to the research, to obtain information or offer input about the research, contact the Office of Research Integrity and Compliance at (304) 293-7073.

In addition if you would like to discuss problems, concerns, have suggestions related to research, or would like to offer input about the research, contact the Office of Research Integrity and Compliance at 304-293-7073.

\section{Introduction}

You, , have been asked to participate in this research study, which has been explained to you by Ms. Hui Ci. This study is being conducted by $\mathrm{Dr}$. Ashish Nimbarte and Hui Ci in the Department of Industrial and Management System Engineering at West Virginia University.

\section{Purpose(s) of the Study}

The purpose of this study is to test the hypothesis that muscle fatigue evaluation parameters, under non-fatigued/fresh conditions, will not be affected by different work-related factors.

\section{Description of Procedures}

Phone: 304-293-7073

Fax: 304-293-3098

http://oric.research.wvu.edu
Chestnut Ridge Research Building

886 Chestnut Ridge Road

PO Box 6845

Morgantown, WV 26506-6845
P a g e | 61

Subject's 


\section{W- WestVirginiaUniversity.}

Human Research Protocol

Only Minimal Risk Consent

Form

Without HIPAA

1) Upon arrival, the procedures of the experiment will be explained to participants and informed consents will be obtained. 2) Basic anthropocentric measurements including age, body weight, height and elbow height will be measured. 3) Participants will then be given a $\sim 10$ minutes training session in order to become familiar with the tasks to be performed. 4) Surface EMG electrodes will be placed over the skin at shoulder muscles, two electrodes will be placed on the upper right side of the human back and five electrodes will be placed on the upper arm. 5) Participants will be asked to perform the designated tasks in a standing posture. In each trial, the participant will be required to resist a hand loading (0, 2.5 or $5 \mathrm{lb}$.) in one of five directions (Pull Back, Pull Down, Pull Left, Pull Right or Pull Up) for 10 seconds with an elevated shoulder angle $\left(60^{\circ}\right.$ or $\left.120^{\circ}\right)$ in one of those planes (sagittal or scapular). Each trial will have two repetitions. A 1-minute rest time will be provided between trails. A total of 120 trials will be performed and the SEMG data will be recorded continuously during the exertions.

\section{Discomforts}

There is a minimal risk for shoulder muscles strain and fatigue while performing the maximum exertions. Therefore, you will be required to complete a warm-up before these tasks and sufficient rest between trials.

\section{Alternatives}

You do not have to participate in this study.

\section{Benefits}

You may not receive any direct benefit from this study. The knowledge gained from this study may eventually benefit others.

\section{Confidentiality}

Any information about you that is obtained as a result of your participation in this research will be kept as confidential as legally possible. Your research records and test results, just like hospital records, may be subpoenaed by court order or without your additional consent.

\section{Voluntary Participation}

Participation in this study is voluntary. You are free to withdraw your consent to participate in this study at any time. Refusal to participate or withdrawal will not affect your class standing or grades, as appropriate, and will involve no penalty to you. Refusal to participate or withdrawal will not affect your future care, or your employee status, as appropriate, at West Virginia University.

In the event new information becomes available that may affect your willingness to participate in this study, this information will be given to you so that you can make an informed decision about whether or not to continue your participation.

You have been given the opportunity to ask questions about the research, and you have received answers concerning areas you did not understand. Upon signing this form, you will receive a copy.

I willingly consent to participate in this research.

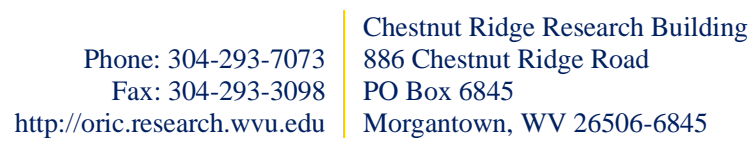

Phone: 304-293-7073 http://oric.research.wvu.edu
P a g e | 62

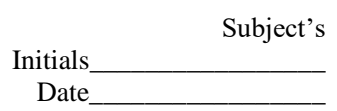




\section{Signatures}

Signature of Subject

Printed Name

Date

Time

The participant has had the opportunity to have questions addressed. The participant willingly agrees to be in the study.

Signature of Investigator or Co-Investigator

P a g e $\mid \mathbf{6 3}$

Subject's
Initials

Date 